Energy Technology Division Energy Technology Division Energy Technology Division Energy Technology Division Energy Technology Division Energy Technology Division

\section{A Review of Dynamic Characteristics of Magnetically Levitated Vehicle Systems}

by Y. Cai and S. S. Chen

Argonne National Laboratory, Argonne, Illinois 60439 operated by The University of Chicago

for the United States Department of Energy under Contract W-31-109-Eng-38 
Argonne National Laboratory, with facilities in the states of Illinois and Idaho, is owned by the United States government, and operated by The University of Chicago under the provisions of a contract with the Department of Energy.

\section{DISCLAIMER}

This report was prepared as an account of work sponsored by an agency of the United States Government. Neither the United States Government nor any agency thereof, nor any of their employees, makes any warranty, express or implied, or assumes any legal liability or responsibility for the accuracy, completeness, or usefulness of any information, apparatus, product, or process disclosed, or represents that its use would not infringe privately owned rights. Reference herein to any specific commercial product, process, or service by trade name, trademark, manufacturer, or otherwise, does not necessarily constitute or imply its endorsement, recommendation, or favoring by the United States Government or any agency thereof. The views and opinions of authors expressed herein do not necessarily state or reflect those of the United States Government or any agency thereof.

Reproduced from the best available copy.

Available to DOE and DOE contractors from the

Office of Scientific and Technical Information

P.O. Box 62

Oak Ridge, TN 37831

Prices available from (423) 576-8401

Available to the public from the

National Technical Information Service

U.S. Department of Commerce

5285 Port Royal Road

Springfield, VA 22161 


\section{A Review of Dynamic Characteristics of Magnetically Levitated Vehicle Systems}

by

Y. Cai and S. S. Chen

Energy Technology Division

November 1995

Work supported by

U.S. DEPARTMENT OF ENERGY

Office of Transportation Technologies 


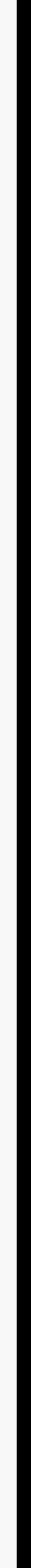




\section{Contents}

Abstract ............................................................................. 1

1 Introduction ..................................................................... 1

2 Dynamic Stability of Maglev Systems .......................................... 5

2.1 Motion-Dependent Magnetic Forces …...................................... 6

2.2 Stability of Maglev Systems ................................................ 8

2.3 Stability Experiments........................................................ 10

2.4 Analytical and Numerical Studies.............................................. 11

2.5 Remarks ..................................................................... 14

3 Dynamics of Maglev Guideways.................................................. 17

3.1 Guideway Structure.......................................................... 17

3.1.1 Substructure ....................................................... 17

3.1.2 Superstructure ...................................................... 18

3.1.3 Materials.............................................................. 19

3.2 Guideway Characteristics............................................... 19

3.2.1 Periodic Disturbances .............................................. 21

3.2.2 Random Disturbances.............................................. 22

3.3 Guideway Loads............................................................ 25

3.3.1 Static Loads................................................................. 25

3.3.2 Impact Loads ............................................................ 25

3.3.3 Longitudinal Loads................................................. 26

3.3.4 Lateral Loads ......................................................... 26

4 Dynamic Vehicle/Guideway Interaction.................................... 26

4.1 General Vehicle/Guideway Interaction Problem........................... 27

4.2 A Flexible Guideway Model ................................................ 30

4.3 Simplified Vehicle Models ..................................................... 33

4.4 Dynamic Analysis of Vehicle/Guideway Interactions ..................... 38

4.4.1 Single- and Double-Span Guideways ............................... 38

4.4.2 Effects of Distributed Loads ............................................ 39

4.4.3 Dynamics of Multicar Vehicle......................................... 40

4.5 Remarks ........................................................................ 41 
5 Ride Quality ................................................................. 42

5.1 Fatigue Time Method........................................................ 43

5.1 .1 Early Criteria ......................................................... 43

5.1.2 International Standards Organization Criterion................... 45

5.1.3 Urban Tracked Air Cushion Vehicle Criterion......................... 45

5.2 Ride Index Method ......................................................... 46

5.2.1 British Railways Ride Index ....................................... 46

5.2.2 Composite Model by Pepler et al...................................... 46

5.2.3 Frequency-Weighting Method ...................................... 48

5.3 Relationship between Ride Quality and System Costs.................... 49

5.4 Suspension Controls for Better Ride Quality.................................... 49

6 Aerodynamic Effects............................................................. 53

6.1 Aerodynamic Drag ....................................................... 53

6.2 Crosswinds...................................................................... 57

6.3 Pressure Wave .............................................................. 60

6.4 Aerodynamic Noise ........................................................ 61

6.5 Aerodynamic Braking..................................................... 62

6.6 Control of Aerodynamic Effects .............................................. 64

6.7 Aerodynamic Design of Maglev Vehicles..................................... 65

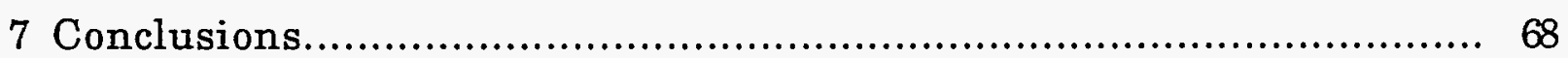

References..................................................................... 69

\section{Figures}

1 Schematic diagram of the electromagnetic system ................... 3

2 Schematic diagram of the electrodynamic suspension system .......... 3

3 Displacement components of a maglev system ........................ 7

4 Schematic diagram of vehicle model with four levitation and four guidance magnets .................................................... 11

$5 \quad$ Experimental results with guidance magnet gap $=13.5 \mathrm{~mm} \ldots \ldots \ldots \ldots . . .12$ 
6 Maglev system with vehicle on double L-shaped aluminum sheet guideway

7 Imaginary part of eigenvalues of maglev system vs. vehicle levitation height with $\mathrm{Y}^{*}=12.7 \mathrm{~mm}$

8 Real part of eigenvalues of maglev system vs. lateral location of vehicle with $\mathrm{h}=7 \mathrm{~mm}$ and $\mathrm{g}_{0}=10,15,20$, and $25 \mathrm{~mm}$ 14

9 Time histories of vehicle motions with various vertical air gaps $\mathrm{h}_{0}$ when $\mathrm{g}_{0}=12.7 \mathrm{~mm}$ 15

10 Time histories of vehicle motions with various lateral air

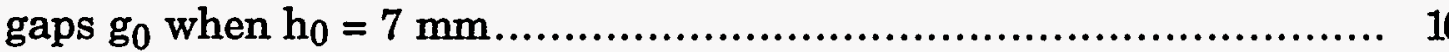

11 Elevation power spectral densities for runways and first $3000 \mathrm{ft}$ of TACRV guideway

12 Dynamics of vehicle/guideway interaction. 28

13 One-dimensional two-DOF vehicle model with primary and secondary suspensions for maglev systems

14 EMS- and EDS-type vehicle models on guideway 36

15 Effects of single-span and double-span beams on maximum guideway displacement and vehicle acceleration ratios for a two-DOF vehicle

16 Maximum midspan displacements of guideway when a single car with various magnets travels along the guideway at various speeds

17 Midspan displacements of guideway for multicar vehicles with eight magnets on each car traveling along the guideway at $100 \mathrm{~m} / \mathrm{s}$

18 Janeway criteria based on the limits of vertical oscillations 44

19 ISO limits of sinusoidal vertical and lateral acceleration levels for high-speed vehicles in the early $1960 \mathrm{~s}$

20 UTACV ride comfort specification for random vibration 46 
21 Wayside noise levels showing the effect of the aerodynamic component.

22 Pressure distribution on MLU 002

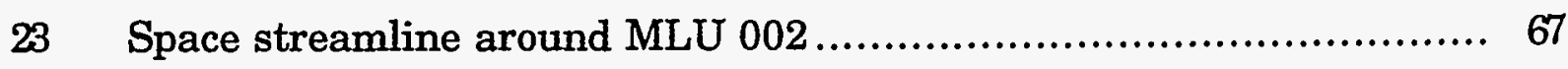

\section{Tables}

1 Component drag of several existing maglev systems....................... 54

2 Drag coefficients........................................................... 56 


\title{
A Review of Dynamic Characteristics of Magnetically Levitated Vehicle Systems
}

\author{
by
}

Y. Cai and S. S. Chen

\begin{abstract}
The dynamic response of magnetically levitated (maglev) ground transportation systems has important consequences for safety and ride quality, guideway design, and system costs. Ride quality is determined by vehicle response and by environmental factors such as humidity and noise. The dynamic response of the vehicles is the key element in determining ride quality, while vehicle stability is an important safety-related element. To design a guideway that provides acceptable ride quality in the stable region, vehicle dynamics must be understood. Furthermore, the trade-off between guideway smoothness and levitation and control systems must be considered if maglev systems are to be economically feasible. The link between the guideway and the other maglev components is vehicle dynamics. For a commercial maglev system, vehicle dynamics must be analyzed and tested in detail. This report, which reviews various aspects of the dynamic characteristics, experiments and analysis, and design guidelines for maglev systems, discusses vehicle stability, motiondependent magnetic force components, guideway characteristics, vehicle/ guideway interaction, ride quality, suspension control laws, aerodynamic loads and other excitations, and research needs.
\end{abstract}

\section{Introduction}

A high-speed ground transportation system based on magnetically levitated (maglev) vehicles propelled by a linear electric motor has been proposed to meet future intercity transportation requirements. One possible and attractive approach is to replace air travel for selected intercity trips of 100-600 miles. Maglev systems will offer the advantages of lower noise and emissions, better ride quality, potential energy savings and economic benefits, and potential international trade benefits, as well as relief of traffic congestion (Bohn and Steinmetz 1985; Chen et al. 1992; Coffey et al. 1991; He et al. 1991; Johnson et al. 1989; Katz et al. 1974; Zicha 1986; GangaRao et al. 1992; Cai et al. 1992, 1995). 
Many research studies of scale model magnetic suspension systems were developed in the U.S. and abroad in the 1970s (Coffey et al. 1972; Danby and Powell 1972; Carmichael and Dorn 1991) and two types of full-scale maglev prototype vehicle systems have been developed during last two decades, in Germany and Japan (Johnson et al. 1989; Uher 1989; He et al. 1992; Wormley et al. 1992):

- Attractive-force or electromagnetic system (EMS) - Based on the principle of attraction in magnetism, this approach uses conventional electromagnets on the vehicle. The electromagnets are attracted upward toward ferromagnetic rails above the magnets. Such suspension of a vehicle by attractive magnetic forces is inherently unstable and the air gap must be continuously maintained by a feedback system that adjusts the strength of the suspending electromagnets. Air gaps are usually 7-10 mm. (See the schematic diagram of the German Transrapid system in Fig. 1).

- Repulsive-force or electrodynamic system (EDS) - Based on the principle of repulsion in magnetism, whereby a magnet moving over a conductor induces in the conductor eddy currents, which, in turn, produce a magnetic field that repels the original magnet. The repulsive forces provide inherently stable magnetic support of the vehicle above a particular takeoff speed $(\approx 80 \mathrm{~km} / \mathrm{h})$. Air gaps of 10$15 \mathrm{~cm}(4-6 \mathrm{in}$.) have been tested to $515 \mathrm{~km} / \mathrm{h}(320 \mathrm{mi} / \mathrm{h})$. (See the schematic diagram of the Japanese electrodynamic suspension system in Fig. 2).

Although some design concepts have been developed nearly to commercial application, the attractiveness of maglev systems is expected to be enhanced even further over the next several years by new or improved concepts, improved design and construction methods, and new material (including high-temperature superconductors, high-energy permanent magnets, and advanced material for guideways). Therefore, it is reasonable to expect that maglev systems may indeed be a key transportation mode in the 21st century (Chen et al. 1992; Rote 1993; Coffey 1993; Ozeki 1993; Raschbichler and Wackers 1993; Wiescholek et al. 1993a, 1993b; Inone and Kokubun 1993; Miller and Konigorski 1993; Masada 1993; Martinelli and Morini 1993; Lian et al. 1993; Parker et al. 1993; Wyczalek 1993).

For several decades, research and development have been performed in the areas of magnetic levitation, response of maglev vehicles to rough guideways, interaction of variously suspended vehicles with flexible guideways, and 


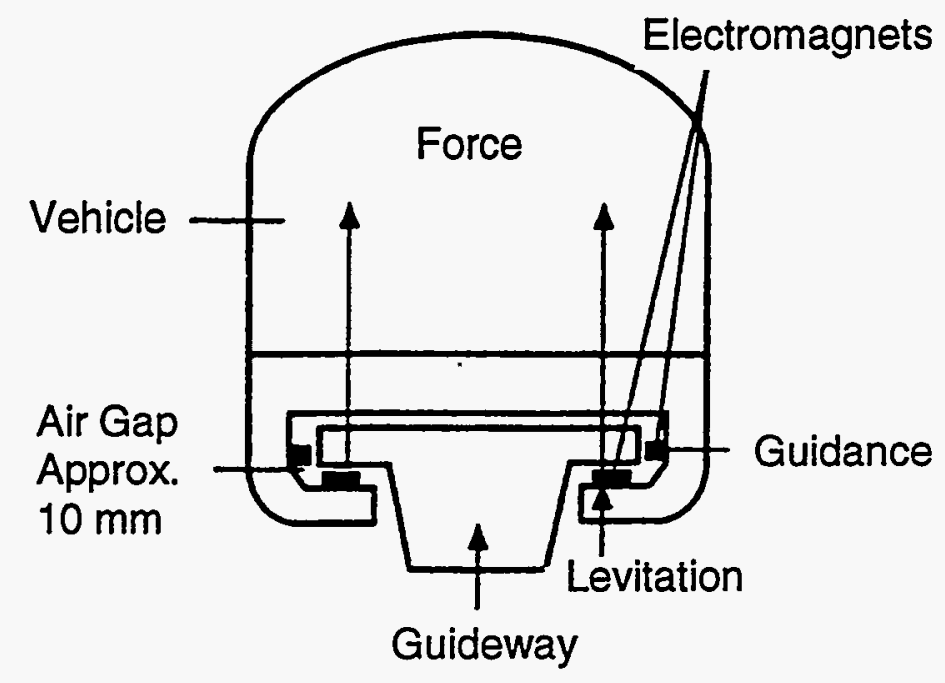

Fig. 1. Schematic diagram of the electromagnetic system

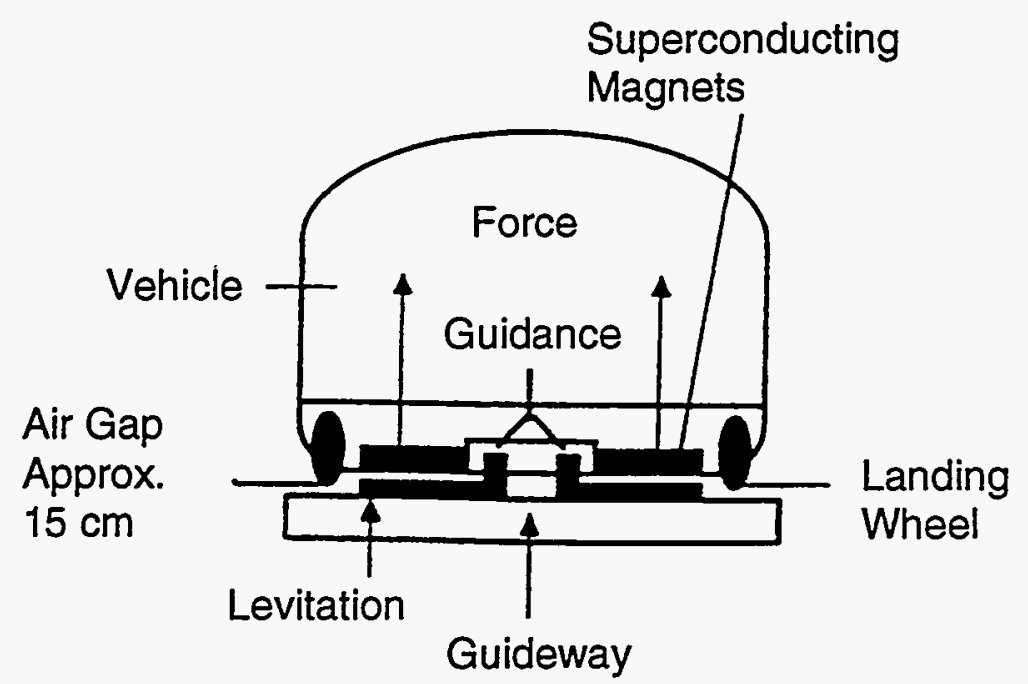

Fig. 2. Schematic diagram of the electrodynamic suspension system

optimization of vehicle suspensions. The results of these efforts are useful in providing appropriate criteria for the design of maglev systems (Bohn and Steinmetz 1985; Chiu et al. 1971; Iguchi and Hara 1985; Katz et al. 1974; Sinha 1987).

The dynamic response of magnetically levitated vehicles is important because of safety, ride quality, guideway design, and system cost. More emphasis should be placed on guideway design, because the cost of the guideway structure is expected to be $60-80 \%$ of the overall initial capital investment cost (Uher 1989; 
Zicha 1986). Thus, guideway design is a critical area of potential capital savings. More flexible guideways are less expensive, but cause complex vehicle/guideway interactions and affect ride quality. An optimized guideway design will be important for a high-speed maglev system that offers good ride quality. As maglev vehicle speeds increase to $200-300 \mathrm{mi} / \mathrm{hr}$, or as guideways become lighter and more flexible to reduce costs, the dynamic interactions between vehicle and guideway will become an important problem and play a dominant role in establishing vehicle suspension requirements and specifications for guideway stiffness, weight, and span length (Cai and Chen 1992; Cai et al. 1992b; Chiu et al. 1971; Vu-Quoc and Olsson 1989; Zicha 1986).

Light guideways, especially those made of steel, may be susceptible to dynamic instability and unacceptable vibration; thus, dynamic evaluation must be included in structural analysis. Various dynamic responses of coupled vehicle/guideway systems may be observed, including periodic oscillation, random vibration, dynamic instability, chaotic motion, parametric resonance, combination resonance, and transient response (Chen et al. 1992).

To design a guideway that provides acceptable ride quality, the dynamic interaction of vehicles and guideways must be understood. Furthermore, the trade-off between guideway smoothness and design of the levitation and control systems must be considered if the maglev system is to be economically feasible (Cai and Chen 1992).

Magnetically suspended systems are intrinsically underdamped. Safe, stable operation and acceptable ride comfort require some form of control of vehicle motion. Moreover, vehicle tolerance of guideway flexibility and roughness and of transient perturbing forces, such as wind gusts and guideway misalignments, will be influenced by air-gap size and suspension control characteristics, including response time and dynamic range. To the extent that tolerances can be increased through suitable suspension control systems, guideway costs can be reduced and systems can be made more robust (Cai et al. 1992; Faye et al. 1989; Kortum et al. 1988; Sinha 1987).

For safety, maglev systems should be stable. Thus, stability characteristics must be studied because instabilities have been observed in maglev system models at Argonne National Laboratory and other organizations (Cai et al. 1992a, 1992b; Cai and Chen 1993; Chu and Moon 1983; Moon 1974, 1977). With a better understanding of vehicle stability characteristics, better control laws can be adopted to ensure a high level of ride comfort and safety. The design of vehicle suspension controls, therefore, must meet stability requirements of maglev systems. 
The purposes of this report are to summarize the state-of-the-art technology related to maglev dynamics, to discuss engineering requirements, and to identify research needs. Included is discussion of recent techniques and studies of maglev dynamics on various characteristics of maglev systems, experiments and analyses, and design guideline. Also covered are vehicle stability, motiondependent magnetic force components, guideway characteristics, vehicle/ guideway interaction, ride quality, suspension control laws, aerodynamic loads and other excitations, and valuable research needs in the future.

\section{Dynamic Stability of Maglev Systems}

For safety, maglev systems should be stable. Because dynamic instabilities are not acceptable for any commercial maglev system, it is important to consider these phenomena when designing and developing maglev suspension systems. However, to date, this issue has not received much attention worldwide (Masada 1993; Wiescholek et al. 1993a, 1993b; Coffey 1993; Ozeki 1993; Kim et al. 1993; Martinelli and Morini 1993; Lian et al. 1993; Parker et al. 1993; Wyczalek 1993) even though instabilities of maglev systems were confirmed earlier by several investigators (Chu and Moon 1983; Chen et al. 1992; Cai et al. 1992, 1995).

The repulsive levitation system, or EDS, is often thought to be inherently stable. However, its response to perturbations is frequently unstable and susceptible to catastrophic oscillations, particularly in rectangular-trough configurations. So far, only a few analytical and experimental studies (Cai et al. 1995) have been performed to gain an understanding of the stability characteristics of EDS-type maglev systems. Davis and Wilkie (1971) studied a magnetic coil moving over a conducting track and concluded that negative damping occurs at velocities greater than the characteristic velocity based on thin-track theory. Ohno et al. (1973) studied the pulsating lift forces in a linear synchronous motor. These pulsating forces may cause parametric and combination resonance, in addition to heaving and pitching oscillations. Experiments on the Massachusetts Institute of Technology (MIT) magneplane showed obvious evidence of dynamic instabilities on film in the early 1970s, but the dynamic stability was not studied in detail. An experimental vehicle with three degrees of freedom (DOF), floating above a large rotating wheel, was found by Moon (1974) to have a lateral-roll-yaw instability. Also, experiments performed on a test track at MIT showed pitch-heave instability. Negative magnetic damping was demonstrated, but the instability was dominated by aerodynamic damping (Moon 1977). In an experimental and analytical study by Chu and Moon (1983), divergence and flutter of a vehicle model were obtained. Researchers at Argonne National Laboratory (ANL) have developed a general approach to investigating 
and predicting the occurrence of instabilities in maglev suspension systems and to providing a better understanding of the conditions (design features and parameter values) that can lead to dynamic instabilities (Cai et al. 1995).

\subsection{Motion-Dependent Magnetic Forces}

Magnetic forces are basically position dependent, although some are also velocity dependent. The significant velocity-dependent force, which appears to be magnetic drag, decreases with velocity and hence is a negative damping contribution. Damping forces are generally considered to be quite small (Chen et al. 1992).

The motion-dependent magnetic forces can induce various types of instability. In addition, the periodic structure of the motion-dependent magnetic forces may, in some cases, also induce parametric and combination resonances (Cai et al. 1992a, 1992b).

Consider a rigid-body vehicle with six DOF (three translations, $u_{x}, u_{y}, u_{z}$ and three rotations, $\omega_{x}, \omega_{y}, \omega_{z}$ ), as shown in Fig. 3. Let $U$ be the vector consisting of the six motion components, i.e.,

$$
\mathrm{U}=\left\{\begin{array}{l}
\mathrm{u}_{1} \\
\mathrm{u}_{2} \\
\mathrm{u}_{3} \\
\mathrm{u}_{4} \\
\mathrm{u}_{5} \\
\mathrm{u}_{6}
\end{array}\right\}=\left\{\begin{array}{l}
\mathrm{u}_{\mathrm{x}} \\
\mathrm{u}_{\mathrm{y}} \\
\mathrm{u}_{\mathrm{z}} \\
\omega_{\mathrm{x}} \\
\omega_{\mathrm{y}} \\
\omega_{\mathrm{z}}
\end{array}\right\}
$$

The motion-dependent magnetic forces can be written as

$$
f_{i}=\sum_{j=1}^{6}\left(m_{i j} \ddot{u}_{j}+c_{i j} \dot{u}_{j}+k_{i j} u_{j}\right),
$$

where $\mathrm{m}_{\mathrm{ij}}, \mathrm{c}_{\mathrm{ij}}$, and $\mathrm{k}_{\mathrm{ij}}$ are magnetic-mass, damping, and stiffness coefficients. These coefficients can be obtained analytically, numerically, or experimentally, and are functions of the system parameters (Cai et al. 1992a, 1992b). 

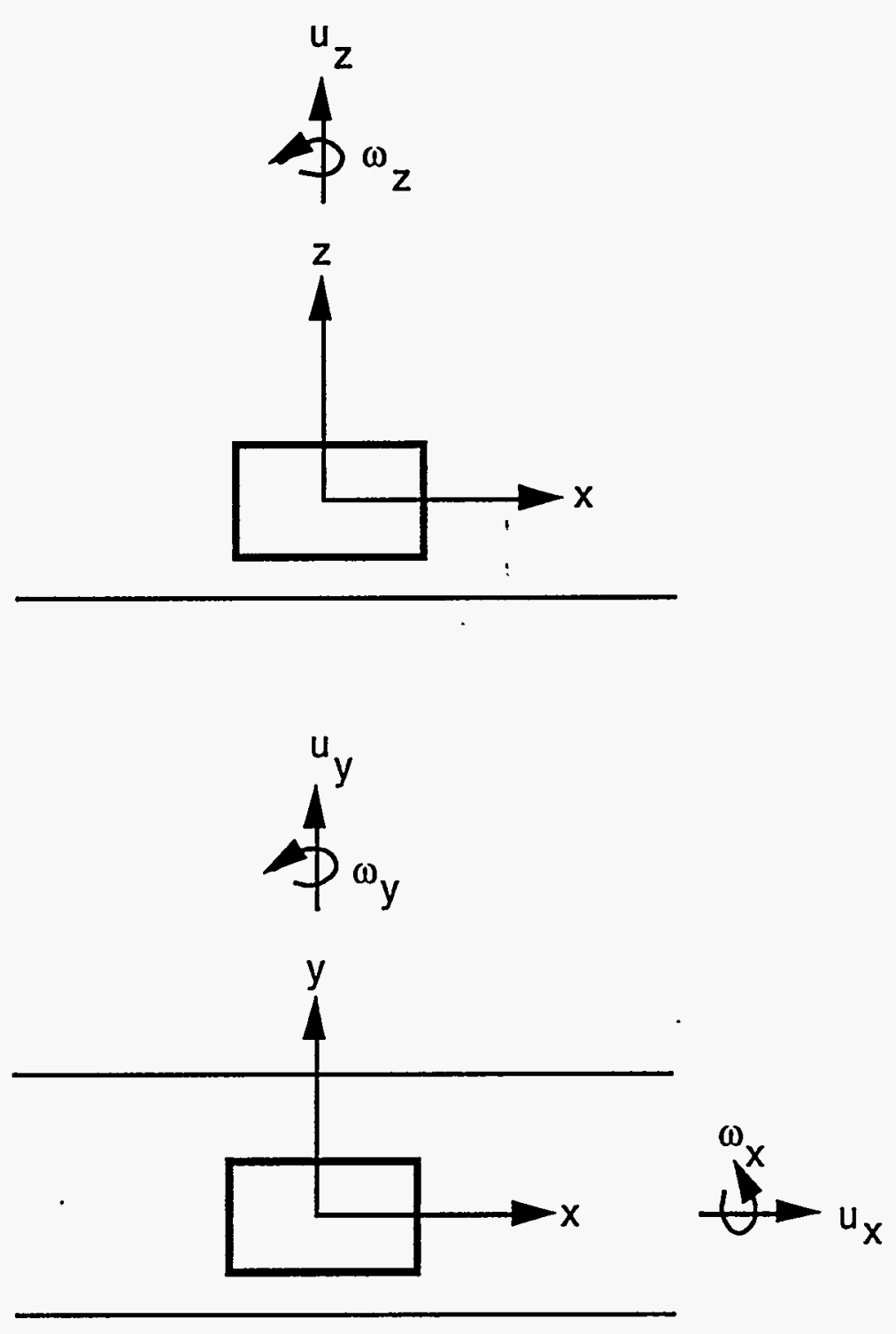

Fig. 3. Displacement components of a maglev system

To date, magnetic forces are obtained mainly from experimental measurements. At ANL, two experiments to measure force were performed. In the first experiment, a quasistatic method was applied to measure magnetic forces when a permanent magnet was moving over an aluminum L-shaped ring mounted on the top surface of a 1.2-m-diameter rotating wheel. The measured forces are a function of position at a given steady speed (Cai et al. 1995). The magnetic force data, obtained from steady-state experiments, play a very important role in the analysis of numerical simulation of dynamic stability of maglev vehicles. The integrating magnetic force data (see Cai et al. 1995) will provide potential references for future maglev programs. 
In the second experiment, dynamic (motion-dependent) magnetic force measurements were based on an unsteady-motion theory. A direct method was used to measure magnetic damping and stiffness, and to investigate the effect of various parameters, such as conductivity, gap, excitation frequency, and oscillation amplitude (Chen et al. 1993; Zhu et al. 1994). Experimental results indicated that negative magnetic damping will develop once the characteristic speed is exceeded. In the maglev system, instability will occur when the damping value becomes negative. A computer model simulation of magnetic damping forces in a maglev system confirmed the existence of negative damping phenomenon (He et al. 1994).

\subsection{Stability of Maglev Systems}

Without motion-dependent magnetic forces, the equation of motion for a vehicle with $\mathrm{N} D O F$ can be written as

$$
\left[\mathrm{M}_{\mathrm{v}}\right]\{\ddot{\mathrm{U}}\}+\left[\mathrm{C}_{\mathrm{v}}\right]\{\dot{\mathrm{U}}\}+\left[\mathrm{K}_{\mathrm{v}}\right]\{\mathrm{U}\}=\{\mathrm{Q}\}
$$

where $M_{V}$ is the vehicle mass matrix, $C_{v}$ is the vehicle damping matrix, $K_{V}$ is the vehicle stiffness matrix, and $Q$ is the generalized excitation force.

The motion-dependent magnetic forces are given in Eq. 2. With motiondependent magnetic forces, Eq. 3 becomes

$$
\left[\mathrm{M}_{\mathrm{v}}+\mathrm{M}_{\mathrm{m}}\right]\{\ddot{\mathrm{U}}\}+\left[\mathrm{C}_{\mathrm{v}}+\mathrm{C}_{\mathrm{m}}\right]\{\dot{\mathrm{U}}\}+\left[\mathrm{K}_{\mathrm{v}}+\mathrm{K}_{\mathrm{m}}\right]\{\mathrm{U}\}=\{\mathrm{Q}\},
$$

where $M_{m}$ is the magnetic mass matrix, $C_{m}$ is the magnetic damping matrix, and $K_{m}$ is magnetic stiffness; the elements of these parameters are $m_{i j}$, $c_{i j}$, and $\mathbf{k}_{\mathbf{i j}}$.

Once the magnetic-force coefficients are known, analysis of vehicle stability is straightforward. Equation 4 may be written as

$$
[\mathrm{M}]\{\ddot{\mathrm{U}}\}+[\mathrm{C}]\{\dot{\mathrm{U}}\}+[\mathrm{K}]\{\mathrm{U}\}=\{\mathrm{Q}\} \text {. }
$$

In general, $M, C$, and $K$ are functions of $U, \dot{U}$, and $\ddot{U}$; therefore, it is difficult to obtain a complete solution. In many practical situations, where the threshold parameters associated with dynamic instability are of primary interest, one can ignore all nonlinear terms, so that $\mathrm{M}, \mathrm{C}$, and $\mathrm{K}$ are independent of vehicle motion. 
By premultiplying by $\{\dot{U}\}^{T}$ and forming the symmetric and antisymmetric components of the matrices

$$
\begin{array}{ll}
{\left[\mathrm{M}_{1}\right]=\frac{1}{2}\left([\mathrm{M}]+[\mathrm{M}]^{\mathrm{T}}\right),} & {\left[\mathrm{M}_{2}\right]=\frac{1}{2}\left([\mathrm{M}]-[\mathrm{M}]^{\mathrm{T}}\right),} \\
{\left[\mathrm{C}_{1}\right]=\frac{1}{2}\left([\mathrm{C}]+[\mathrm{C}]^{\mathrm{T}}\right),} & {\left[\mathrm{C}_{2}\right]=\frac{1}{2}\left([\mathrm{C}]-[\mathrm{C}]^{\mathrm{T}}\right),} \\
{\left[\mathrm{K}_{1}\right]=\frac{1}{2}\left([\mathrm{~K}]+[\mathrm{K}]^{\mathrm{T}}\right),} & {\left[\mathrm{K}_{2}\right]=\frac{1}{2}\left([\mathrm{~K}]-[\mathrm{K}]^{\mathrm{T}}\right),}
\end{array}
$$

we can separate the terms and obtain

$$
\begin{aligned}
& \{\dot{U}\}^{\mathrm{T}}\left[\mathrm{M}_{1}\right]\{\ddot{\mathrm{U}}\}+\{\dot{\mathrm{U}}\}^{\mathrm{T}}\left[\mathrm{C}_{2}\right]\{\dot{\mathrm{U}}\}+\{\dot{\mathrm{U}}\}^{\mathrm{T}}\left[\mathrm{K}_{1}\right]\{\mathrm{U}\} \\
= & -\left(\{\dot{\mathrm{U}}\}^{\mathrm{T}}\left[\mathrm{M}_{2}\right]\{\ddot{\mathrm{U}}\}+\{\dot{\mathrm{U}}\}^{\mathrm{T}}\left[\mathrm{C}_{1}\right]\{\dot{\mathrm{U}}\}+\{\dot{\mathrm{U}}\}^{\mathrm{T}}\left[\mathrm{K}_{2}\right]\{\mathrm{U}\}\right)+\{\dot{\mathrm{U}}\}^{\mathrm{T}}\{\mathrm{Q}\}
\end{aligned}
$$

Equation 7 equates rates of work. The terms on the right-hand side of the equation produce a net work resultant when integrated over a closed path through the space $\{U\}$, the magnitude depending on the path taken. The forces that correspond to the matrices $\mathrm{M}_{2}, \mathrm{C}_{1}$, and $\mathrm{K}_{2}$, on the right-hand side, are thus, by definition, the nonconservative parts of the forces represented by $\mathrm{M}, \mathrm{C}$, and $\mathrm{K}$. The terms on the left-hand side similarly can be shown to give rise to a zero work resultant over any closed path; therefore, together, they are the sum of the rates of work from the potential forces and the rate of change of kinetic energy.

Various types of instability can be classified according to the dominant terms in Eq. 7 (Chen 1987; Cai et al. 1992a):

- Magnetic-damping-controlled instability (single-mode flutter). The dominant terms are associated with the symmetric damping matrix $\left[\mathrm{C}_{1}\right]$. Flutter arises because the magnetic damping forces create "negative damping," that is, a magnetic force that acts in phase with vehicle velocity.

- Magnetic-stiffness-controlled-instability (coupled-mode flutter). The dominant terms are associated with the antisymmetric stiffness matrix $\left[\mathrm{K}_{2}\right]$. It is called coupled-mode flutter because at least two modes are required to produce it.

In practical cases, two or more mechanisms may interact with one another, and Eq. 5 is applicable for general cases. 
Maglev systems are subjected to several groups of forces, including magnetic forces, aerodynamic forces, and forces due to guideway perturbation. The theory presented here is applicable to maglev systems when they are subjected to other types of forces. In particular, the aerodynamic effects can be described identically to those given in Eqs. 1-7, and the response of dynamic characteristics to aerodynamic forces is similar to that of magnetic forces (Chen 1987; Cai et al. 1992a).

\subsection{Stability Experiments}

Except for stability experiments on the MIT magneplane in the early 1970s, only $\mathrm{Chu}$ and Moon (1983) experimentally and analytically studied a conducting guideway consisting of L-shaped aluminum segments attached to a rotating wheel to simulate the full-scale Japanese guideway at Miyazaki. Divergence and flutter of a vehicle model with two DOF were obtained for coupled yaw-lateral vibration; the divergence leads to two stable equilibrium yaw positions, and the flutter instability leads to a limit cycle of coupled yaw and lateral motions near the magnetic-drag peak.

Researchers at ANL conducted two series of extensive experimental investigations on the dynamic stability of maglev systems with a free vehicle moving on a double L-shaped aluminum guideway mounted on the top of a rotating wheel. Five modes (vertical heave, lateral slip, pitch, yaw, and roll) of the vehicle motion were measured in experiments during which the rotating speed of the wheel was varied. Instabilities of an EDS-type maglev system have been observed through the experiments. Stable and unstable motion of the maglev vehicle was observed and recorded (Cai et al. 1995).

Figure 4 schematically shows the vehicle model with four $25.4 \times 50.8 \times 6.35$ $\mathrm{mm}$ levitation magnets and four $12.7 \times 50.8 \times 6.35-\mathrm{mm}$ guidance magnets in ANL's stability experiments (Cai et al. 1995). The clearances between the sheet guideway and the guidance and levitation magnets can be set at several values. Four small wheels are attached to the vehicle to prevent damage from dynamic instability. The vehicle weight is $2.502 \mathrm{~kg}$ or $24.52 \mathrm{~N}$. Moments of inertia from measurement are $0.4389,0.2840$, and $0.1920 \mathrm{kgm}^{2}$ for $\mathrm{x}, \mathrm{y}$, and $\mathrm{z}$ axes, respectively. Typical results are replotted in Fig. 5, with RMS values of heave, slide, yaw, pitch, and roll motion of the vehicle as a function of wheel surface velocity ranging from 15 to $31 \mathrm{~m} / \mathrm{s}$, with the lateral gap between guidance magnets and the vertical part of the guideway $\mathrm{L}$ equal to $13.5 \mathrm{~mm}$. Large motion (instability) occurred between 19 and $23 \mathrm{~m} / \mathrm{s}$. When the velocity was lower than $18 \mathrm{~m} / \mathrm{s}$ or higher than $24 \mathrm{~m} / \mathrm{s}$, the vehicle was very stable. 


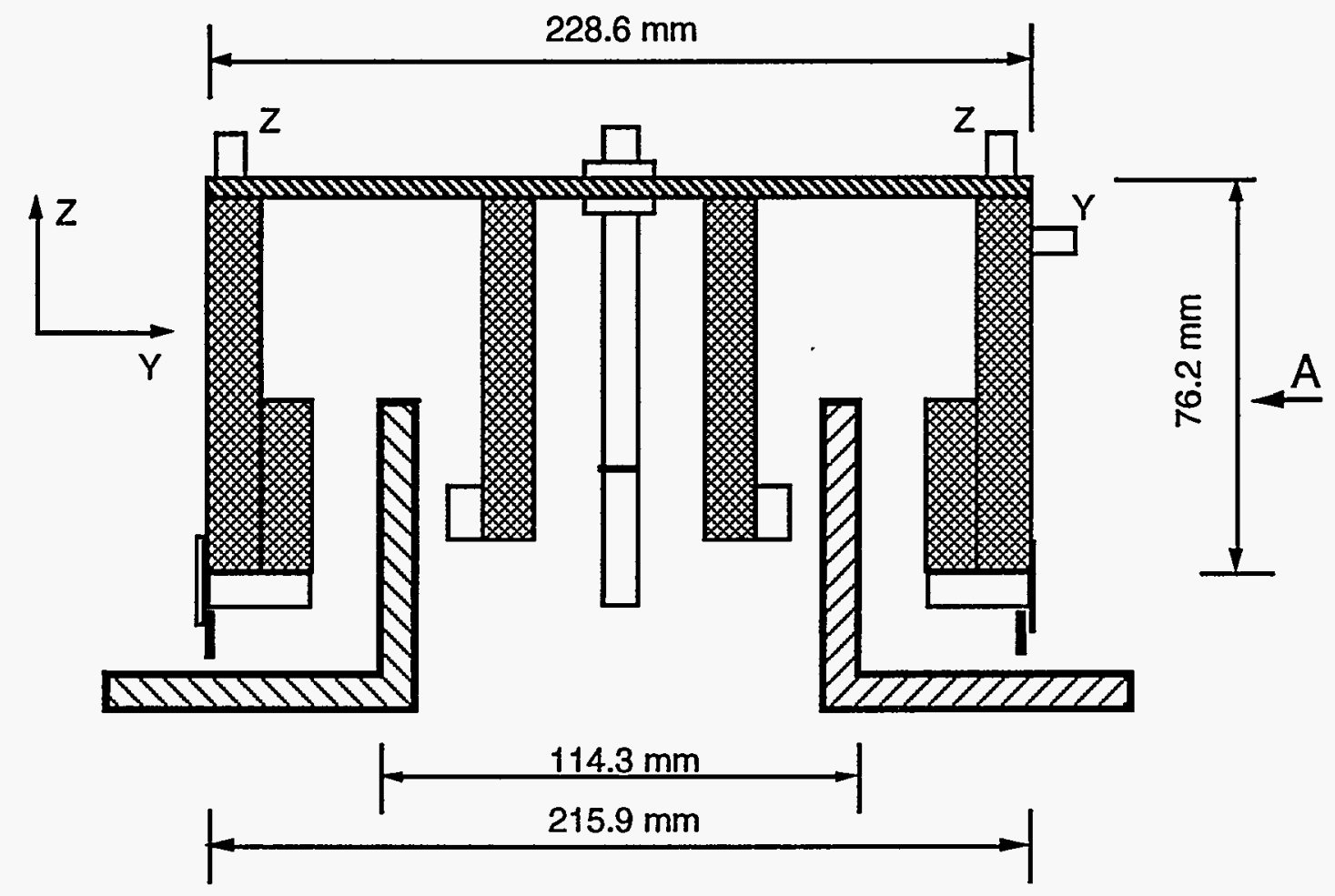

Fig. 4. Schematic diagram of vehicle model with four levitation and four guidance magnets (Cai et al. 1995)

\subsection{Analytical and Numerical Studies}

Only a few analytical and numerical investigations can be found in the literature (Chu and Moon 1983; Cai et al. 1992a, 1995; Cai and Chen 1993). At ANL, an analysis of dynamic instabilities of an EDS-type maglev suspension system with vehicles of three and five DOF traveling on a double-L-shaped set of guideway conductors, was conducted (Cai et al. 1993a, 1993b). Both analytical and numerical approaches were used; and various magnetic suspension forces, compiled from experimental data, were incorporated into the theoretical models. Divergence and flutter were obtained from analytical and numerical solutions for coupled vibration of the maglev vehicle model with three DOF. A computer code for numerically simulating dynamic stability of the vehicle model with five DOF was developed, and extensive computations with various parameters were performed to determine the stability characteristics of EDS-type maglev systems. Instabilities of five directions of motion (heave, slip, roll, pitch, and yaw) of the dynamic vehicle model were observed and it was demonstrated that system parameters, such as system damping, vehicle geometry, and coupling effects among five different motions, play very important roles in the occurrence of dynamic instabilities in maglev systems (Cai et al. 1995). 

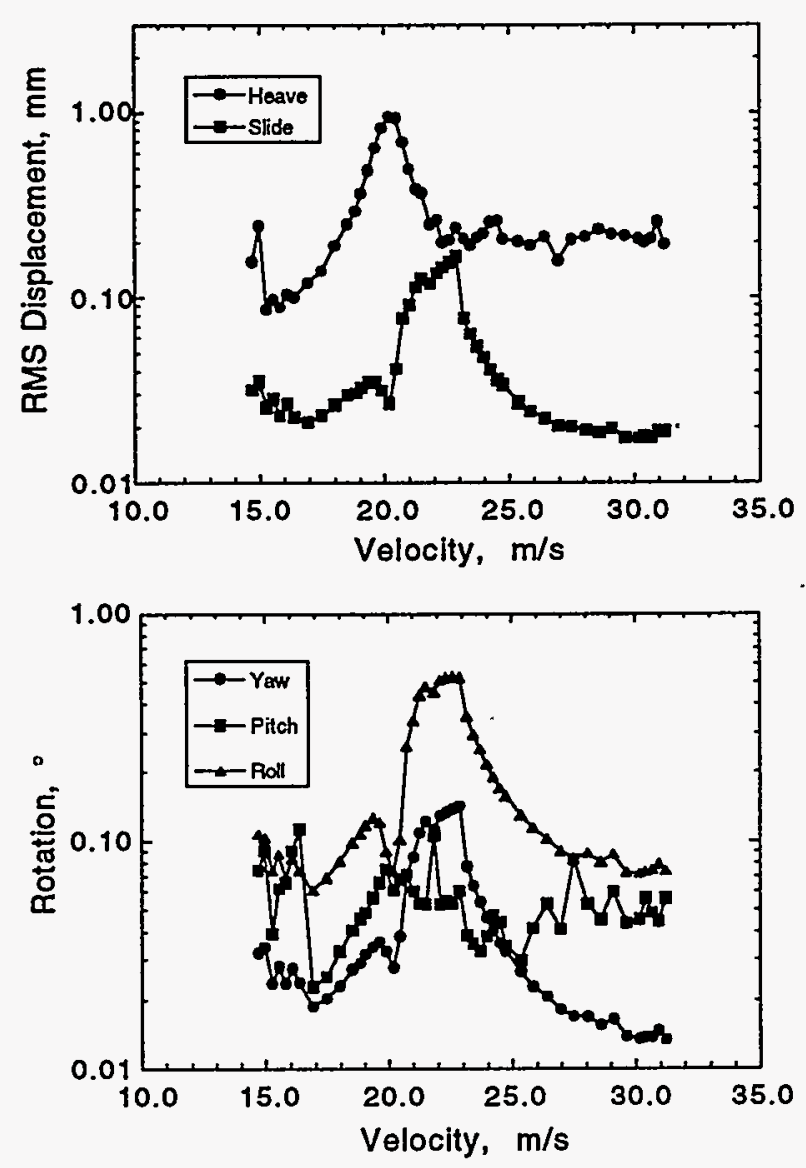

Fig. 5. Experimental results with guidance magnet gap = $13.5 \mathrm{~mm}$ (Cai et al. 1995)

Figure 6 shows the cross section of a simplified vehicle and guideway with three DOF (Cai et al. 1992a). Assume that the vehicle is traveling at a constant velocity in the $\mathrm{x}$ direction. Two permanent magnets are attached to the bottom of the vehicle and provide lift and guidance force. Figure 7 shows that the imaginary part of eigenvalues of vehicle motion versus levitation height vary when guidance gaps are fixed $\left(g_{1}=g_{2}=12.7 \mathrm{~mm}\right)$. The first mode $\omega_{1}$ shows an uncoupled heave motion; the imaginary part of its eigenvalue is zero. The second and third modes are coupled roll-slip motions. Within a range of height $h$ of 19.0$35 \mathrm{~mm}$, the imaginary parts of the eigenvalues appear not to be zero. This indicates that, within this range, flutter does exist for these coupled roll-slip vibrations. Figure 8 shows the real part of the third mode (which presents the transversal motion of the vehicle) versus lateral location of the vehicle when parameter-equilibrium guidance gap varies as $g_{1}=g_{2}=g_{0}=10,15,20$, and $25 \mathrm{~mm}$, and levitation height $\mathrm{h}=7 \mathrm{~mm}$. We found that the real part is zero only when $\mathrm{g}_{0}=25 \mathrm{~mm}$. This indicates that the divergence is subjected to the lateral motion of the vehicle with those vehicle and guideway parameters. 


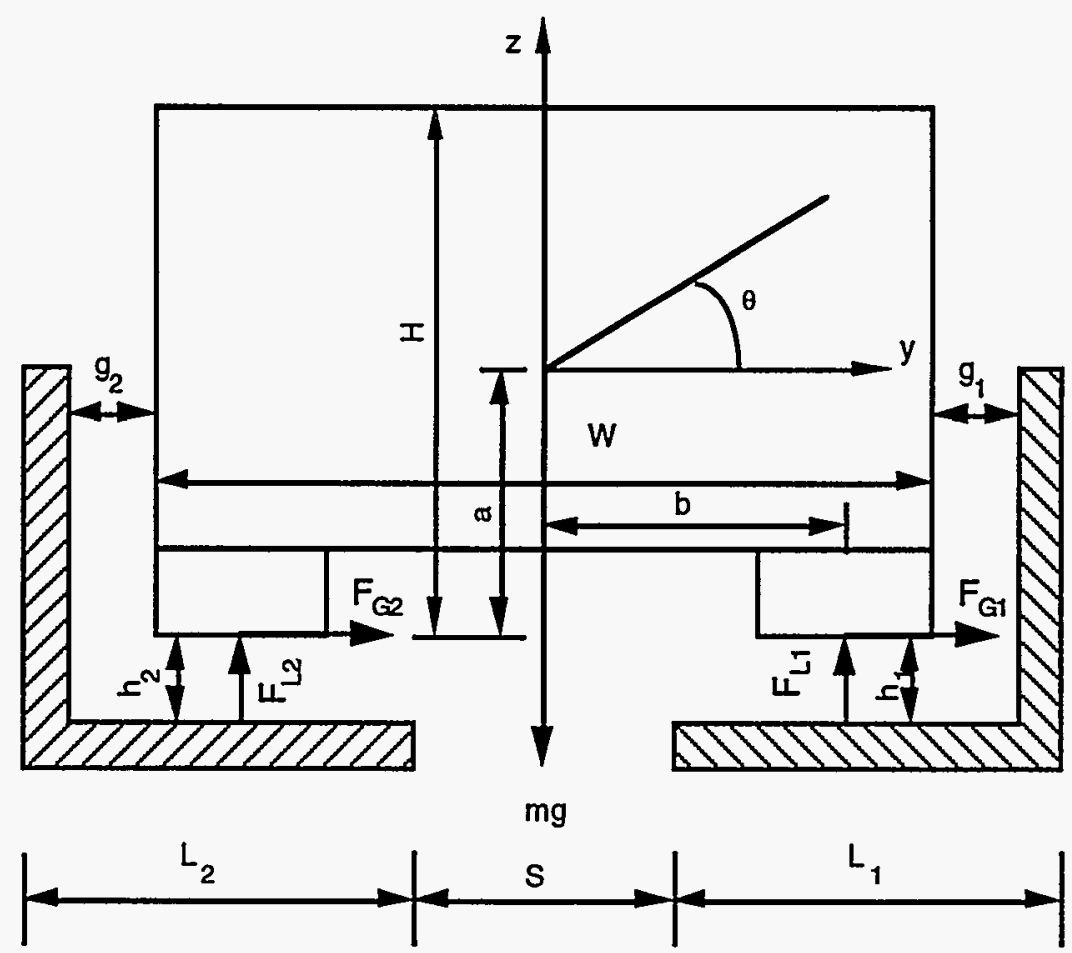

Fig. 6. Maglev system with vehicle on double $L$-shaped aluminum sheet guideway

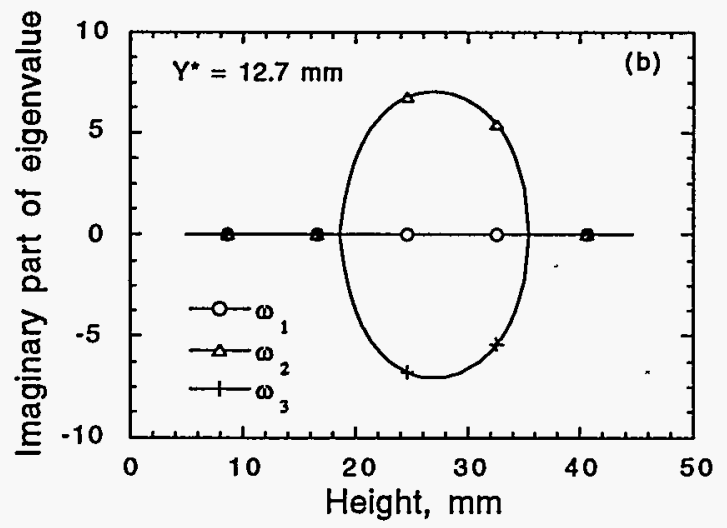

Fig. 7. Imaginary part of eigenvalues of maglev system vs. vehicle levitation height with $Y^{*}=12.7 \mathrm{~mm}$ 


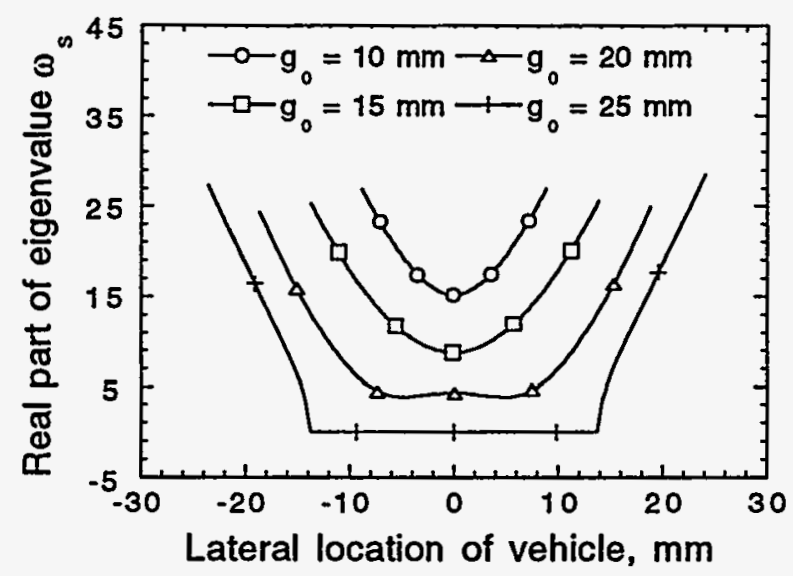

Fig. 8. Real part of eigenvalues of maglev system vs. lateral location of vehicle with $h=7 \mathrm{~mm}$ and $g_{0}=10,15,20$, and $25 \mathrm{~mm}$

The flutter (Fig. 7) and divergence (Fig. 8) instabilities have been verified by numerical simulations with a computer code that has been developed by the authors at ANL and can simulate the nonlinear dynamic response of maglev systems with six DOF when the user inputs vehicle and guideway configurations (Cai and Chen 1995). Figures 9 and 10 show the time histories of vehicle motions with the vehicle configuration shown in Fig. 4. In Fig. 9, the slip and roll motions are apparently stable when $h_{0}=10 \mathrm{~mm}$, but unstable when $h_{0}=25 \mathrm{~mm}$, which indicates that coupled roll-slip flutter indeed occurs. In Fig. 10, divergence of slip and roll motions occurs when $\mathrm{g}_{0}=25 \mathrm{~mm}$. This not only indicates that the divergence is subjected to lateral vehicle motion but also reflects the coupling effects between two motions.

\subsection{Remarks}

- Motion-dependent magnetic forces are the key elements in modeling and understanding dynamic instabilities of maglev systems. At this time, it appears that very limited data are available for motiondependent magnetic forces (Chen et al. 1993; Zhu et al. 1994). Efforts should be made to compile analytical results and experimental data for motion-dependent magnetic forces. When this work is completed, recommendations can be presented on research needs on magnetic forces. In addition, specific methods to obtain motion-dependent magnetic forces should be described in detail (Chen et al. 1993). 

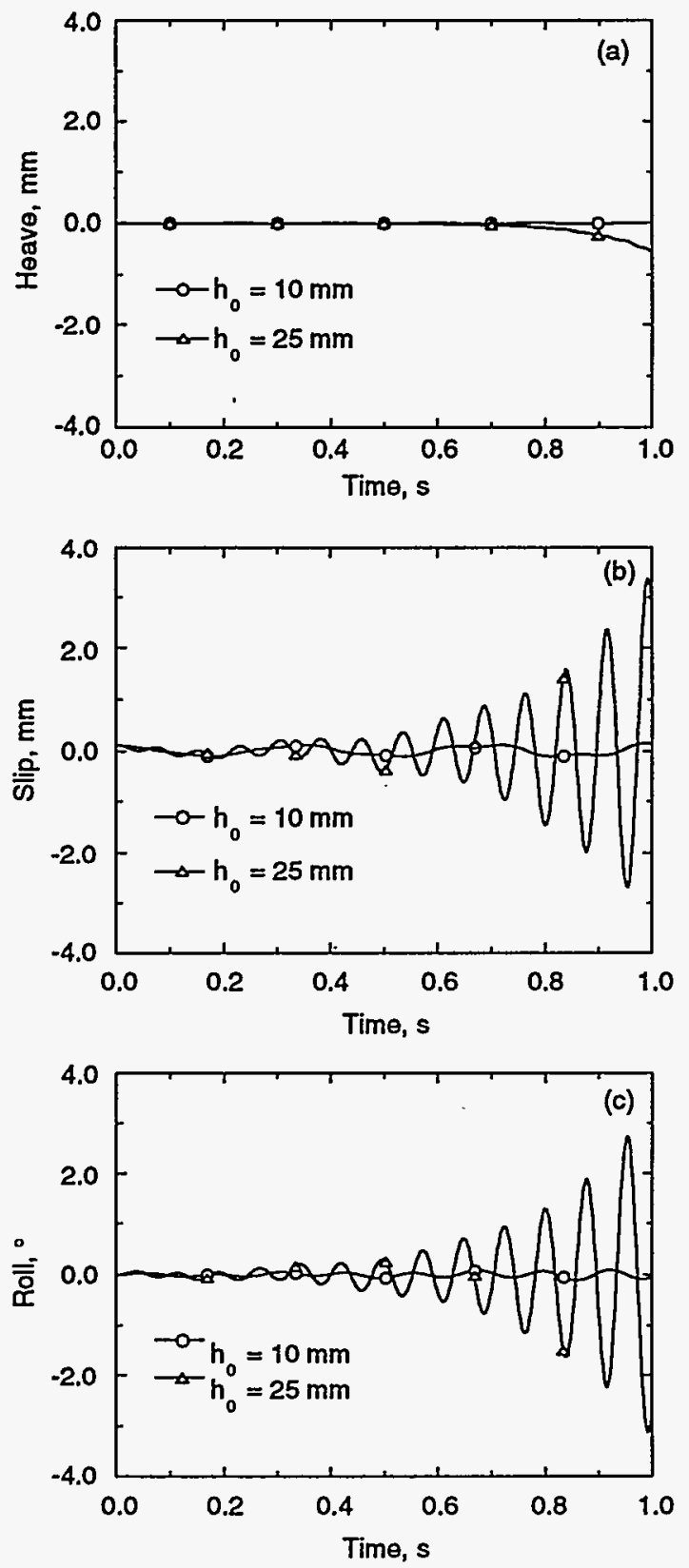

Fig. 9. Time histories of vehicle motions with various vertical air gaps ho when $g_{0}=12.7 \mathrm{~mm}$

- Various options can be used to stabilize a maglev system: passive or active electrodynamic primary suspension damping, and passive or active mechanical secondary suspension. With a better understanding of vehicle stability characteristics, a better control law can be adopted to ensure a high level of ride comfort and safety. 

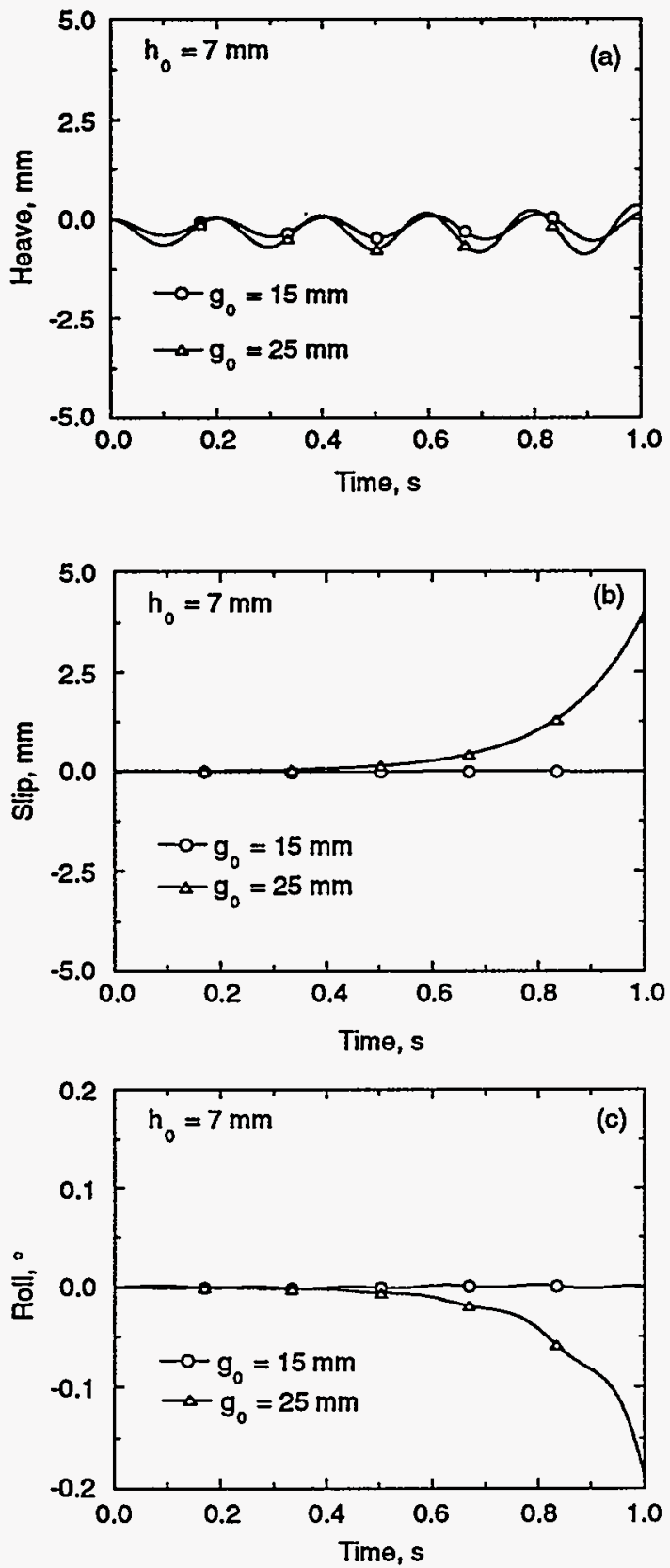

Fig. 10. Time histories of vehicle motions with various lateral air gaps go when $h_{0}=7 \mathrm{~mm}$

- Computer programs are needed to screen new system concepts, evaluate various designs, and predict vehicle response. It appears that the stability characteristics of maglev vehicles under various conditions have not been studied in detail in existing computer codes. 
When information on motion-dependent magnetic forces becomes available, the existing computer codes can be significantly improved.

- Instabilities of maglev-system models have been observed at ANL and other organizations. An integrated experimental/analytical study of stability characteristics is an important aspect of maglev research.

\section{Dynamics of Maglev Guideways}

The successful implementation of maglev systems will depend to a great extent on the feasibility of constructing safe and economical guideways. Maglev vehicles have unique requirements that make them different from other mass transportation systems. Some of these requirements impose greater demands on cost and/or serviceability than tracked guideways of low-speed conventional rail systems. Guideway dynamics significantly affect total capital investment and ride quality of maglev systems.

Structural configurations shall be based upon the parameters of strength, stiffness, manufacturing, erection, unit weight, maintenance, joint location, sectional efficiency, materials, depth, super- and substructure integrity, single vs. continuous spans, construction tolerances, and substructure height (GangaRao et al. 1992).

Ride quality plays a very crucial role in guideway design and construction. Greater ride comfort can be achieved by properly accounting for the following in guideway design and construction: geometric design, camber and deflection limits for service loads, differential movements of piers, construction tolerances, surface roughness, and construction and maintenance of joints (GangaRao et al. 1992).

\subsection{Guideway Structure}

A guideway can be constructed of continuous or discrete beams and can be either elevated or at ground level. The major structural design considerations are those of the substructure, superstructure, and construction material.

\subsubsection{Substructure}

Design of the substructure is aimed at providing economical support of the guideway beams to allow high-speed running and proper loading distribution. The relatively lightweight characteristics of maglev vehicles and the large 
horizontal loadings at high speeds may lead to unusual movement of the piers and footings due to high overturning moments.

Pier foundations may be placed on piles, depending on soil characteristics. One of the most economical and effective systems, chosen by Germany, consists of four concrete piles that are inclined so as to reduce pile bending (Heinrich and Kretzschmar 1987; Zicha 1986).

To reduce construction costs, a narrow guideway with widely spaced supports is desirable, whereas, to achieve an acceptable ride comfort level and/or to meet constraints on guideway stress, a wide guideway with narrow support spacing would be better. In meeting ride comfort specifications, guideway stiffness usually becomes the controlling factor. Furthermore, the amount of guideway flexibility and irregularity that can be tolerated depends on the vehicle suspension and other motion-controlling systems.

\subsubsection{Superstructure}

The guideway superstructure supports the maglev vehicles and the guidance, propulsion, and control equipment. Elevated structures may represent $\approx 40 \%$ of the initial system cost (Zicha 1986). Because vertical loadings are relatively small, torsional stiffness of the superstructure is required for stability. Therefore, a closed section (of the box-girder type) is desirable. Trapezoidal and rectangular sections are efficient in resisting loads in lateral, transverse, and longitudinal directions under bending and torsion (GangaRao et al. 1992). For example, the German Transrapid system at Emsland used a simple box girder with a horizontally cantilevered top plate or slab (Heinrich and Kretzschmar 1987). The steel girders and precast, prestressed, posttensioned, and reinforced concrete girders were manufactured and erected with state-of-the-art technology (He et al. 1991).

The beams of maglev systems are relatively stiff and vertical deflection is usually small. For example, the vertical deflection on the Emsland Test Track was specified to the span length divided by 4000 (Bohn and Steinmetz 1985; Menden et al. 1989) and British Railroads tested a guideway with a midspan static stiffness equal to $1 / 30$ of that at the Birmingham airport (North 1985). The required stiffness of the guideway depends on the dynamics of the coupled vehicle/ guideway systems.

Single- and/or multiple-span systems can be used for maglev guideways. Multiple-span systems have a smaller number of discontinuous joints than single-span systems, leading to improved ride quality. Comparison of dynamic 
responses of single- and multiple-span beams for a maglev vehicle traveling on a flexible guideway will be discussed in detail in Section 4 .

\subsubsection{Materials}

To match the expected low maintenance and great durability of maglev systems, the guideway should be constructed of materials that have a longer life than conventional structures that are used for wheel-on-rail tracks. Moreover, to make construction faster and less expensive, prefabricated support columns and guideway spans should be considered. Indeed, elevated superstructures in Japan and Germany have usually been prefabricated. In EMS systems, any of the common construction materials can be used; both steel and concrete girders have been developed. However, in EDS systems, steel girders generate magnetic drag.

While in motion, a magnetically levitated vehicle induces eddy currents in metal that is within the magnetic field of the lift magnets. These undesirable eddy currents cause electromagnetic forces (drag forces) that resist forward motion and lead to increased guideway component temperatures. Such temperature increases become a source of energy loss for maglev systems. Metal reinforcement within the guideway can greatly increase the drag force, depending on the system design. If steel reinforcement is used, steel mesh increases the drag force much more than individual steel rods, because the latter provide a better conducting path for eddy currents. Therefore, nonconducting materials, such as polymer-matrix composites, have been recommended for maglev guideways (GangaRao et al. 1992). Fiber-reinforced plastic composite materials appears to be very promising in terms of cost and performance, and may be applied to guideway superstructures, concrete reinforcement for piers or frames that support the guideways, walkways, cable ducts, and tunnel panels. Composite materials are magnetically inert; therefore, they may yield significant energy savings if they can be used in lieu of steel reinforcement. Glass, carbon, and aramid are commonly utilized to reinforce composite structures.

\subsection{Guideway Characteristics}

Cost must be minimized if a maglev system is to be economically feasible. Because guideway costs are significantly higher than vehicle suspension system costs, total costs can be minimized by trading off improved suspension system characteristics against increased guideway rigidity and tightened tolerances on guideway alignment and roughness. However, to conduct a quantitative study of such tradeoffs it is important to be able to express the guideway requirements in analytical terms that can be readily related to construction and maintenance costs (Hullender 1975). 
Guideway roughness can be measured and statistically studied to determine quantitative relationships between tolerances and resulting guideway smoothness. The guideway profile is the sum of (1) a static profile due to static deflection, construction tolerances, settlement movements, and thermal effects and (2) a dynamic profile due to guideway deflections from the moving vehicle. Therefore, the guideway profile may be expressed as

$$
G(x, t)=G_{s}(x)+G_{d}(x, t),
$$

where the total profile $G(x, t)$ is the sum of a static profile $G_{S}(x)$ that is a function of location, time of day, climate conditions, and age, and a dynamic profile $G_{d}(x, t)$ resulting from traveling vehicle loads.

Static irregularities depend on construction practice, settling, dead-weight loads, and environmental conditions. The following elements are important (Snyder and Wormley 1977):

- Differing pier heights, which may produce vertical offsets in the spans;

- Dead-weight loading, intentional camber, or thermal effects, which may produce span camber;

- Local surface variations, which may cause surface roughness.

To reduce aesthetic impact, a guideway with long spans is desirable. To meet ride quality standards or stress limits, the cross section should be large. In general, pier spacing is $15-45 \mathrm{~m}$ (50-150 ft). For most highway bridges $3-30 \mathrm{~m}$ (10$100 \mathrm{ft}$ ) in length, the fundamental frequency is $2-10 \mathrm{~Hz}$, whereas for railway bridges of the same lengths, it is 7-20 Hz. Low vehicle-to-guideway mass and frequency ratios are necessary to keep vibrational accelerations below $0.05 \mathrm{~g}$ at high vehicle speeds (Richardson and Wormley 1974).

The mass of the support/guidance system is coupled via the air gap with a maximum frequency of $<10 \mathrm{~Hz}$ (Rogg 1986). The natural frequencies of maglev guideways are $6-10 \mathrm{~Hz}$ (Zicha 1986). It is important to know the vibrational characteristics of the vehicle/guideway system to achieve acceptable ride quality.

The dynamic profile of a guideway is composed of periodic and random motions or disturbances. 


\subsubsection{Periodic Disturbances}

The motion of an elevated guideway with supporting posts will include periodic components. For example, a single-span guideway with its span $\lambda$ for a vehicle traveling with a speed $V$ will have a periodic disturbance $h$ of the form

$$
\text { or } \begin{aligned}
& \mathrm{h}=\mathrm{a} \sin \left(\Omega_{0} \mathrm{x}\right), \\
& \mathrm{h}=\mathrm{a} \sin \left(\omega_{0} \mathrm{t}\right),
\end{aligned}
$$

where $\mathrm{x}$ is the distance from a post, $\mathrm{a}$ is the deflection at the middle of the span, and

$$
\begin{aligned}
& \Omega_{0}=2 \pi / \lambda, \\
& \omega_{0}=\Omega_{0} \mathrm{~V} .
\end{aligned}
$$

In general, the guideway profile will contain an ensemble of waves such as periodic components with varying wavelength or frequency. The elevation of the surface profile at $x$ from a fixed reference post along the guideway may be expressed as

$$
\mathrm{h}=\sum_{\mathrm{n}} \mathrm{a}_{\mathrm{n}} \sin (\Omega \mathrm{x})
$$

or

$$
\mathrm{h}=\sum_{\mathrm{n}} \mathrm{a}_{\mathrm{n}} \sin (\omega \mathrm{t})
$$

where

$$
\begin{aligned}
& \Omega=\Omega_{0} \mathrm{n}, \\
& \omega=\Omega \mathrm{V},
\end{aligned}
$$

$a_{n}$ is the Fourier coefficient, and $\omega$ is the temporal angular frequency. The profile is frequently specified in terms of the intensity of each component $\left(a_{n}^{2}\right)$. The mean-square value is

$$
\overline{\mathrm{h}}^{2}=\Sigma \mathrm{a}_{\mathrm{n}}^{2} / 2,
$$

which is a discrete frequency spectrum. 


\subsubsection{Random Disturbances}

- In addition to periodic disturbances, the roughness of a guideway may exhibit random characteristics that are important to ride quality. These must be defined for easy application to vibration studies that are needed to evaluate ride quality. Roughness in general is measured along the guideway at equally spaced intervals. The differences between the measured points and a reference point as a function of the distance with respect to the reference point form the guideway variation data. From these data, power spectral density (PSD) can be evaluated in terms of wave number. For a specific traveling speed, the PSD can be transformed into the frequency domain.

Surface roughness of guideways can be described approximately by the PSD of the surface profile

$$
\mathrm{S}(\Omega)=\mathrm{A} / \Omega^{\mathrm{m}},
$$

where $S(\Omega)$ is the power spectrum of the surface, $\Omega$ is the wave number, and $A$ is the roughness amplitude. Based on a wide variety of experimental data, $m$ ranges from 1.5 for shorter wavelengths (up to $5 \mathrm{~m}$ ) to 2.5 for longer wavelengths (up to $100 \mathrm{~m}$ ). In the medium-to-longer wavelengths, the PSD curve may be approximated by a line with $\mathrm{m}=2$,

$$
\mathrm{S}(\Omega)=\mathrm{A} / \Omega^{2},
$$

where $\Omega$ is wave number (in $\mathrm{rad} / \mathrm{m}$ ), and $\mathrm{A}$ is roughness amplitude (in $\mathrm{m}$ ). Equation 15 has been widely used. The value of A ranges from $0.6 \times 10^{-6} \mathrm{~m}$ to $20 \times$ $10^{-6} \mathrm{~m}$. A guideway with roughness close to that of an aircraft runway can be represented by Eq. 15 , with $A=1.5 \times 10^{-6} \mathrm{~m}$. This equation is shown to be accurate for wavelengths of 2-60 m but becomes inaccurate at longer wavelengths (Fearnsides et al. 1974; Sussman 1984). Examples are given in Fig. 11 for the data associated with the first $915 \mathrm{~m}$ (3000 ft) of the U.S. Department of Transportation TACRV guideway at Pueblo, Colorado. Included in the figure are the PSDs determined by National Aeronautics and Space Administration for runways that need repair, newly constructed runways, and very smooth runways.

Another form of PSD is also used (Gottzein et al. 1974; Brock 1973):

$$
\mathrm{S}(\omega)=\mathrm{AV} / \omega^{2} .
$$

This equation implies that the acceleration PSD is $A V \omega^{2}\left(\right.$ in $\mathrm{m}^{2} / \mathrm{sec}^{4}$ per $\left.\mathrm{rad} / \mathrm{s}\right)$. 


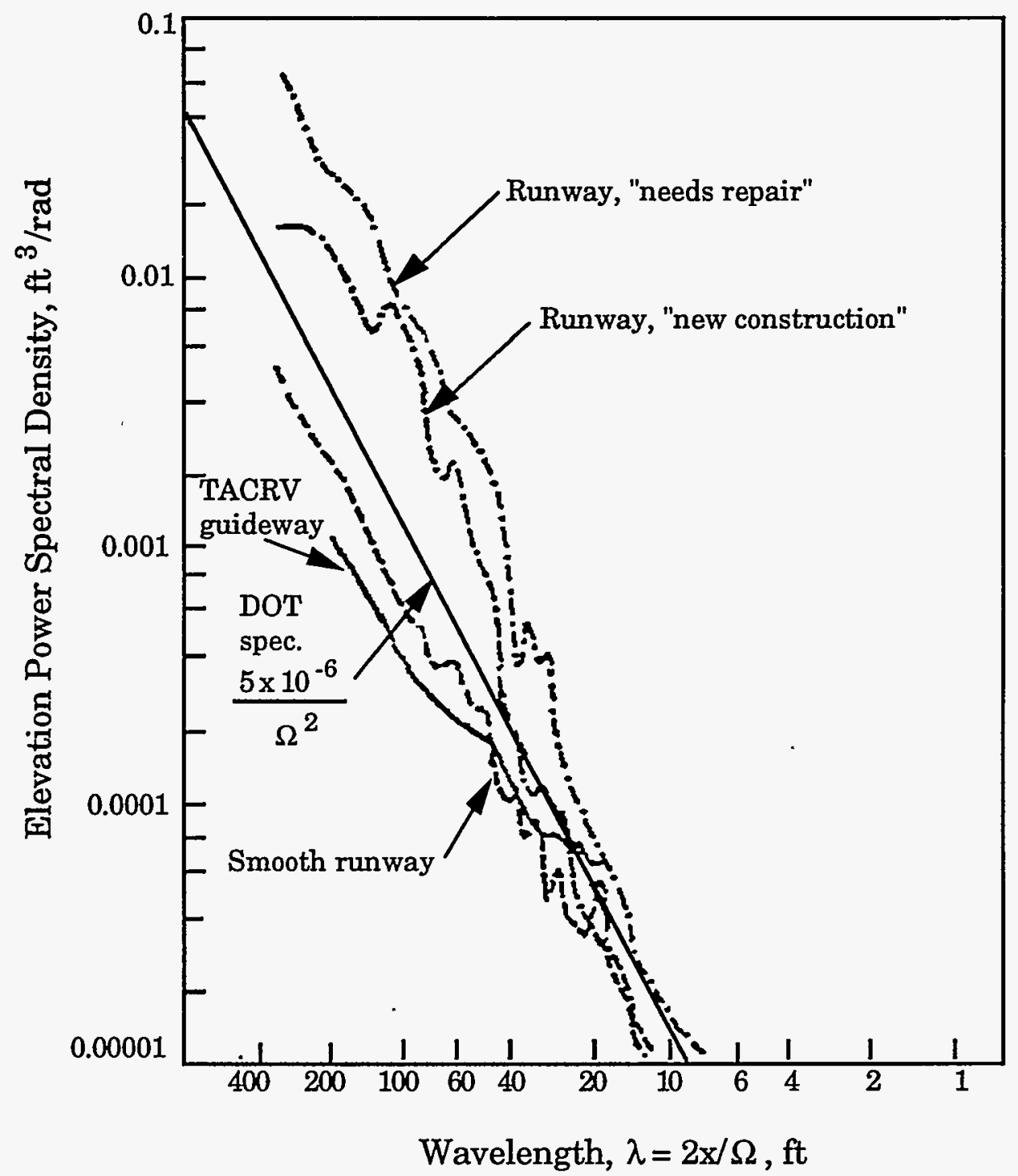

Fig. 11. Elevation power spectral densities for runways and first $3000 \mathrm{ft}$ of TACRV guideway (adapted from Hullender and Bartley 1975)

To define the correlation between the PSD associated with the surface roughness and the corresponding construction tolerances and constraints, a generalized equation was obtained by Hullender and Bartley (1975):

$$
\mathrm{S}(\Omega)=\left(4 \sigma^{2} / \lambda^{3} \Omega^{4}\right)(1-\cos \Omega \lambda),
$$


where $\sigma^{2}$ is the variance of the surface elevation and $\lambda$ is the span length. For wavelengths that are relatively long when compared with $\lambda$, Eq. 17 is simplified to Eq. 15 where

$$
A=2 \sigma^{2} / \lambda \text {. }
$$

Equation 18 can be used to relate the ride quality and guideway construction specifications to specific tolerances. For example, consider the U.S. Department of Transportation PSD specification for a $480-\mathrm{km} / \mathrm{h}(300-\mathrm{mi} / \mathrm{h})$ guideway, $1.4 \times 10^{-7} / \Omega^{2} \mathrm{~m}^{3} / \mathrm{rad}\left(5 \times 10^{-6} / \Omega^{2} \mathrm{ft} 3 / \mathrm{rad}\right)$. For a general span length of $23 \mathrm{~m}(75 \mathrm{ft})$, the corresponding standard deviation for construction and maintenance is $\sigma=(\mathrm{A} \lambda / 2)^{0.5}=0.417 \mathrm{~cm}(0.164 \mathrm{in}$.) (Hullender and Bartley 1975).

Equation 15 is convenient to use. However, data are available only for wavelengths of $\approx 2-120 \mathrm{~m}(5-400 \mathrm{ft})$, and applications of this equation outside of these bounds are questionable. In particular, for a high-speed maglev system, the critical wavelengths are on the order of $300 \mathrm{~m}(1000 \mathrm{ft})$. The roughness characteristics for such long wavelengths are important in a maglev system. Hullender and Bartley (1975) suggested that for long wavelengths, Eq. 15 can be written as

$$
\mathrm{S}(\Omega)=\mathrm{A} /\left(\Omega^{2}+\mathrm{C}\right) .
$$

This equation does not yield an infinitely large amplitude for irregularities with long wavelengths. More detailed studies are needed to quantify C. At this time, data pertaining to maglev guideways are very limited. It is expected, however, that the specification requirements for maglev will continue to improve.

To understand maglev characteristics, artificial guideway irregularities were deliberately added to the guideway (Yoshioka and Miyamoto 1986). The effects of the initial and artificial irregularities on the maglev vehicle were measured and calculated.

The PSD of the vehicle response is determined by the product of the vehicle transfer function and the guideway roughness PSD, whereas the RMS vehicle response is the square root of the integral of the vehicle response PSD. Therefore, the RMS vehicle response increases as the square root of the forward velocity. This shows that the problem of maintaining satisfactory ride comfort becomes more difficult as vehicle speed increases.

An important problem is to estimate the sensitivity of the guideway costs to the guideway roughness. To address this problem, it is helpful to define a system. 
A procedure for selecting guideway parameters for such a system definition can be briefly stated as follows (Ravera and Angeres 1974):

- Estimate an upper bound for guideway roughness.

- Select a span length range.

- Estimate an upper limit for guideway deflection due to the vehicle.

- Determine the vehicle response from an appropriate vehicle model and guideway information.

- Compare the vehicle response with the accepted ride-quality criteria.

If the accepted criteria are satisfied, the selected guideway parameters are appropriate. If not, the procedure is repeated. In addition, the procedure can be repeated for alternate construction techniques, thus allowing the least-expensive guideway to be chosen.

\subsection{Guideway Loads}

Guideways are subjected to different types of loads that must be considered in analyses.

\subsubsection{Static Loads}

The ratio of payload to total vehicle load in maglev systems is $\approx 20 \%$. For example, the dead weight per seat for a modern high-speed wheel-on-rail train is $\approx 1200 \mathrm{~kg}$ at $250 \mathrm{~km} / \mathrm{h}(2640 \mathrm{lb}$ at $157 \mathrm{mi} / \mathrm{h})$ whereas it is $520 \mathrm{~kg}(1145 \mathrm{lb})$ for the Transrapid 06 maglev system (Rogg 1986).

The pressure between wheel and rail for a high-speed train is higher than that of maglev systems by factors of 1000-10000. For example, the Transrapid 06 load is $\approx 6 \mathrm{~N} / \mathrm{cm}^{2}$ (Rogg 1986). Hence, the static loading for maglev is small when compared with steel-wheel on steel-rail systems.

\subsubsection{Impact Loads}

Large impact loads may be generated during touchdown of a maglev vehicle and when it is running over guideway joints, misalignments, and irregularities. Impact due to a vehicle fall caused by a sudden loss of magnetic field was 
described by British Rail as a critical guideway design parameter. The most severe loading case in the design of the Birmingham Airport maglev system was associated with a vehicle fall of $3 \mathrm{~cm}$ (1.125 in.) (Zicha 1986); dynamic response of the vehicle and guideway was also examined in an impact of two vehicles in tandem on a single guideway.

\subsubsection{Longitudinal Loads}

Longitudinal loads include magnetic and aerodynamic drag, as well as propulsion and braking forces. The magnetic drag on the Japanese National Railroad EDS is 2 tons at $51.5 \mathrm{~km} / \mathrm{h}(32 \mathrm{mi} / \mathrm{h})$ and it decreases with increasing speed; it is replaced by 2 tons of aerodynamic drag at $500 \mathrm{~km} / \mathrm{h}(310 \mathrm{mi} / \mathrm{h})($ Zicha 1986). Total drag on the EMS Transrapid 06 was 3.15 tons. The controlling longitudinal force for the guideway design is the emergency braking force. (For the Japanese EDS, the emergency braking system includes a mechanical friction brake sliding on the concrete guideway and an aerodynamic braking system [Fujie 1989]). Peak longitudinal acceleration during emergency braking is $\approx 0.3 \mathrm{~g}$.

\subsubsection{Lateral Loads}

Lateral loads are due to wind forces and to centrifugal and guiding forces inherent to high-speed maglev systems (see Section 6).

\section{Dynamic Vehicle/Guideway Interaction}

To design a guideway that provides acceptable ride quality, the dynamic interaction of vehicles and guideways must be understood. Furthermore, the trade-off between guideway smoothness and design of the levitation and control systems must be considered if the maglev system is to be economically feasible. The coupled vehicle/guideway dynamics are the link between the guideway and the other maglev components. Thus, reliable analytical and simulation techniques are needed in the design of vehicle/ guideway systems (Cai et al. 1992, 1994; Chen et al. 1992; Smith et al. 1975; Smith and Wormley 1975; Richardson and Wormley 1974; Limbert et al. 1979; Pickersgill 1990). Furthermore, the coupled vehicle/guideway dynamic model with multiple cars and multiple loads must be developed to meet the design requirements of maglev systems. This analytical model should also be easily incorporated into the computer code for dynamic simulation of maglev systems (Cai et al. 1992). 


\subsection{General Vehicle/Guideway Interaction Problem}

Figure 12 shows the essential elements of an interaction model for vehicles and guideways. As the vehicle moves, it is acted upon by external forces, suspension system forces, guidance system forces, and control system forces. The vehicle may deform if it is flexible. The suspension systems, as well as the guidance and control systems, respond to vehicle motion and guideway dynamics. The guideway responds to suspension system forces and support dynamics. The process of interaction is extremely complicated.

Analytical methods to predict dynamic vehicle/guideway interaction can be divided into three groups: lumped-mass, direct numerical, and modal-analysis methods. The lumped-mass method is simple and can be used easily to account for nonuniform properties, whereas the direct numerical method is accurate but requires more computer time. The modal-analysis method is an efficient compromise between the other two methods (Chen et al. 1992; Fryba 1972; Olsson 1985; Richardson and Wormley 1974).

In the modal-analysis method, the Bernoulli-Euler equation is used as the basis for solving distributed guideway dynamics, and space- and time-varying guideway motion is represented as an infinite summation of the natural-mode solutions. The summation is formulated as the infinite sum of the products of mode shapes and time-varying modal amplitudes. Time-varying modal amplitudes depend on the forcing functions (i.e., interaction forces between vehicle and guideway) and initial conditions.

In practice, a finite number of modes is used to represent guideway motion. The number of modes required for a given level of accuracy depends on the frequency of the guideway forcing function, the traverse speed of this function, and the beam properties.

Mode shapes are determined from the natural unforced vibration of the span and are affected by support boundary conditions at the ends of the beams, and, in the case of multiple-span beams, at intermediate supports. Boundary conditions are defined by the characteristics of the supports and the coupling between successive beam spans. The simplest case occurs for beams of only one span length, which are simply supported on rigid supports. If the beam extends over more than one span, then, at interior simple supports, the slope and bending moment must be continuous across the support. Single-, multiple-, and continuous-span guideway models for vehicle/guideway interaction in high-speed maglev systems can be found in the literature (Chiu et al. 1971; Smith et al. 1975; 


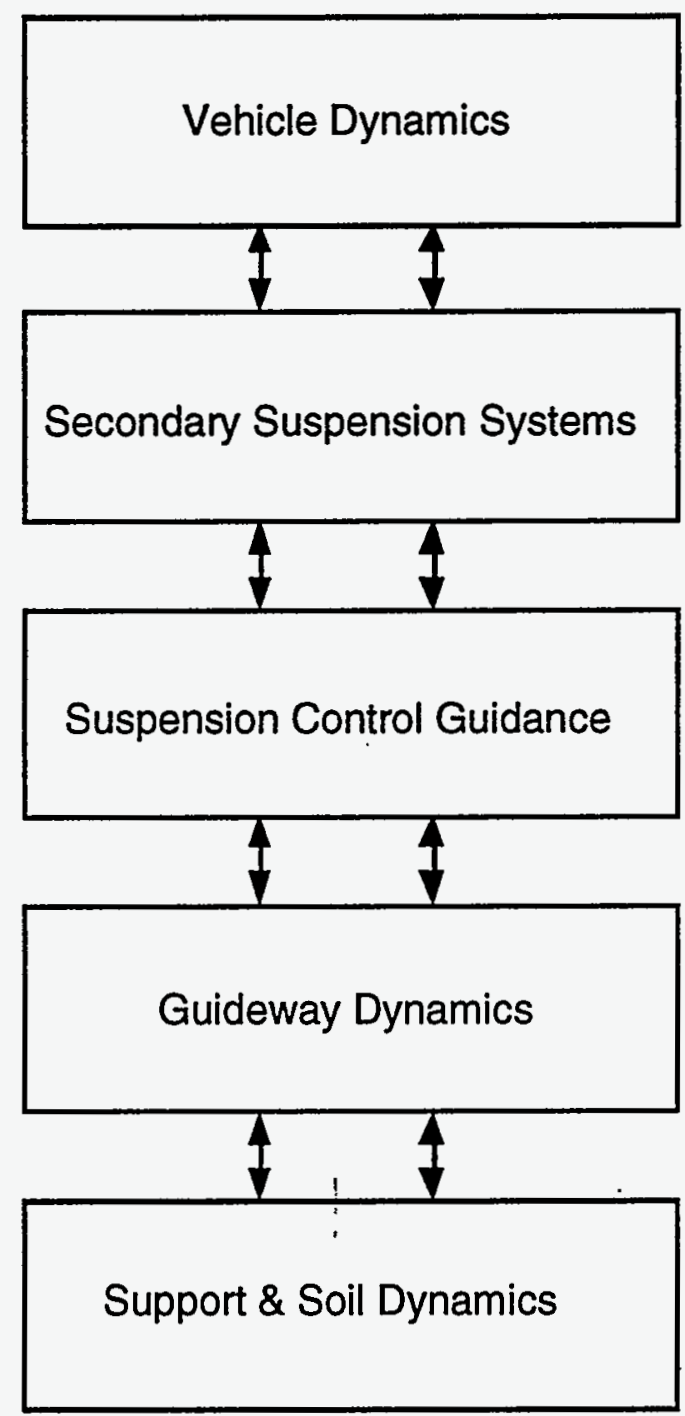

Fig. 12. Dynamics of vehicle/ guideway interaction

Smith and Wormley 1975). In most of these studies, however, vehicles were described as constant concentrated or distributed force traveling along the beams. Cai et al. (1992, 1993a) presented a detailed analysis for a two-DOF vehicle traveling along both single- and double-span guideways.

In a simplified model, the consideration of vertical motion of a maglev vehicle is based on the assumption that vertical motion is dominant and other motions can be ignored when the vertical motion is evaluated. This assumption is applicable in a system in which passenger compartment accelerations are limited to $<0.05 \mathrm{~g}$ and in which the unsprung-mass (i.e., mass associated with the primary suspension) inertia forces are small when compared with the vehicle weight (Richardson and Wormley 1974). 
For maglev vehicles restricted to accelerations of $<0.05 \mathrm{~g}$, the inertia force is much smaller than the static load, normally on the order of $5 \%$ or less. Also, the coupling will be small, i.e., if the dynamic suspension forces acting on the guideway are small when compared with the static forces due to vehicle weight, dynamic coupling will be small (Richardson and Wormley 1974). In this case, the guideway deflection profile is computed by assuming that the suspension forces are constant at their static values and move along the guideway at vehicle speed. The deflection is then used as a known displacement input into the suspension and the vehicle dynamic motions are obtained by standard transfer function analysis.

When the unsprung mass is $>25 \%$ of the vehicle mass, such as in an EMS system, or when vehicle accelerations can be $>0.1 \mathrm{~g}$, guideway deflection may be significantly affected by dynamic suspension forces, and a fully coupled analysis of vehicle/guideway interaction is needed. In the EMS system, the large accelerations of the primary suspension system mass due to guideway roughness cause significant excursions in magnet reaction force, and it appears that the vehicle/guideway equations should not be decoupled (Katz et al. 1974). However, once an active control system is used in the Transrapid system, the vehicle magnets follow the guideway very closely so that they constitute a very stiff system with only very small excursions. Cai et al. $(1992,1993 a)$ extensively investigated coupled effects of vehicle/guideway interactions in a wide range of vehicle speeds with various vehicle and guideway parameters for maglev systems and provided appropriate criteria for decoupling at critical vehicle speeds or crossing frequencies.

To evaluate a wide range of vehicle and guideway designs for an equally wide range of operating conditions, it is necessary to develop dynamic models to describe vehicle response and guideway interaction, as well as suspension and control systems. Various computer codes have been developed to provide the necessary dynamic simulations (Wang et al. 1991). Some computer codes have been developed for simulating dynamic interaction of vehicle/guideway when considering the guideway as a flexible beam (Cai et al. 1992; Phelan 1993b; Daniels and Ahlbeck 1993).

When the lift force fluctuates sinusoidally as a result of guideway roughness, a maglev system may experience both heaving and pitching oscillations. Analytical and experimental studies have been performed to understand this excitation mechanism (Yabuno and Takabayashi 1989).

Resonance of the guideway with external excitation may cause largeamplitude oscillations; this is parametric resonance. External excitation is due to magnetic forces, wind forces, vehicle motion, and other sources. For example, on 
the Miyazaki Test Track at $300 \mathrm{~km} / \mathrm{h}$, guideway oscillations are attributed to the coil pitch of the vehicle (Sato et al. 1985).

Evenly spaced coupled vehicles moving on a guideway at high speed can cause resonance of the guideway as the vehicles pass. A simply supported beam was considered by Iguchi and Hara (1985); at a specific speed, large oscillations occur, and methods, such as designing the guideway span equal to 1.5 times the distance between tracks, are recommended to avoid resonance in such situations.

\subsection{A Flexible Guideway Model}

For a flexible guideway, elastic deformation must be considered. The guideway vertical motion is excited by the full vehicle weight, whereas lateral and longitudinal motions are excited by only a fraction of vehicle weight; therefore, attention is focused on vertical guideway deflection when vehicle/guideway interactions are analyzed (Cai and Chen 1992; Cai et al. 1992, 1993a).

Beam theory has been verified as a good approximation for guideway dynamics when span width-to-length ratio is $<0.7$ (Richardson and Wormley 1974). For typical maglev guideway systems, span length-to-width ratios are large enough so that individual spans may be considered as beams rather than plates. Thus, a Bernoulli-Euler beam model can be applied to a freely supported, homogeneous, isotropic, and uniform-cross-section guideway.

The equations of motion for guideway spans where a multicar, multiload vehicle is traveling along may be derived as

$$
\mathrm{EI} \frac{\partial^{4} y_{k}}{\partial x^{4}}+C \frac{\partial y_{k}}{\partial t}+m \frac{\partial^{2} y_{k}}{\partial t^{2}}=F_{k}(x, t)
$$

where $\mathrm{x}$ is the axial coordinate of the beams, $\mathrm{t}$ is time, $\mathrm{EI}$ is the bending rigidity of the beams, $\mathrm{C}$ is the viscous damping coefficient (where we assume that damping in a span is linear, viscous damping), and $\mathrm{m}$ is the beam mass per unit length. $\mathrm{y}_{\mathrm{k}}$ is displacement of the $\mathrm{k}$-th beam where the vehicle is traveling. $F_{k}(x, t)$ is the excitation force of the $\mathrm{k}$-th beam due to the multicar, multiload vehicle acting on the beam,

$$
F_{k}(x, t)=\sum_{k_{1}=1}^{k_{n}} f_{k_{i}}(t) \delta\left(x_{k_{i}}-v t\right) .
$$


For simply supported beams, the boundary conditions of the $\mathrm{k}$-th beam are

$$
\begin{aligned}
& y_{k}(t, 0)=\frac{\partial^{2} y_{k}(t, 0)}{\partial x^{2}}=0, \\
& y_{k}(t, L)=\frac{\partial^{2} y(t, L)}{\partial x^{2}}=0 .
\end{aligned}
$$

If a double-span beam (i.e., total length is $2 \mathrm{~L}$ ) is present, the slope and bending moment at an interior simple support must be continuous (Cai et al. 1992); thus

$$
\begin{aligned}
& \left.y_{k}(t, x)\right|_{x \rightarrow L-}=\left.y_{k}(t, x)\right|_{x \rightarrow L+}=0, \\
& \left.\frac{\partial y_{k}(t, x)}{\partial x}\right|_{x \rightarrow L-}=\left.\frac{\partial y_{k}(t, x)}{\partial x}\right|_{x \rightarrow L+}, \\
& \left.\frac{\partial^{2} y_{k}(t, x)}{\partial x}\right|_{x \rightarrow L-}=-\left.\frac{\partial^{2} y_{k}(t, x)}{\partial x}\right|_{x \rightarrow L+},
\end{aligned}
$$

and

$$
y_{k}(t, 2 L)=\frac{\partial^{2} y(t, 2 L)}{\partial x^{2}}=0
$$

The initial conditions are

$$
\mathrm{y}_{\mathrm{k}}(\mathrm{x}, 0)=\frac{\partial \mathrm{y}_{\mathrm{k}}(\mathrm{x}, 0)}{\partial \mathrm{t}}=0
$$

In the modal-analysis method, displacement of the beam is expressed as

$$
y_{k}(x, t)=\sum_{n=1}^{\infty} q_{k n}(t) \varphi_{n}(x)
$$

where $q_{k n}(t)$ are time-varying modal amplitudes and $\varphi_{n}(x)$ are modal shape functions that are orthogonal over the beam length $0<x<L$. For a single-span beam,

$$
\varphi_{\mathrm{n}}(\mathrm{x})=\sqrt{2} \sin \left(\frac{\mathrm{n} \pi \mathrm{x}}{\mathrm{L}}\right)=\sqrt{2} \sin \left(\lambda_{\mathrm{n}} \frac{\mathrm{x}}{\mathrm{L}}\right), \quad \mathrm{n}=1,2,3, \ldots
$$


for a double-span beam

$$
\left.\begin{array}{c}
\varphi_{n}(x)=\sin \left[\frac{(n+1) \pi}{2} \frac{x}{L}\right]=\sin \left(\lambda_{n} \frac{x}{L}\right), \quad n=1,3,5,7,9, \ldots, \\
\varphi_{n}(x)=\sin \lambda_{n} \frac{x}{L}-\frac{\sin \lambda_{n}}{\sinh \lambda_{n}} \sinh \lambda_{n} \frac{x}{L} \\
0 \leq x \leq L \\
\varphi_{n}(x)=\sin \lambda_{n}\left(\frac{2 L-x}{L}\right)-\frac{\sin \lambda_{n}}{\sinh \lambda_{n}} \sinh \lambda_{n}\left(\frac{2 L-x}{L}\right) \\
L \leq x \leq L
\end{array}\right\} n=2,4,6,8,10, \ldots,
$$

where $\lambda_{n}$ in Eq. 29 (eigenvalue of the $n$-th mode for double-span beam vibration) is the solution of the characteristic equation

$$
\tan \lambda_{\mathbf{n}}=\tanh \lambda_{\mathbf{n}}
$$

The values of $\lambda_{n}$ obtained from Eq. 30 are 3.39, 7.07, 10.21, 13.35, .. .

$\mathrm{q}_{\mathrm{kn}}(\mathrm{t})$ are the solutions of the equations

$$
\frac{\mathrm{d}^{2} q_{\mathrm{kn}}}{\mathrm{dt}^{2}}+2 \zeta_{\mathrm{n}} \omega_{\mathrm{n}} \frac{\mathrm{dq} \mathrm{q}_{\mathrm{kn}}}{\mathrm{dt}}+\omega_{\mathrm{n}}^{2} q_{\mathrm{kn}}=\frac{1}{\mathrm{Lm}} \int_{0}^{L} \mathrm{~F}_{\mathrm{k}}(\mathrm{x}, \mathrm{t}) \varphi_{\mathrm{n}}(\mathrm{x}) \mathrm{dx},
$$

where $\omega_{n}$ and $\zeta_{n}$ (the circular frequency and modal damping ratio of the beams) are given by

$$
\omega_{\mathrm{n}}=\frac{\lambda_{\mathrm{n}}^{2}}{\mathrm{~L}^{2}} \sqrt{\frac{\mathrm{EI}}{\mathrm{m}}}, \quad \zeta_{\mathrm{n}}=\frac{\mathrm{C}}{2 \mathrm{~m} \omega_{\mathrm{n}}}
$$

Guideway surface irregularities are very important to the ride quality of maglev systems. These irregularities may be caused by imperfections in manufacturing and assembling of the structural components, as well as by thermal effects or surface wear. In practice, guideway surface irregularities are an important input to maglev vehicles and affect dynamic interactions (Cai et al. 1992, 1993a). Guideway irregularities can be measured and statistically studied to determine quantitative relationships between tolerances and resulting guideway smoothness. The guideway profile is the sum of a static and a dynamic profile. Static irregularities depend on construction practice, settling, dead-weight loads, 
and environmental conditions (Snyder and Wormley 1977). The dynamic profile of a guideway is composed of periodic and random motions or disturbances due to guideway deflections from the moving vehicle (Chen et al. 1992).

\subsection{Simplified Vehicle Models}

To simplify the vehicle model, only vertical motions of the vehicle are considered, based on the assumption that vertical motion is dominant and that other motions can be ignored when vertical motion is evaluated. This simplification is applicable in a system in which passenger compartment vertical accelerations are limited to $<0.05 \mathrm{~g}$ and in which vehicle unsprung mass (i.e., mass associated with the primary suspension) inertia forces are low when compared with vehicle weight. Thus, the influence of vehicle heave acceleration, which is of particular interest because it is used as a measure of passenger comfort, can be determined in this simplified model (Cai et al. 1992; Richardson and Wormley 1974).

In general, at least a two-suspension vehicle model is necessary to model primary and secondary suspensions of maglev vehicles (Cai et al. 1992; Richardson and Wormley 1974; Vu-Quoc and Olsson 1989). Lumped masses and passive parameters, such as linear springs and dashpots, are used to represent these suspensions. For example, in most cases, the secondary suspension was described as consisting of mass, spring, and dashpot, while the primary suspension consists only of spring or mass and spring without dashpot (Richardson and Wormley 1974). The model developed in our previous work included masses, springs, and dampings in both primary and secondary suspensions (Cai et al. 1992). The spring in the primary suspension represents the magnetic-gap stiffness, whereas the damping represents a passive damping control for magnets. Figure 13 presents a one-dimensional vehicle model with two DOF and consists of two lumped masses $m_{p}$ and $m_{s}$, two linear springs $k_{p}$ and $k_{s}$, and two viscous dampings $c_{p}$ and $c_{s}$, representing primary and secondary suspensions, respectively (Cai et al. 1992).

Wormley et al. (1992) proposed four simplified configurations of a onedimensional vehicle model with two DOF to represent several generic maglev vehicle suspensions. Their configurations have been represented with linear stiffness and damping elements and with sprung and unsprung mass elements. They can represent passive suspensions and many of the fundamental characteristics of active suspensions. In particular, they can represent active suspension functions in which forces are generated in response to measurements of either relative or absolute positions and velocities (Wormley et al. 1992). 


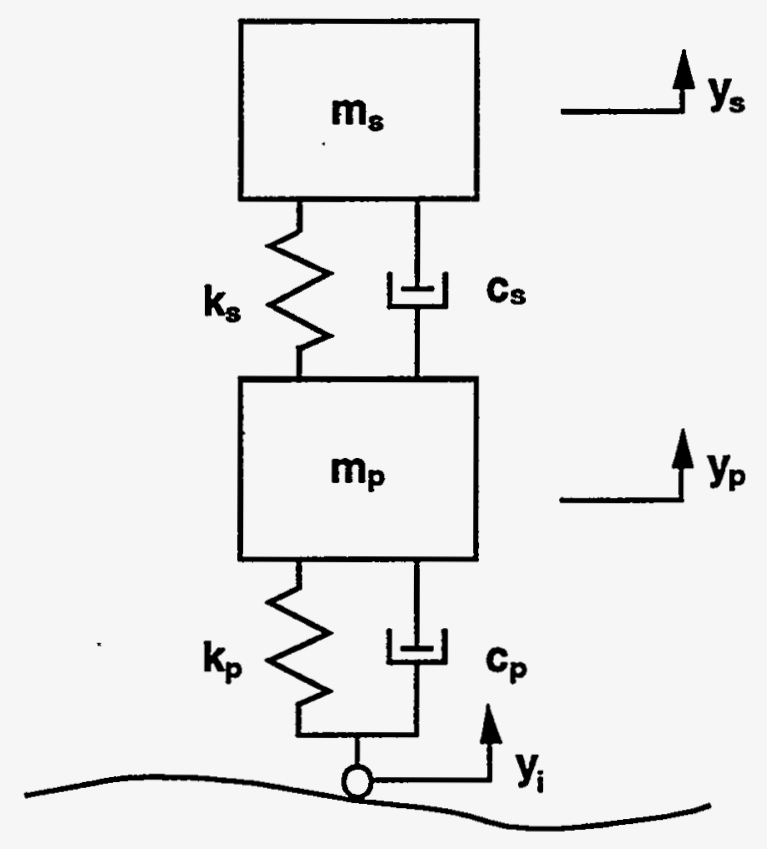

Fig. 13. One-dimensional two-DOF vehicle model with primary and secondary suspensions for maglev systems

Cai et al. (1993a, 1994) studied a vehicle model with two degrees of freedom to understand dynamic response characteristics under various loading conditions and vehicle/guideway parameters. The vehicle/guideway parameters, such as the ratio of the traveling speed to the critical speed, the ratio of the vehicle to the guideway mass and frequency, the ratio of the secondary suspension to the primary suspension mass and frequency, and the vehicle and guideway dampings, were considered in the analysis of vehicle/guideway interactions within the range of practical interest. The influence of these parameters on the magnitude of guideway deflection and vehicle acceleration ratios was evaluated, and results were compared with the situation in which vehicle acceleration forces are neglected and only a constant force due to the vehicle weight is applied on the guideway.

When vehicle acceleration forces are much lower than the constant force due to vehicle weight, a constant moving force can be used to represent the simplest vehicle model. Both concentrated and distributed moving forces were used as suspension forces in previous studies (Richardson and Wormley 1974). Cai et al. (1994) studied different cases for various combinations of constant and pulsating forces moving along the guideway and compared moving-force with quarter-car models. 
Only the single-car model can be found in most of the published literature that analyzes vehicle/guideway interactions (Cai et al. 1992, 1994). In practice, a maglev vehicle may include two or more cars. Moreover, couplings between car bodies will certainly affect vehicle/guideway dynamics because of constraint forces. Therefore, a model that represents a multicar vehicle should be developed to study dynamic analysis of vehicle/guideway systems. Cai et al. (1992) discussed the problems associated with modeling vehicle/guideway interactions and explained the response characteristics of maglev systems for a multicar, multiload vehicle traveling on a single- or double-span flexible guideway, with an emphasis on coupling effects of vehicle/guideway, comparison of concentrated and distributed loads, and ride comfort.

Daniels and coworkers $(1992,1993)$ investigated the dynamic response of vehicle/guideway interaction by using a multicar, multiload vehicle configuration for both EMS- and EDS-type vehicles traveling on simple or continuous-span guideways, in each of the three principal planes of motion. Therefore, the EMS vehicle model has $22 \mathrm{DOF}$ and the EDS vehicle model is represented by $14 \mathrm{DOF}$. These models are shown schematically in Fig. 14.

The suspension geometries and characteristics of the two fundamental approaches to the maglev system, EMS and EDS, are completely different. The EMS guideway gap is smaller than the EDS gap; therefore it produces a much higher electromagnetic suspension stiffness, which results in much closer dynamic coupling than is present in the EDS approach. The EMS design approximates a uniform suspension along the full vehicle length to achieve levitation, whereas the EDS design is closer to discrete load points on the guideway, a situation that is similar to conventional rail wheel loading. These differences in configuration and in coupling stiffness produce quite different vehicle/guideway interaction responses between the two maglev systems (Daniels et al. 1992; Daniels and Ahlbeck 1993).

If we consider a multicar, multiload, EDS-type vehicle traveling along a flexible guideway at a velocity $\mathrm{v}$, and the car body is rigid and has a uniform mass, the center of mass is consistent with that of the moment of inertia. Each car is supported by a certain number of magnets (or bogies) with linear springs and dampings, which form the primary and secondary suspensions of the vehicle. If there is only one magnet (i.e., the unsprung mass) attached to the vehicle, there is a single concentrated load and only one-dimensional motion (i.e., heave motion) of the vehicle. If there are multiple magnets on the vehicle, the loads are considered multiple or distributed and the vehicle is capable of both heave and pitch motions. 


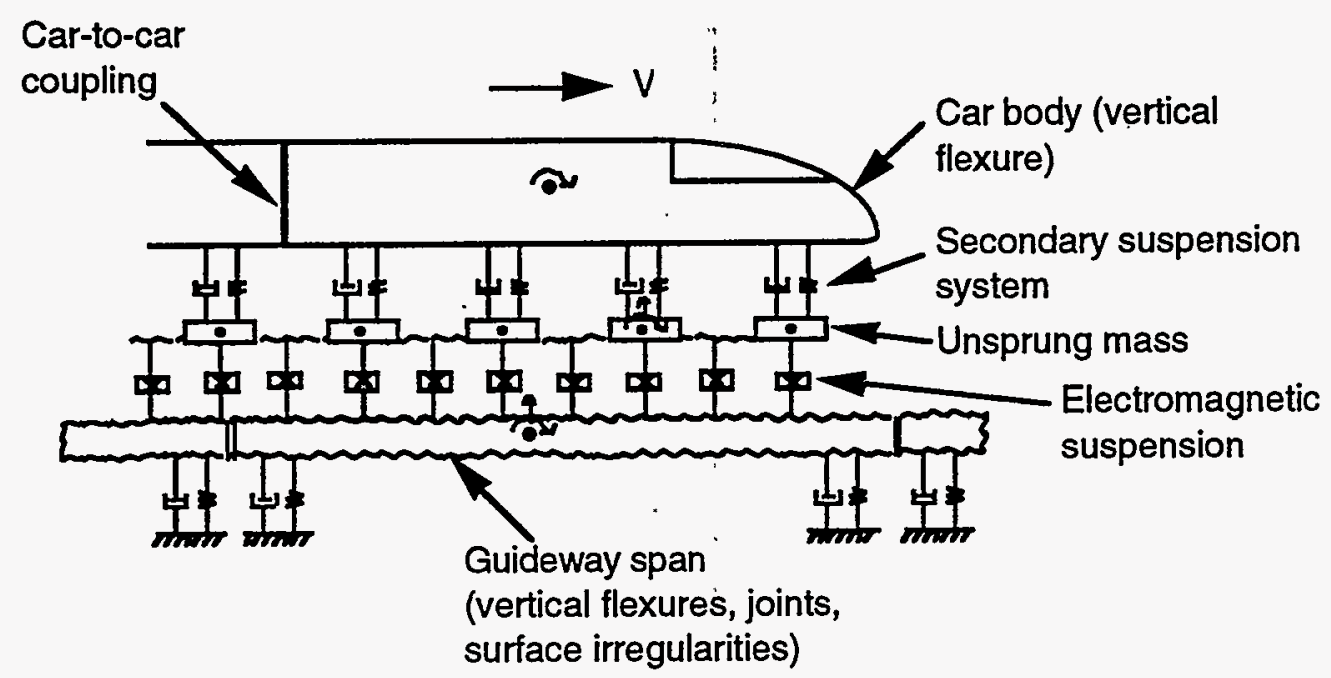

Model of EMS-Type Vehicle on Guideway

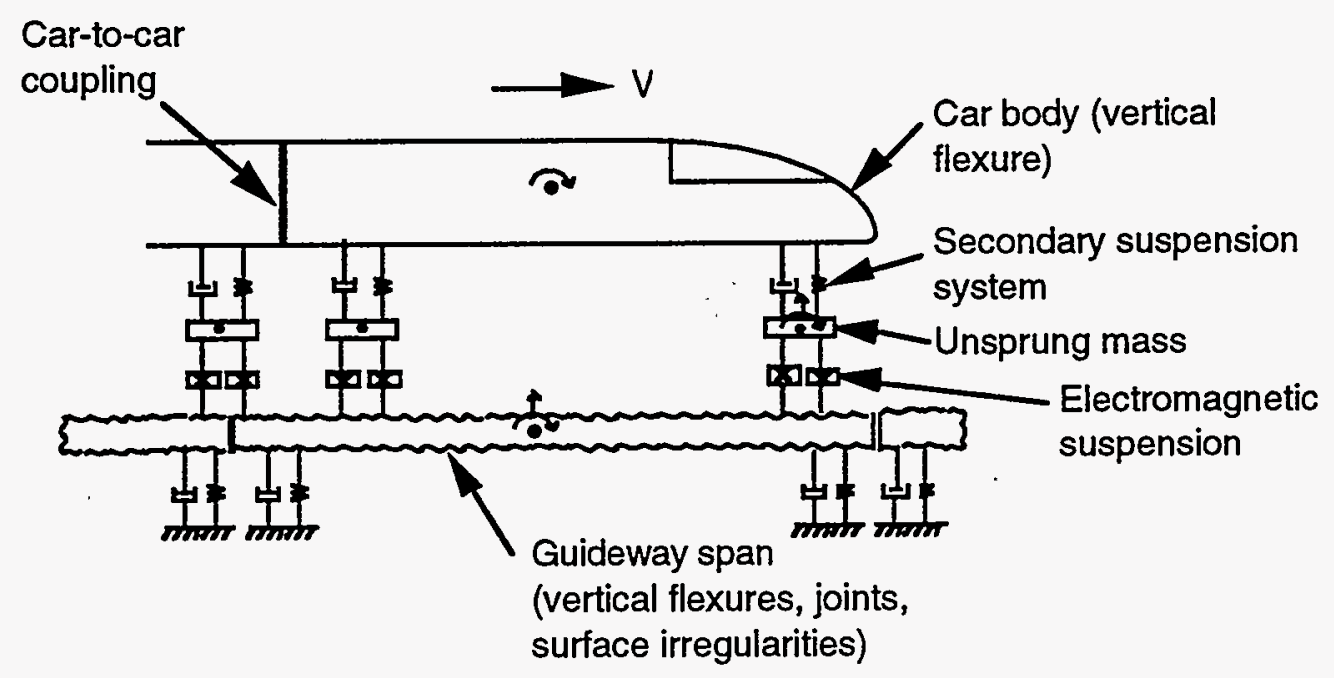

Model of EDS-Type Vehicle on Guideway

Fig. 14. EMS- and EDS-type vehicle models on guideway 
For the vehicle with only vertical motion, because this motion is dominant in the dynamic analysis of vehicle/guideway interactions, the equations of motion are

$$
\begin{aligned}
& m_{s} \ddot{y}_{s i}+c_{s} \sum_{j=1}^{N}\left(\dot{y}_{s i}-\dot{y}_{p i j}\right)+k_{s} \sum_{j=1}^{N}\left(y_{s i}-y_{p i j}\right) \\
& +c_{v}\left\{\left[\dot{y}_{s i}-\dot{y}_{s(i-1)}\right]+\left[\dot{y}_{s i}-\dot{y}_{s(i+1)}\right]\right\} \\
& +\mathrm{k}_{\mathrm{v}}\left\{\left[\mathrm{y}_{\mathrm{si}}-\mathrm{y}_{\mathrm{s}(\mathrm{i}-1)}\right]+\left[\mathrm{y}_{\mathrm{si}}-\mathrm{y}_{\mathrm{s}(\mathrm{i}+1)}\right]\right\}=-\mathrm{m}_{\mathrm{s}} \mathrm{g} \\
& (i=2, \ldots, M-1 ; j=1, \ldots, N) \\
& \mathrm{m}_{\mathrm{s}} \ddot{\mathrm{y}}_{\mathrm{s} 1}+\mathrm{c}_{\mathrm{s}} \sum_{\mathrm{j}=1}^{\mathrm{N}}\left(\dot{\mathrm{y}}_{\mathrm{s} 1}-\dot{\mathrm{y}}_{\mathrm{p} 1 \mathrm{j}}\right)+\mathrm{k}_{\mathrm{s}} \sum_{\mathrm{j}=1}^{\mathrm{N}}\left(\mathrm{y}_{\mathrm{s} 1}-\mathrm{y}_{\mathrm{p} 1 \mathrm{j}}\right) \\
& +c_{v}\left(\dot{y}_{s 1}-\dot{y}_{s 2}\right)+k_{v}\left(y_{s 1}-y_{s 2}\right)=-m_{s} g \\
& (i=1 ; j=1, \ldots, N) \\
& \mathrm{m}_{\mathrm{s}} \ddot{y}_{\mathrm{sM}}+\mathrm{c}_{\mathrm{s}} \sum_{\mathrm{j}=1}^{\mathrm{N}}\left(\dot{\mathrm{y}}_{\mathrm{sM}}-\dot{\mathrm{y}}_{\mathrm{pMj}}\right)+\mathrm{k}_{\mathrm{s}} \sum_{\mathrm{j}=1}^{\mathrm{N}}\left(\mathrm{y}_{\mathrm{sM}}-\mathrm{y}_{\mathrm{pMj}}\right) \\
& +c_{v}\left[\dot{y}_{s M}-\dot{y}_{s}(M-1)\right]+k_{v}\left[y_{s M}-y_{s}(M-1)\right]=-m_{s} g \\
& (i=M ; j=1, \ldots, N)
\end{aligned}
$$

and

$$
\begin{array}{r}
m_{p} \ddot{y}_{p i j}+c_{p}\left(\dot{y}_{p i j}+\dot{y}_{g i j}\right)+k_{p}\left(y_{p i j}+y_{g i j}\right) \\
-c_{s}\left(\dot{y}_{s i}-\dot{y}_{p i j}\right)-k_{s}\left(y_{s i}-y_{p i j}\right)=-m_{p} g \\
(i=1, \ldots, M ; \quad j=1, \ldots, N),
\end{array}
$$


where lumped masses $m_{p}$ and $m_{s}$, linear springs $k_{p}$ and $k_{s}$, and dampings $c_{p}$ and $c_{s}$ represent primary and secondary suspensions; the displacement of two suspensions are $y_{p}$ and $y_{s}$; subscripts $i$ represent the $i$-th car body and $j$ represents the $j$-th magnet on the $i$-th car; $M$ is number of cars; $N$ is number of magnets on each car; and $\mathrm{k}_{\mathrm{v}}$ and $\mathrm{c}_{\mathrm{v}}$ are intercar stiffness and damping, representing constraints between adjacent cars; and $y_{g i j}$ is guideway displacement input at the $i$-th car and the $j$-th magnet. For a magnetic primary suspension, $k_{p}$ and $c_{p}$ represent magnetic gap stiffness and passive damping.

Uncoupled natural frequencies and modal damping ratios are defined as follows:

$$
\begin{array}{ll}
\omega_{\mathrm{p}}=\sqrt{\frac{\mathrm{k}_{\mathrm{p}}}{\mathrm{m}_{\mathrm{p}}}}, \quad \zeta_{\mathrm{p}}=\frac{\mathrm{c}_{\mathrm{p}}}{2 \mathrm{~m}_{\mathrm{p}} \omega_{\mathrm{p}}}, \\
\omega_{\mathrm{s}}=\sqrt{\frac{\mathrm{Nk}_{\mathrm{s}}}{\mathrm{m}_{\mathrm{s}}}}, \quad \zeta_{\mathrm{s}}=\frac{\mathrm{Nc}_{\mathrm{s}}}{2 \mathrm{~m}_{\mathrm{s}} \omega_{\mathrm{s}}} .
\end{array}
$$

If $M=1$ and $N=1$ in Eqs. 35 and 36, the vehicle appears to be a two-DOF model (Fig. 13) that provides a relatively simple explanation of the dynamic behavior of vehicle/guideway systems (Cai et al. 1992, 1994).

\subsection{Dynamic Analysis of Vehicle/Guideway Interactions}

\subsubsection{Single- and Double-Span Guideways}

For a two-DOF vehicle traveling on a flexible guideway, Fig. 15 shows the maximum guideway displacement ratio $\mathrm{Y}_{\mathrm{g}}\left(=\mathrm{y}_{\mathrm{g}} / \mathrm{y}_{\mathrm{m}}\right)$ and maximum vehicle acceleration ratios $\ddot{\mathrm{Y}}_{\mathrm{p}}\left(=\ddot{\mathrm{y}}_{\mathrm{p}} / \mathrm{y}_{\mathrm{m}}\right)$ and $\ddot{\mathrm{Y}}_{\mathrm{s}}\left(=\ddot{\mathrm{y}}_{\mathrm{s}} / \mathrm{y}_{\mathrm{m}}\right)$ for both primary and secondary suspensions as a function of the vehicle-traveling-speed ratio $v / v_{c}$ on both singleand double-span guideways. For a single-span beam, the peak of maximum displacement ratio is $\approx 1.7$ when $\mathrm{v} / \mathrm{v}_{\mathrm{c}}$ is $\approx 0.6$ for an uncoupling model, whereas, for a coupling model, the peak of maximum displacement decreases to 1.5 when $\mathrm{v} / \mathrm{v}_{\mathrm{c}}$ is $\approx 0.4$. When $\mathrm{v} / \mathrm{v}_{\mathrm{c}}$ is $<0.4$, the coupled and uncoupled modes remain in good agreement. Therefore, for small values of $\mathrm{v} / \mathrm{v}_{\mathfrak{c}}$, an uncoupling model may be sufficient to simulate dynamics of vehicle/guideway systems, i.e., dynamic motion of the vehicle and guideway can be decoupled, the vehicle may be considered a moving force on the guideway, and guideway deflection is then used as a known displacement input into the suspensions. For a double-span guideway, when the vehicle-traveling-speed ratio $\mathrm{v} / \mathrm{v}_{\mathrm{c}}<0.5$, the maximum displacement ratios at both $\xi=0.5$ and $\xi=1.5(\xi=\mathrm{x} / \mathrm{L})$ are much smaller than 


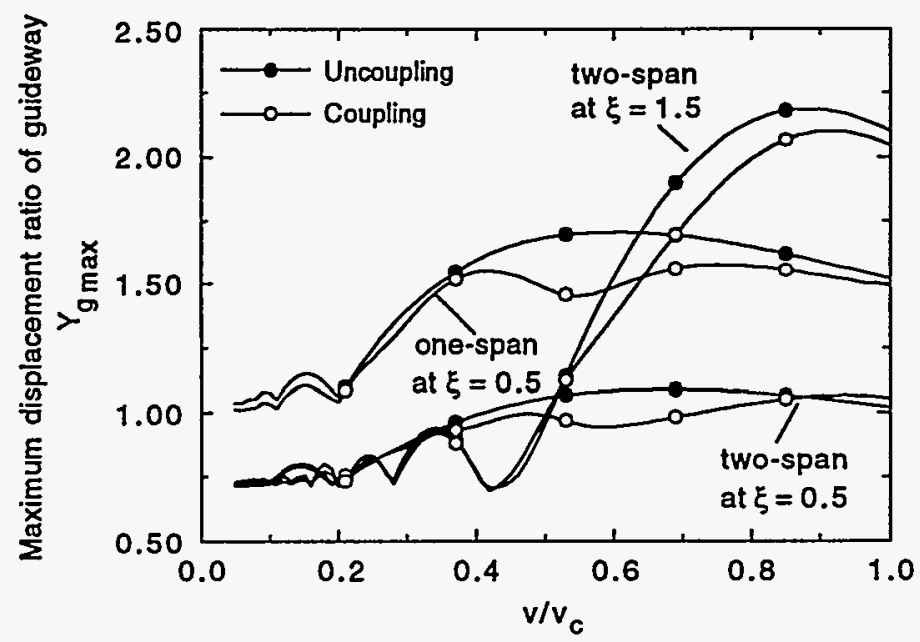

Fig. 15. Effects of single-span and double-span beams on maximum guideway displacement and vehicle acceleration ratios for a two-DOF vehicle

those observed for the single-span guideway. The differences between uncoupling and coupling models for the double-span guideway are smaller than those of the single-span guideway. From comparisons of vehicle accelerations, the amplitudes of maximum accelerations of both primary and secondary suspensions for the double-span guideway are lower than those of the single-span guideway. Because $\mathrm{v} / \mathrm{v}_{\mathrm{c}}$ in maglev systems is expected to be no larger than 0.5 (Sinha 1987), and without considering other factors, a two-span beam appears to be more efficient in achieving better ride quality.

\subsubsection{Effects of Distributed Loads}

In a dynamic analysis of vehicle/guideway interactions, an understanding of the effects of distributed loads is essential. In a single-car vehicle, for any given span configuration, span deflections decrease as the number of magnets is increased and total force is held constant. These effects exist when the vehicle travels at certain speeds. Figure 16 shows the maximum midspan deflections as a function of vehicle traveling velocity when one, two, four, and eight magnets are attached to a single-car vehicle. Apparently, the one-magnet case, which represents a two-DOF vehicle with a concentrated load, causes the largest beam deflection. The responses of four and eight magnets exhibit almost the same order deflections when the traveling velocity is $>50 \mathrm{~m} / \mathrm{s}$.

After comparing the dynamic effects of several point-concentrated and fully distributed vehicle loads, Phelan (1993a) concluded that guideway residual vibration can be reduced by strategically spacing vehicle pads. This conclusion 


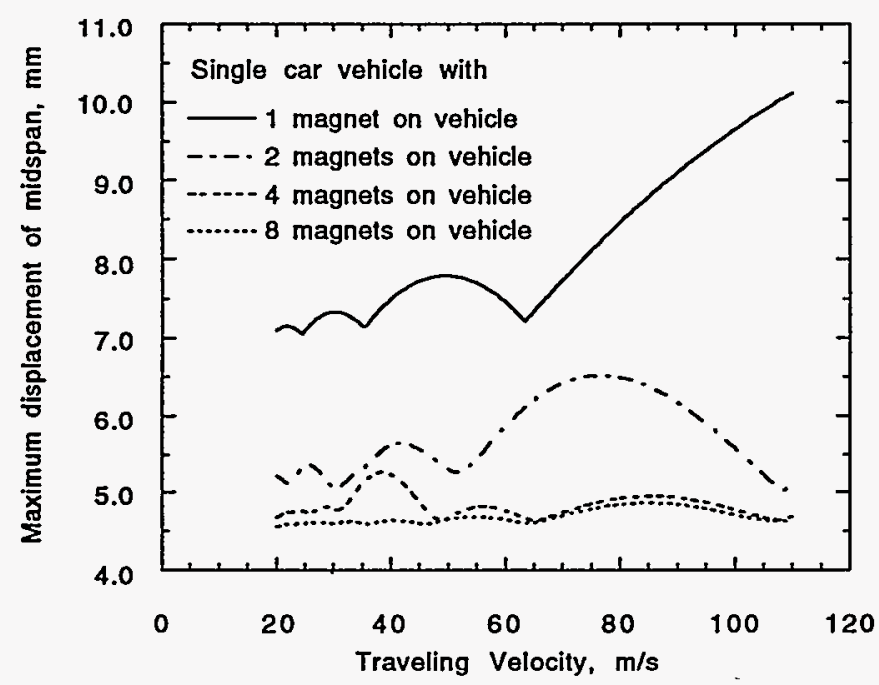

Fig. 16. Maximum midspan displacements of guideway when a single car with various magnets travels along the guideway at various speeds

means that a vehicle length and loading pad configuration can be adjusted for a particular beam to produce convergent conditions, whereby all beam residual vibration is canceled at desired vehicle speed ranges. The ability to cancel beam residual response is remarkable and potentially has several important maglev design implications, including benefits such as increased guideway lifespan, reduced nonmagnetic concrete reinforcement requirements, and potentially shorter operational vehicle headway allowances (Phelan 1993a).

\subsubsection{Dynamics of Multicar Vehicle}

Figure 17 shows midspan beam deflections when multicar vehicles $(1,2,3$, and 4 cars) travel at $100 \mathrm{~m} / \mathrm{s}$. No matter how many cars are included in the vehicle, the maximum beam deflection remains the same; however, the duration of deflections increases as car number increases.

Further results and discussion about multiple-car dynamics can be found in the literature (Cai et al. 1992), including maximum guideway displacements, car body accelerations, effects of intercar constraints, and satisfaction with ride comfort. Daniels and coworkers $(1992,1993)$ compared the responses of EMS and EDS system dynamics for various guideway configurations. The EDS system produces a resonance in the $200-400 \mathrm{~km} / \mathrm{h}$ speed range but generally exhibits much lower response outside the resonance range; the EMS system responds 


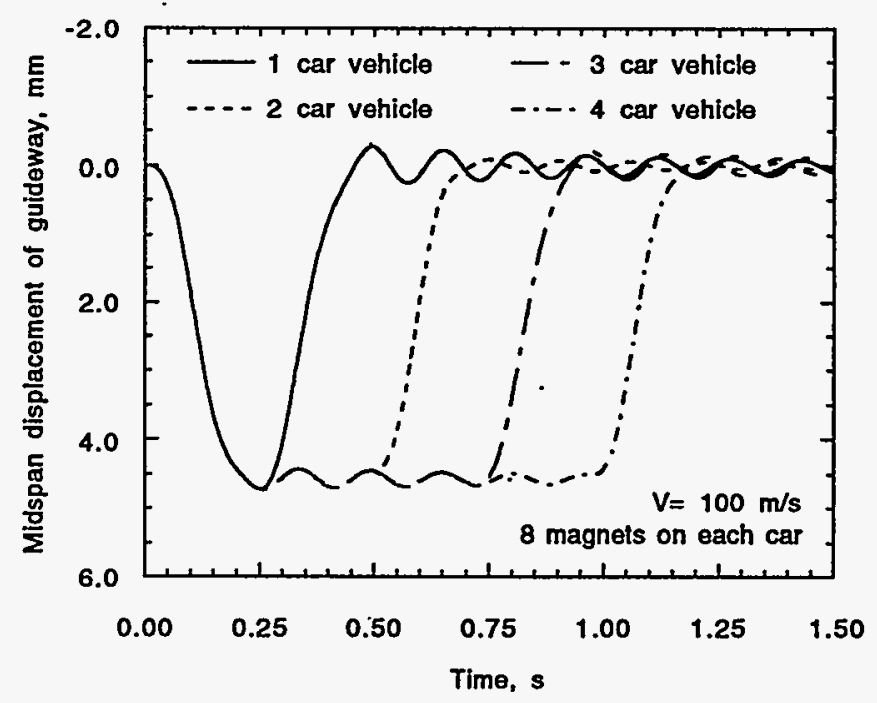

Fig. 17. Midspan displacements of guideway for multicar vehicles with eight magnets on each car traveling along the guideway at $100 \mathrm{~m} / \mathrm{s}$

with increasing accelerations as speed increases, but largely without the EDS $200-400 \mathrm{~km} / \mathrm{h}$ resonance. The slope of the curves becomes steeper at a speed between 400 and $500 \mathrm{~km} / \mathrm{h}$ for EMS-type vehicles, depending on the configuration.

\subsection{Remarks}

It is necessary to determine the trade-offs between large-gap (EDS) and small-gap (EMS) systems with respect to guideway costs in terms of initial construction and maintenance. However, only a few data are available for comparison and identification of the critical parameters for EDS and EMS in terms of guideway tolerances and stiffness requirements to meet appropriate ride quality (Chen et al. 1992; Daniels et al. 1992; Daniels and Ahlbeck 1993). Several research needs can be identified:

- The critical system parameters for EDSs and EMSs relative to guideway costs should be identified and studied and the relationships quantified. The sensitivity of guideway costs to the use of single- versus trained-vehicle sets is an important issue that requires qualification.

- A series of appropriate vehicle/guideway interaction models should be developed to assess the requirements for guideway design for both EDSs and EMSs. 
- Design guidelines for future maglev systems should be developed with the best existing technologies.

- Very few experimental data are available for a well-instrumented vehicle/guideway system, and further detailed data on guideways, vehicles, suspension forces, and motions would be valuable.

- Intentional guideway camber (Snyder and Wormley 1977) can improve ride quality under some operating conditions; further study is needed to determine its effectiveness under various operating conditions and to find ways to control camber magnitude in practical structures.

- Maglev vehicles themselves may be flexible. The vehicle bending modes may be excited and may produce. significant variations in acceleration and guideway deflection from those predicted when the vehicle is assumed to be rigid; these must be studied.

- The effect of support dynamics on vehicle performance can be improved by proper design of support damping, mass, and stiffness. Experimental studies of support constraints, including damping, rigidity, and apparent mass of guideway piers and beam attachment elements, are of particular interest.

- The lateral and torsional behavior of vehicle guideway systems requires additional attention, and the dynamic interaction between vehicles and curved guideways must.be adequately investigated.

\section{Ride Quality}

The level of human comfort offered by a moving vehicle is known as ride quality and is determined by changes in motion in all directions, and by other environmental effects. Of major importance is ride quality due to motion changes, i.e., the capability of a vehicle to limit its motion within the range of human comfort. A rigorous analysis of ride quality is difficult because it depends on many physiological and environmental factors, as well as on human perception, which is highly subjective and difficult to quantify precisely.

Ride quality is important because (1) a smooth ride is important in determining the potential of maglev systems, (2) initial investment costs will be lower when a design is not overly conservative in terms of ultimate ride quality, and (3) maintenance costs may be lower if the design is not overly conservative 
(Fearnsides et al. 1974). The potentially high costs of maglev systems are not necessarily due to exotic construction techniques or materials or to innovative designs; rather, they may be due to uncertainties associated with meeting specifications for unconventional designs.

A primary objective in designing a maglev system of the EMS type is to maintain an air gap close to the value chosen to avoid contact of the magnets with the guideway. Consequently, the suspension magnets closely follow the guideway profile. In EDS systems with larger clearances, the gap is adjusted to assist in achieving ride comfort while avoiding contact with the guideway. In either system, ride quality is ultimately determined by the horizontal and vertical profile of the support guideway and by the levitation and guidance systems.

The human body is sensitive to vibration in the frequency range of $\approx 0.5-20 \mathrm{~Hz}$, because most body-organ resonances occur in this range. For the hand/arm system, the sensitive range is up to $2 \mathrm{kHz}$. In the low-frequency range of $<1 \mathrm{~Hz}$, vibration can cause motion sickness; the effects of such low-frequency vibration depend on complicated individual characteristics and are not simply related to the intensity, frequency, or duration of motion. Therefore, most criteria for ride comfort are established for a frequency range of $=0.5-80 \mathrm{~Hz}$.

Ride quality also depends on vehicle velocity, acceleration, jerking, and other factors such as noise, dust, humidity, and temperature. Overall ride quality can be determined by either the fatigue time method or the ride index method.

\subsection{Fatigue Time Method}

A person traveling in a vehicle will experience fatigue after a certain period of time, depending on the conditions of the vehicle motion; this duration is known as the fatigue time.

\subsubsection{Early Criteria (Sinha 1987)}

Studies of ride quality during the 1930s were based on the perception levels of the human body when exposed to short periods of oscillations at various sinusoidal frequencies. Several definitions of ride comfort were developed; among them, the Janeway limits for ride quality were widely used until the 1960s. The criteria given in Fig. 18 are based on sinusoidal oscillations at discrete frequencies. If the RMS amplitude of each of the sinusoidal components does not exceed the proposed limits, the ride should be comfortable. 


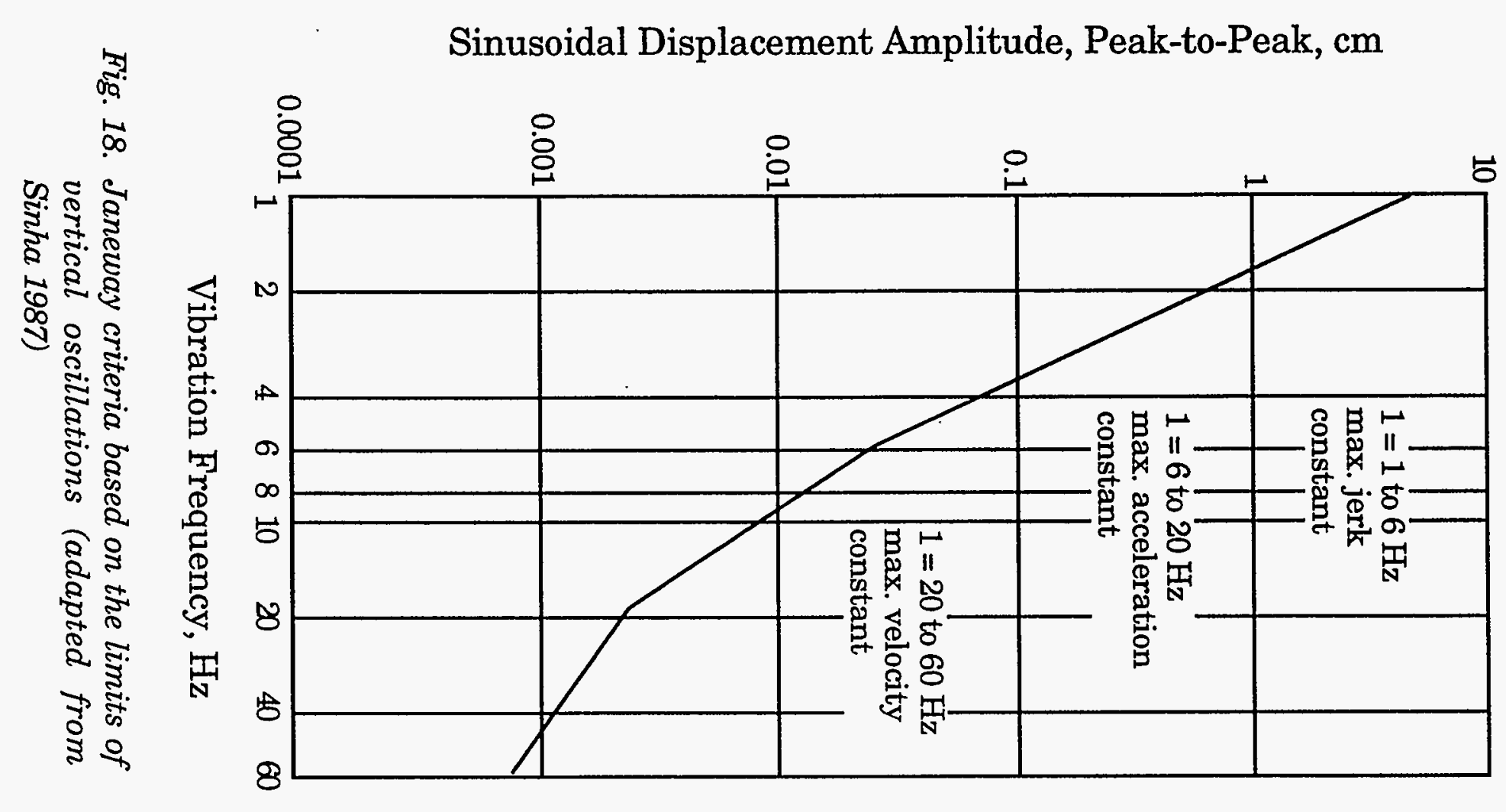




\subsubsection{International Standards Organization Criterion (Sinha 1987; Garg and Dukkipati 1984)}

In 1974, the International Standards Organization (ISO) specified the levels of vertical and horizontal RMS acceleration at discrete frequencies in three different groups: exposure limit, fatigue-decreased proficiency boundary (equal to $\approx 1 / 2$ of the exposure limit), and reduced-comfort boundary (equal to $\approx 1 / 3$ of the fatigue-decreased proficiency boundary) for an 8-h exposure time. Although the ISO guide does not define acceleration limits for passenger vehicles, the reducedcomfort boundary is generally taken as the definition of acceptable ride quality.

During the early development of air-cushion vehicles, more formal definitions of acceleration profile were adopted as criteria; these are shown in Fig. 19. Later, it was recognized that it is better to specify ride characteristics in terms of the PSD of vehicle motion.

\subsubsection{Urban Tracked Air Cushion Vehicle Criterion}

In 1971, the U.S. Department of Transportation proposed a new guideline, known as the Urban Tracked Air Cushion Vehicle (UTACV) criterion, which is given in Fig. 20. It has been widely used to study the dynamic behavior (due to the PSD of guideway surface roughness) of advanced ground transportation vehicles.

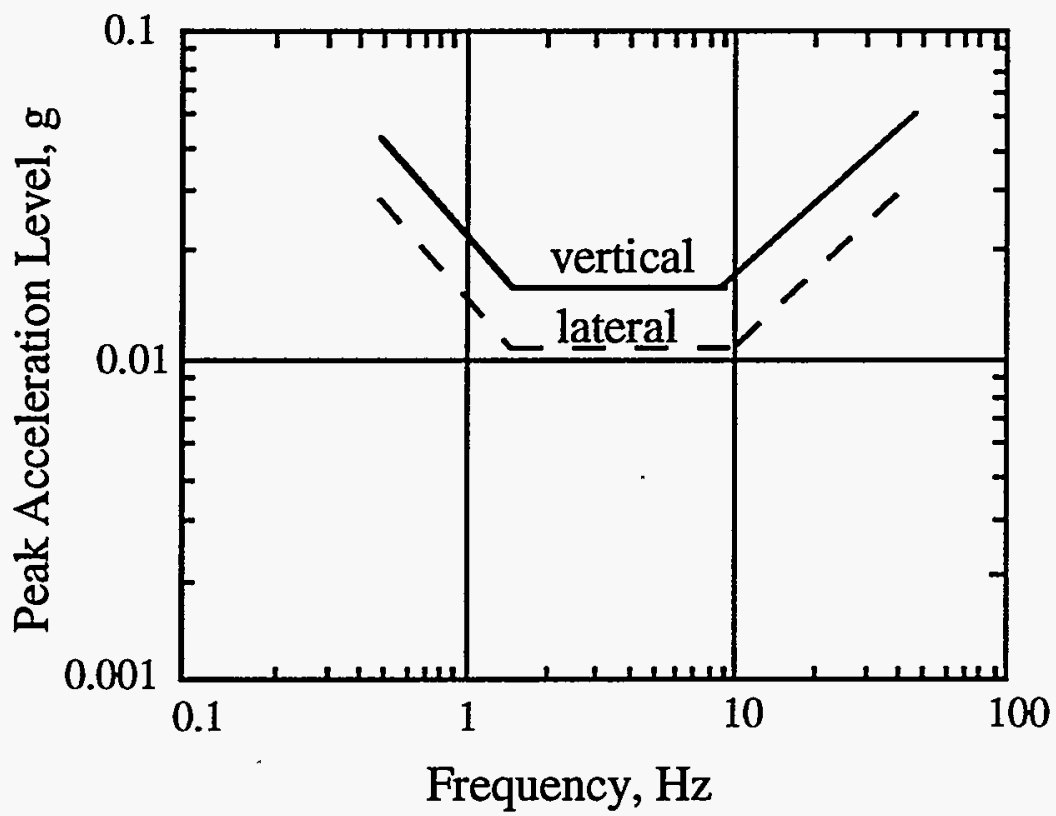

Fig. 19. ISO limits of sinusoidal vertical and lateral acceleration levels for high-speed vehicles in the early 1960s (adapted from Sinha 1987) 


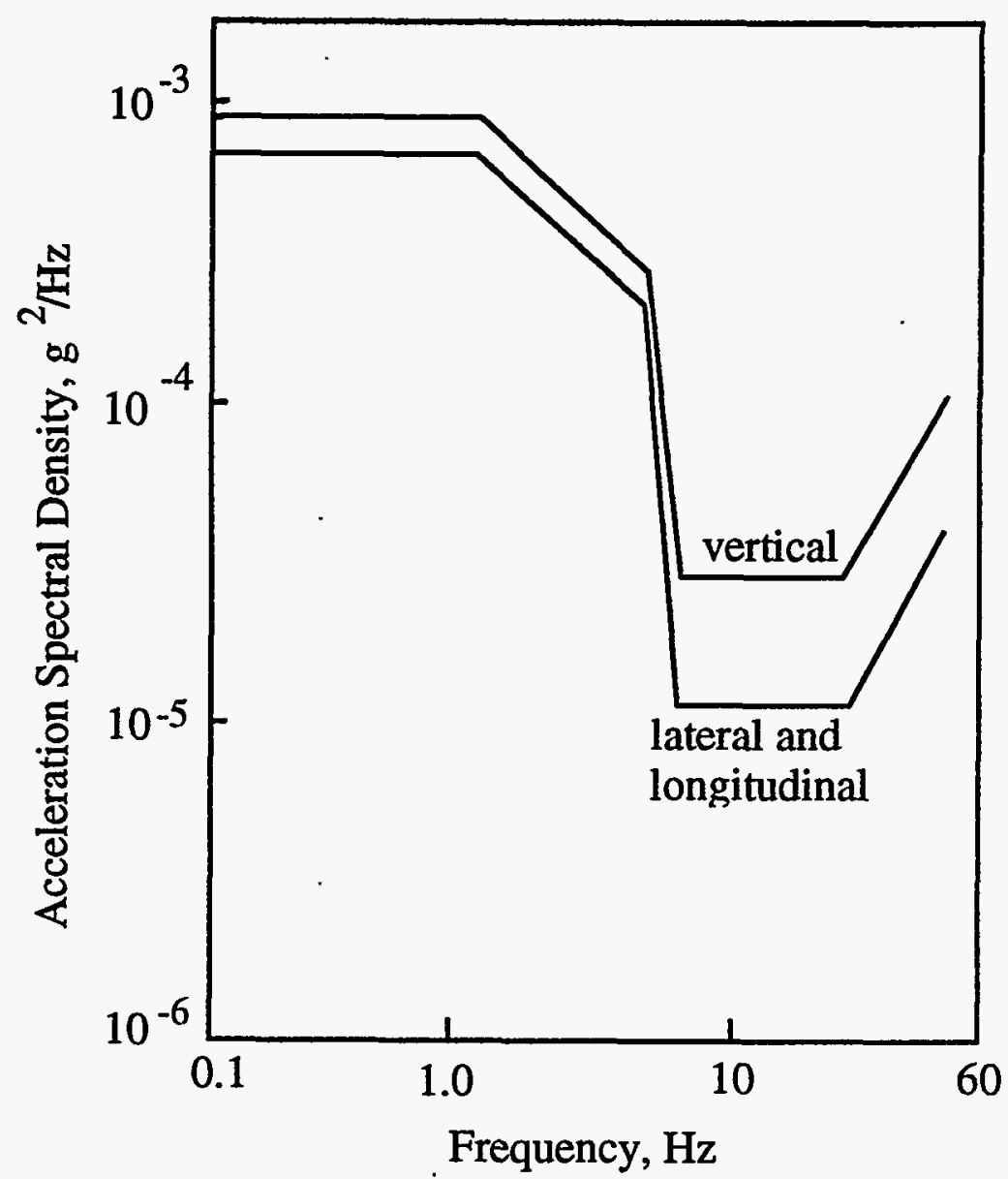

Fig. 20. UTACV ride comfort specification for random vibration (adapted from Fearnsides et al. 1974)

\subsection{Ride Index Method}

\subsubsection{British Railways Ride Index (Garg and Dukkipati 1984)}

In this version, ride index is calculated from octave-band accelerations and the corresponding center frequency. Vertical and lateral ride indices are defined separately.

\subsubsection{Composite Model by Pepler et al. (1978)}

A quantitative model of subjective reaction to the ride environment of city buses and intercity trains was developed by Pepler et al. (1978) with field data from both paid subjects and regular passengers. The following seven-point comfort scale was used: 
Ride Index (W) Ride Quality

$\begin{array}{ll}1 & \text { Very Comfortable } \\ 2 & \text { Comfortable } \\ 3 & \text { Somewhat Comfortable } \\ 4 & \text { Neutral } \\ 5 & \text { Somewhat Uncomfortable } \\ 6 & \text { Uncomfortable } \\ 7 & \text { Very Uncomfortable }\end{array}$

Different ride quality models were obtained for buses, trains, and future modes of transportation based on the following parameters:

$\omega_{\mathrm{r}}=\mathrm{RMS}$ roll rate

$A_{t}=$ mean transverse acceleration

$a_{t}=$ RMS transverse acceleration

$a_{v}=$ RMS vertical acceleration

$d B(B)=$ decibels measured by a B-weighting system

The models are summarized as follows:

Ride Quality Models for Buses on

Straight/Level Roads and Hills,

$$
\mathrm{W}=0.87+1.05 \omega_{\mathrm{r}}
$$

Curves,

$$
\mathrm{W}=1.4+7.7 \mathrm{~A}_{\mathrm{t}}+8.25 \mathrm{at}_{\mathrm{t}}
$$

Train Ride Quality Model

$$
\mathrm{W}=1.0+0.96 \omega_{\mathrm{r}}+0.1[\mathrm{db}(\mathrm{B})-63] .
$$

Composite Ride Quality Model

$$
\mathrm{W}=1.0+0.5 \omega_{\mathrm{r}}+0.1[\mathrm{~dB}(\mathrm{~B})-65]+17 \mathrm{a}_{\mathrm{t}}+17 \mathrm{a}_{\mathrm{v}} .
$$


The composite ride quality model can be used for maglev systems; it incorporates features associated with buses, trains, and airplanes. Although this model was not developed specifically for maglev systems, it can be improved as additional data become available.

\subsubsection{Frequency-Weighting Method}

Because human sensitivity to vibration is a function of frequency, a weighting function can be used to weight vibration spectra according to each criterion's definition of vibration sensitivity at given frequencies. Several criteria were based on this concept. The index quantity for a given ride is defined as the frequency-weighted index,

$$
Y=\int_{0}^{f_{m}} F(f) P(f) d f,
$$

where $F(f)$ is the weighting function, $P(f)$ is the $P S D$ of the ride acceleration trace, and $f_{m}$ is the highest frequency of interest. Several concepts of this method result in differing criteria.

Absorbed Power by Lee and Pradko (Smith et al. 1978)

$$
\begin{aligned}
& F(f)=\left|Z_{i}(f)\right|^{2}, \\
& W=Y,
\end{aligned}
$$

where $\mathrm{Z}_{\mathrm{i}}(\mathrm{f})$ is the impedance of the human body at the contact point, and the PSD is that of the vehicle vibration at the contact point. The integral in Eq. 42 represents the average power absorbed by the passenger due to riding vibrations.

Weighted RMS Accelerations by Butkunas (Smith et al. 1978)

$$
\mathrm{W}=\mathrm{Y}^{0.5} \text {. }
$$

A generalized transfer function that represents human perception of ride is used as the weighting function; the perception is not necessarily related to the mechanical impedance. The weighted RMS acceleration is used as the index.

Sperling's Ride Index (Garg and Dukkipati 1984)

The index is calculated from 


$$
\mathrm{W}=\left(\int_{0.5}^{30} \mathrm{a}^{3} \mathrm{~B}^{3} \mathrm{df}\right)^{0.1}
$$

where $a$ is the peak acceleration as a function of frequency, and $B$ is the acceleration weighting factor. $B$ is defined in various manners, depending on the direction of motion.

\subsection{Relationship between Ride Quality and System Costs}

It is important to understand the relationship between ride quality and system costs. Good ride quality can be achieved by a combination of track profile and alignment, as well as by levitation control and guidance. In the design of a maglev system, it is important to understand the required vehicle suspension design for given system dynamics or the disturbances that are permissible for a given system suspension design. With this understanding, one can achieve a meaningful trade-off between the costs of the suspension system and the guideway (Fearnsides et al. 1974).

In criteria based on pure sinusoidal oscillations, such as the Janeway and ISO criteria, the interaction between oscillation frequencies is not considered. In frequency spectral techniques, such as the UTACV criterion, all frequencies are considered for motion in a specific direction; the interaction of components in various directions is not accounted for. The ride index technique is to represent ride quality as a single scale number. All of these criteria have their limitations, and their applicability to high-speed maglev systems remains to be determined. It is expected that maglev ride quality will be an important subject for further study.

\subsection{Suspension Controls for Better Ride Quality}

To ensure a high level of ride comfort, a secondary suspension is used in EMS systems, and damping control or a secondary suspension is used in EDS systems. The suspension system should provide good guideway tracking and acceptable ride comfort. In general, good tracking demands small levitation clearances and stiffness of the support, while good ride comfort requires weak coupling between passenger cabin and guideway: Active or passive suspension control can be developed to provide the required stiffness for vehicle support and softness for the passenger cabin (Chen et al. 1992; Cai et al. 1993c).

The characteristics of the motion of a levitated magnet when it is perturbed from steady motion have been analyzed by Wilkie (1972). The magnetic forces 
obtained by Reitz (1970) for steady motion of a magnet over a conducting plane can be used to determine the perturbed motion. Motion due to a vertical perturbation is an essentially undamped vertical oscillation with a frequency of $\approx 1 \mathrm{~Hz}$ and an exponentially growing motion that results from a perturbation in the direction of motion if air drag is not included in the analysis. The response to perturbations may be unacceptable in a passenger-carrying vehicle. Thus, it is likely that feedback control of the motion of levitated magnets is necessary to obtain stability and ride characteristics suitable for carrying passengers at high speeds.

With a large clearance of $\approx 0.35 \mathrm{~m}$, a ride quality comparable to that of a jet aircraft on a calm day is obtainable over a moderately rough track. It is essential that the absolute vertical velocity of the vehicle be used for control. There is little to be gained in ride quality by using acceleration for control (Wilkie 1972).

To achieve a quick response and a high-quality ride over a less-expensive guideway, design of suspension systems control must be exploited in suspension systems. Moreover, with the assistance of suspension controls, a rougher guideway surface could be used and overall investment cost of the guideway could be reduced.

Suspension systems are dominant in determining the basic dynamic and vibrational behavior of maglev vehicles. Primary suspensions, which consist of magnets, provide basic support and guidance along the guideway and should respond quickly to guideway disturbances and perturbations. Secondary suspensions support the vehicle bodies and provide acceptable ride comfort to the passengers.

Primary suspension control strategies include two basic principles: position control and air-gap control. The position control maintains the vehicle in a stable levitation and guidance attitude against the various guideway irregularities that are the dominant excitation force on the suspension systems and may be represented by a stationary stochastic signal. This control guides the vehicle on the guideway curve purely on the basis of alignment and compensates for all deviations of the guideway from the ideal line. Primary suspension controls must also respond quickly to small air-gap changes and overcome the effects of highfrequency perturbations. The goal of air-gap control is to follow the actual path of the track, including its deviations from the line of alignment caused by construction features, to maintain a constant air-gap.

Secondary suspension control systems should provide ride comfort to passengers over guideway sections that are irregular or when the vehicle is operating in gusty winds. 
Even though design of suspension control is important to maglev systems, few studies in the literature are concerned with the design of maglev suspension control. Katz et al. (1974) studied a linearized control system for magnets with a proportional feedback in primary suspension. Kortum and Utzt (1984) used quadratic synthesis in the control design of a vertical maglev vehicle model. Kortum et al. (1988) and Faye et al. (1989) studied dynamic modeling of maglev vehicles for control design and performance evaluations. They applied two control strategies, i.e., feedback controls with pole assignment and with the Riccati (quadratic) design.

Existing maglev suspension systems contain passive control elements such as dampers and springs (Bohn and Alscher 1986; Bohn and Steinmetz 1985), which are passive in the sense that no power source is required, i.e., the vibration-control elements only store or dissipate the energy associated with vibration. Such passive suspension systems may be insufficient to improve suspension performance unless radical changes are made to the basic principle of suspension operation (Faye et al. 1989; Kortum et al. 1988).

The alternative proposed here is that of an active suspension system, which has been investigated by many researchers over the last 30 or more years on conventional ground vehicles because it has the potential to improve vehicle performance (Bernard et al. 1987; Chalasani 1987; Elmadany 1990; Dukkipati et al. 1992; Goodal and Kortum 1983; Karnopp et al. 1974; Karnopp and Margolis 1984; McCormac et al. 1992). Some investigators have dealt with methods to design active suspension systems for maglev vehicles to get high ride quality (Nakagawa and Nagai 1993; Cai et al. 1992, 1993b).

An active suspension system offers a solution to the conflicting requirements of a constant-parameter suspension design and allows continuous or discrete variation in effective spring constants and damping coefficients. An active suspension may be adapted to specific vehicle/guideway conditions by control devices that can adjust the dynamics of hydraulic or pneumatic actuators. In such a system, the passive spring and damper of a conventional suspension are replaced by force actuators that continuously supply and modulate the flow of energy by generating forces on the basis of some control law to achieve the required performance (Bernard et al. 1987). It is apparent that an active system exhibits significantly low PSD values, i.e., the active system does not amplify accelerations as one would expect with a passive system. Also, in the activesystem concept, algorithms can be designed (in software rather than hardware) to provide the same function to achieve suspension performance (McCormac et al. 1992). In general, however, active systems are more costly, more complex, and often less reliable than passive systems (Bernard et al. 1987; Karnopp et al. 1974). 
In Canada (Kotb 1983a, 1983b), an active secondary suspension system was recommended for vertical suspension to achieve acceptable ride quality without compromising the primary suspension system design. It was found that the lateral dynamic response could be achieved by both passive primary and secondary suspension systems. However, control of vehicle dynamics with passive vertical suspension offers the potential of a higher degree of reliability; it is analogous to the design of conventional automobile and railway suspension systems.

Semiactive suspensions, which have been under development in recent years (Alonoly and Sankar 1987, 1988; Hrovat et al. 1988; Karnopp et al. 1974), present a compromise between active and passive suspensions. Semiactive suspensions can achieve performance close to that of active suspensions with much lower cost and complexity. These systems, which require relatively little external power, contain an active damper in parallel with a passive spring. Desired forces in the damper are generated by modulating fluid-flow orifices via a control scheme that involves feedback variables.

Although semiactive dampers based upon the electrohydraulic servovalve do not consume as much power as fully active systems, they do require several mechanical components, each manufactured to fine tolerances. One way to simplify the construction of a semiactive device is to obtain continuous control of damping by exploiting "smart" materials. Among these materials, the electrorheological (ER) fluids, which have variable-shear characteristics, can undergo significant instantaneous reversible changes in damping characteristics when subjected to electrostatic potentials. This makes their application to realtime semiactive vibration control very attractive. ER fluids were discovered by Willis M. Winslow in 1939 and have attracted intense interest in recent years (Stanway et al. 1989; Wong et al. 1992; Wu et al. 1990). Because the apparent viscosity of ER fluids can be conveniently controlled by an applied electric field, permitting the fluids to change from normal to viscous and back again in less than a millisecond, the damping effect can be altered even at high speeds.

It is thought that ER fluids are particularly suited for continuously adjustable dampers in semiactive suspension systems for ground vehicles. In essence, this type of damper behaves like a conventional viscous damper with an adjustable orifice, but is controlled by activating the electrodes and thus needs no mechanical moving parts. In addition, such devices could be made without precision machining, special fits, or exotic materials. It should be possible to reduce component costs, relative to active system, by employing continuously controllable damping available with ER fluids. The use of ER fluids as a direct interface between mechanical suspension components and control electronics offers an elegant solution to the problem of implementing semiactive control. 
A semiactive suspension system with ER dampers that employs the continuouscontrol strategy has the potential to provide ground vehicles with significantly improved ride comfort over that of conventional passive suspensions (Wong et al. 1992, Bhadra et al. 1993).

\section{Aerodynamic Effects}

As the operation speeds of high-speed rail and maglev vehicles are increased, a larger and larger percentage of the vehicles' total traction power is needed to overcome aerodynamic drag. At speeds in excess of $400 \mathrm{~km} / \mathrm{h}$, the aerodynamic drag of a high-speed rail car can require $80 \%$ of the traction power (Peters 1983). In the absence of wheel/rail drag, maglev vehicles require a proportionately higher percentage of this power to balance the aerodynamic retarding force (Balow and Sivier 1993; Flueckiger et al. 1993).

Because a high-speed maglev vehicle is affected significantly by aerodynamic forces, aerodynamic problems become a deciding factor in maglev systems. It is important to provide a better understanding of the effects of aerodynamic forces on a maglev system. Several aspects of the problem should be considered: aerodynamic forces should not force the vehicle off the track, dynamic instability should not occur, and noise level and ride quality must be acceptable.

\subsection{Aerodynamic Drag}

Although there is a considerable amount of literature on the aerodynamics of trains (trains passing, train-in-tunnel effect, etc.), there are very few published methods for determining the aerodynamic drag of maglev vehicles (Balow and Sivier 1993). Most traditional methods are based on wind tunnel or field testing of multicar wheel/rail trains. Current maglev design, however, focuses on singlecar configurations. This makes many of the previous approaches inapplicable for proper evaluation of the important aerodynamic features of current and future systems.

Fortunately, both Japanese and German investigators have performed extensive experimental work on the aerodynamic problem and it is their work that forms part of the basis for what we present here.

Peters (1983) divided the aerodynamic drag into four major categories: bogie drag, skin friction drag, roof equipment drag, and pressure drag. These breakdowns are given in Table 1. 
Table 1. Component drag of several existing maglev systems

Drag Component

Bogie(s)

Skin Friction

Roof Equipment

Pressure Drag
Percentage of Total Aerodynamic Drag

$38-66$

$27-30$

$8-20$

$8-13$

Bogie drag is the sum total of both the bogie aerodynamic drag and the associated guideway interference drag. Guideway interference drag is caused by the turbulent flow between the guideway and the vehicle. Skin friction drag is the retarding force that results from viscous shearing stresses over a wetted area of the vehicle. Roof equipment drag includes the drag from air conditioners, generators, and pantographs that appear unfaired (i.e., unblended) anywhere on the surface of the vehicle (excluding surfaces in close proximity to the guideway). Pressure drag is due mainly to contributions from the shape of the nose and tail of the vehicle (Peters 1983).

The bogie drag associated with guideway interference drag, and roof equipment drag are a large part of the overall aerodynamics of maglev vehicles as shown in Table 1. Unfortunately, there is no simple way to estimate those effects from fundamental principles. Therefore, wind tunnel or field testing may still be needed for vehicle aerodynamic design. To select a percentage from Table 1 might be an alternative (Balow and Sivier 1993).

Several methods are available for estimating the skin friction and pressure drag components for maglev vehicles.

Skin friction drag is proportional to the surface area of vehicles and can be estimated from the vehicle geometry, the operating speed, and vehicle boundary layer type, which depends on the Reynolds number characteristics of the vehicle.

The pressure drag or form drag of a cylindrical body (such as an aircraft fuselage or maglev vehicle) is determined by the shape of the nose and tail and is independent of the length of the vehicle. The nose geometry is the smaller of the two contributions. A properly shaped nose will contribute almost no pressure drag to the total. The key requirement is that vortex-shedding surfaces be avoided. 
The aerodynamic drag $F_{d}$ acting on a vehicle traveling at a speed $V$ is given as follows:

In an open area (Matsunuma et al. 1989; Brockie and Baker 1990)

$$
\mathrm{F}_{\mathrm{d}}=0.5 \rho \mathrm{AC}_{\mathrm{Do}} \mathrm{V}^{2}+0.5 \rho \mathrm{PLC}_{\mathrm{fo}} \mathrm{V}^{2} \text {, }
$$

where $\rho$ is air density, $A$ is the cross-sectional area of the vehicle, $C_{D_{0}}$ is the pressure drag coefficient, $P$ is the vehicle perimeter, $L$ is the vehicle length, and $\mathrm{C}_{\mathrm{fo}}$ is the skin-friction coefficient. It can also be combined into one term,

$$
\mathrm{F}_{\mathrm{d}}=0.5 \rho \mathrm{AC}_{\mathrm{D}} \mathrm{V}^{2} \text {. }
$$

If there is a yaw angle $\Psi$, the drag is

$$
\mathrm{F}_{\mathrm{d}}=0.5 \rho \mathrm{AC}_{\mathrm{D}} \mathrm{V}^{2}(1+\mathrm{k} \Psi),
$$

where $\mathbf{k}$ is the yaw correction factor.

In a tunnel (Matsunuma et al. 1989)

$$
\begin{aligned}
F_{d}= & 0.5 \rho\left[A\left(C_{D o}+R\right)(u-V)^{2} /(1-R)^{2}\right. \\
& -P^{\prime} L C_{f_{0}}^{\prime} R(u-R V)|u-R V| /(1-R)^{2} \\
& \left.+P L C_{f_{0}}(u-V)^{2} /(1-R)^{3}\right]
\end{aligned}
$$

where

$$
\begin{aligned}
\mathrm{u}= & V R-\left[V(1-R) R\left(b_{1}-b_{2}\right)\right] / \\
& \left\{(1-R) b_{1}+R b_{2}+\left[\left(b_{1} b_{2}+P^{\prime} L C_{f_{0}}^{\prime} I b_{1}\right.\right.\right. \\
& \left.\left.\left.-b_{2} l / A^{\prime}\right)\right]^{0.5}\right\}, \\
b_{1}= & {\left[P^{\prime} C_{f o}^{\prime}\left(L^{\prime}-L\right) / A^{\prime}+C_{0}\right](1-R), } \\
b_{2}= & {\left[(1-R)\left(C_{D o}+R\right)+P L C_{f o} / A\right] / R, } \\
R= & A / A^{\prime},
\end{aligned}
$$

where $u$ is the velocity of the air flow induced by the train running in the tunnel. The parameters associated with the tunnel are as follows: $A^{\prime}$ is the cross- 
sectional area, $\mathrm{L}^{\prime}$ is the length, $\mathrm{P}^{\prime}$ is the perimeter, $\mathrm{C}_{\mathrm{fo}}^{\prime}$ is the skin friction coefficient, and $C_{0}$ is the pressure loss coefficient at the entrance and exit of the tunnel.

The skin friction drag of a smooth flat plate with a boundary layer turbulence from the leading edge is given by the Prandtl-Schlichting relationship:

$$
\mathrm{C}_{\mathrm{fo}}=0.455 /\left(\log _{10} \operatorname{Re}\right)^{2.58} \text {. }
$$

Equation 51 underestimates the skin friction drag of scaled trains (Brockie and Baker 1990), but a similar expression can be used:

$$
\mathrm{C}_{\mathrm{fo}}=\alpha_{1} /\left(\log _{10} \mathrm{Re}\right) \alpha_{2}
$$

where $\alpha_{1}$ is 0.128 , and $\alpha_{2}$ is 1.814 , based on the data by Brockie and Baker (1990) for the $1 / 76$ and $1 / 40$ scale models of British Rail high-speed trains.

The drag coefficients, including $\mathrm{C}_{\mathrm{D}}, \mathrm{C}_{\mathrm{Do}}$, and $\mathrm{C}_{\mathrm{f}}$, are normally measured in wind tunnels with scale models. Some of the data are given in Table 2.

\begin{tabular}{|c|c|c|c|c|c|}
\hline Authors & $\operatorname{Re}$ & $C_{D}$ & $\mathrm{CDo}_{\mathrm{Do}}$ & $\mathrm{C}_{\mathrm{fo}}$ & Remarks \\
\hline \multirow[t]{3}{*}{$\begin{array}{l}\text { Brockie \& } \\
\text { Baker } 1990\end{array}$} & $2.54 \times 10^{6}$ & 1.85 & 1.1 & 0.0044 & $\begin{array}{l}1 / 76 \text { scale } \\
\text { model of high- } \\
\text { speed train }\end{array}$ \\
\hline & $7 \times 10^{6}$ & 1.84 & - & 0.0039 & $\begin{array}{l}1 / 40 \text { scale } \\
\text { model of high- } \\
\text { speed train }\end{array}$ \\
\hline & - & $\begin{array}{l}1.41- \\
1.56\end{array}$ & - & $\begin{array}{l}0.002- \\
0.004\end{array}$ & $\begin{array}{l}\text { British Rail } \\
\text { high-speed } \\
\text { train }\end{array}$ \\
\hline $\begin{array}{l}\text { Matsunuma } \\
\text { et al. } 1989\end{array}$ & - & - & 0.15 & 0.004 & $\begin{array}{l}\text { Shinkansen } \\
\text { vehicle Series } \\
100 \mathrm{~N}\end{array}$ \\
\hline $\begin{array}{l}\text { Balow \& } \\
\text { Sivier } 1993\end{array}$ & - & 0.45 & - & - & Transrapid 07 \\
\hline
\end{tabular}

Table 2. Drag coefficients 
The drag coefficient $C_{D}$ could be as low as 0.2 for slender vehicles that can carry $\approx 100$ passengers. However, the need for doors, windows, and various minor protuberances makes it very unlikely that a $C_{D}$ of $<0.3$ could be achieved in practice (Rhodes and Mulhall 1981). For example, the $C_{D}$ for the proposed designs for streamlined vehicles by Philco-Ford Corporation (1975) ranged from 0.188 to 0.303 , depending on seat arrangement and passenger capacity.

Several difficulties are encountered when determining drag coefficients: (1) because skin friction drag depends on Reynolds numbers, the relationship between skin friction and Reynolds number must be established; (2) the vehicle boundary layer is strongly three-dimensional in general; and (3) the vehicle may operate close to a fixed ground plane that imposes certain conditions on aerodynamics.

The general understanding of maglev aerodynamics is reasonably well established, and aerodynamic forces for specific maglev systems can be measured in wind tunnel tests. However, because it is difficult to simulate practical maglev conditions in wind tunnels, measurements from a full-scale specific model are needed.

\subsection{Crosswinds}

Because of the light weight of maglev vehicles, concern has been expressed about wind-induced accidents.

Crosswind, or side gust aerodynamic loading, can be significant at the speeds being considered for maglev vehicles. The gust aerodynamic loading depends upon vehicle profile and guideway contour, speed of wind, and the direction of flow. The information on response of guideway-suspension-vehicle systems to airloads and moments at operating speeds of $150-500 \mathrm{~km} / \mathrm{h}$ can be of considerable importance in the design of appropriate body shape and suspension configuration to meet the constraints of stability and acceptable levels of performance (Garg and Barrows 1981). In addition, protection against gust loads may become a critical factor in suspension design and selection of control strategy.

Therefore, knowledge is required of the aerodynamic forces and moments acting on vehicles in crosswinds. In general, a static model of a vehicle in a wind tunnel is used to measure forces and moments; relative motion of the ground and vehicle is not considered. Recently, Robinson and Baker (1990) attempted to use a model vehicle propelled across a wind tunnel. However, it is difficult to simulate an atmospheric boundary layer in a wind tunnel because the aerodynamic forces 
and moments are very strongly affected by the length, scale, and intensity of the turbulence.

The aerodynamic side- and lift-force coefficients $\mathrm{C}_{\mathrm{S}}$ and $\mathrm{C}_{L}$, and the yawing and pitching moment coefficients $\mathrm{C}_{Y}$ and $\mathrm{C}_{P}$ are

$$
\begin{aligned}
& \mathrm{C}_{\mathrm{S}}=\mathrm{F}_{\mathrm{S}} / 0.5 \rho \mathrm{V}^{2} \mathrm{~A}, \\
& \mathrm{C}_{\mathrm{L}}=\mathrm{F}_{\mathrm{L}} / 0.5 \rho \mathrm{V}^{2} \mathrm{~A}, \\
& \mathrm{C}_{\mathrm{Y}}=\mathrm{M}_{\mathrm{Y}} / 0.5 \rho \mathrm{V}^{2} \mathrm{Ah}, \\
& \mathrm{C}_{\mathrm{P}}=\mathrm{M}_{\mathrm{P}} / 0.5 \rho \mathrm{V}^{2} \mathrm{Ah},
\end{aligned}
$$

where $F_{S}, F_{L}, M_{Y}$, and $M_{P}$ are side force, lift force, yawing moment, and pitching moment, respectively; $A$ is a reference side area; and $h$ is the reference height of the vehicle. The variations of force coefficients with yaw angle for various turbulence conditions, obtained by Robinson and Baker (1990), are available.

Several procedures have appeared in the literature (Garg and Barrows 1981) for computing aerodynamic loading due to crosswind. The most important loads for suspension design consist of the side force and the yaw moments, which are given by

$$
F_{\mathrm{S}}=0.5 \rho V_{\mathrm{r}}^{2} \mathrm{~A}\left(\mathrm{C}_{\mathrm{SS}}+\mathrm{C}_{\mathrm{sc}}\right),
$$

and

$$
\mathrm{M}_{\mathrm{y}}=0.5 \rho \mathrm{V}_{\mathrm{r}}^{2} \mathrm{~A} \mathrm{l}_{\mathrm{v}}\left(\mathrm{C}_{\mathrm{ys}}+\mathrm{C}_{\mathrm{yc}}\right),
$$

where

$\mathrm{C}_{\mathrm{ss}}=$ side force coefficient due to slender body part,

$\mathrm{C}_{\mathrm{sc}}=$ side force coefficient due to crossflow,

$\mathrm{C}_{\mathrm{ys}}=$ yaw moment coefficient due to slender body part,

$\mathrm{C}_{\mathrm{yc}}=$ yaw moment coefficient due to crossflow,

$l_{\mathrm{v}}=$ length of the vehicle.

The relative wind velocity is given by 


$$
\mathrm{V}_{\mathrm{r}}=\left(\mathrm{V}^{2}+\mathrm{V}_{\mathrm{c}}^{2}\right)^{1 / 2}
$$

for a vehicle moving at a speed $V$ entering a crosswind gust of velocity $V_{c}$. The wind impacts the vehicle at the side slip angle $\beta$ given by

$$
\beta=\tan ^{-1}\left(V / V_{c}\right),
$$

The slender-body force and moment coefficients are given by

$$
C_{\mathrm{SS}}= \begin{cases}2 \beta \mathrm{x}(2-\mathrm{x}) & \mathrm{x}<1 \\ 2 \beta & \mathrm{x} \geq 1\end{cases}
$$

and

$$
C_{y s}=\frac{1}{2} C_{s s}-\left\{\begin{array}{l}
2 \beta\left(\lambda_{1} / \lambda\right) x^{2}(1-2 x / 3) \\
2 \beta\left(\lambda_{1} / \lambda\right) / 3
\end{array}\right.
$$

where

$$
\begin{aligned}
& \mathrm{x}=\mathrm{Vt} / \mathrm{l}_{1}, \\
& \mathrm{t}=\text { time after gust entry begins, } \\
& \mathrm{l}_{1}=\text { length of the nose section of the vehicle, } \\
& \lambda_{1}=1_{1} / \mathrm{h}, \\
& \lambda=1_{\mathrm{v}} / \mathrm{h} .
\end{aligned}
$$

The viscous crossflow part in Eqs. 54 and 55 is due to the fact that flow separates off the side of the vehicle, producing contributions to the force and moment which become increasingly important at higher crosswind angles. The viscous crossflow force and moment coefficients are given by

$$
\mathrm{C}_{\mathrm{sc}}= \begin{cases}\left(\frac{2 \mathrm{k} \beta}{\pi}\right) \int_{0}^{\beta \lambda z} g(\sigma) d \sigma & \mathrm{z}<1 \\ \left(\frac{2 \mathrm{k} \beta}{\pi}\right) \int_{0}^{\beta \lambda} g(\sigma) d \sigma & \mathrm{z} \geq 1\end{cases}
$$


and

$$
C_{y c}=\frac{1}{2} C_{s c}- \begin{cases}\left(\frac{2 k}{\pi \lambda}\right) \int_{0}^{\beta \lambda z} \sigma g(\sigma) d \sigma & z<1 \\ \left(\frac{2 k}{\pi \lambda}\right) \int_{0}^{\beta \lambda} \sigma g(\sigma) d \sigma & z \geq 1\end{cases}
$$

where

$$
\begin{aligned}
& \mathrm{z}=\mathrm{Vt} / \Lambda_{\mathrm{V}}, \\
& \mathrm{k}=\text { configuration factor, } \\
& \mathrm{g}(\sigma)=\text { modified Bryson function. }
\end{aligned}
$$

The configuration factor $\mathrm{k}$ incorporates the effects of body cross section and nose profile, and the modified Bryson functions, based on whether the boundary layer on the body is laminar or turbulent (Garg and Barrows 1981).

\subsection{Pressure Wave}

When a high-speed vehicle enters a tunnel, a compression wave is generated inside the tunnel in front of the vehicle. A pressure decrease also occurs behind the vehicle, and some of the air flows about the vehicle. When the compression wave exits at the end of the tunnel, a boom due to release of the pressure pulse can be heard. In the low-frequency range, the magnitude of the boom is proportional to the pressure gradient of the compression wave when it arrived at the tunnel exit (Matsunuma et al. 1989). Severity of the effect depends on the amount of tunnel cross-sectional area that is occupied by the vehicle (Hammitt 1974). The transient pressures generated by the train traveling through a tunnel can cause passengers significant ear discomfort (Gawthorpe and Pope 1993).

The boom or sudden explosive sound that radiates from the tunnel exit can be reduced by avoiding sharp changes in the section area of the vehicle nose (Takao et al. 1993; Miyakawa and Hosaka 1993).

On some new high-speed railways, very large tunnel cross-sectional areas (over $100 \mathrm{~m}^{2}$ for double track tunnels) are being proposed to achieve acceptable pressures; these large cross-sectional areas will require substantial tunneling costs. Another approach is to seal the trains. Sealed stock, however, is expensive to construct and a long-term problem can arise with the maintenance of high 
standards of air tightness (Gawthorpe and Pope 1993). Several tests (Wormer 1993) presented pressure fluctuation in sealed and unsealed carriages when trains passed through tunnels. In those tests, outside and inside pressure fluctuations were the same with unsealed carriages; whereas fluctuation of pressure was much smoother inside than outside of sealed carriage.

\subsection{Aerodynamic Noise}

Aerodynamic noise generated by vortex shedding, by flow separations, and by the turbulent boundary layer over a high-speed vehicle can be remarkable; its level is approximately proportional to the sixth power of the vehicle speed. However, in some cases, the dominant sources are associated with gaps between vehicles and with specific regions, such as the vehicle nose. In developing maglev systems, it is important to recognize the noise at an early stage.

In the U.S. the Federal Railroad Administration had specified the total vehicle noise limit as $73 \mathrm{~dB}$ at $15 \mathrm{~m}$ from the vehicle centerline. This was considered a goal because the aerodynamic noise level was expected to be much higher than this value (Philco-Ford Corp. 1975).

In Japan, a method and a program called ACOUSIS, based on a series of assumptions, have been developed to predict the sound field (Matsunuma et al. 1989). The key noise of the Shinkansen train is aerodynamic, and the faster the train runs, the more important the role of aerodynamic noise. Significant noise reduction was achieved by smoothing the uneven surfaces of the ground coils. Furthermore, the front-end profile of the vehicle, a possible noise source, was streamlined and its aerodynamic noise was lowered. When uneven surfaces of the vehicle and guideway are smoothed and soundproof walls are effectively set up, considerable noise reduction can be attained (Fujie 1989). For example, by smoothing the front nose surface, noise reduction of $\approx 10 \mathrm{db}$ has been obtained (Moritoh et al. 1993). Aerodynamic noise reduction procedures have been applied to the new 300-series Shinkansen NOZOMI to achieve a maximum slow-peak level of $75 \mathrm{~dB}$ to meet Japanese regulations at a maximum operating speed of $270 \mathrm{~km} / \mathrm{h}$ through the most populated regions in Japan (Takano et al. 1993).

In Germany, acoustic scanning of noise by microphone array measurements, in conjunction with flow visualization, during wind tunnel testing has been used to optimize vehicle design to reduce aerodynamic noise (Alscher 1989). A general requirement for the Transrapid 06 is that the peak value of external noise is $<84 \mathrm{~dB}$ at $25 \mathrm{~m}$ from the side of the track. 
Schmitz (1993) presented sound measurement on the Transrapid 07 within a speed range of $100-440 \mathrm{~km} / \mathrm{h}$ by conventional sound measurements and microphone array equipment (linear array, triple combined-linear array, and cross array). The conventional measurements show that the sound emission of the TR 07 is very low because of its smooth shape and the absence of any friction (no sharp edges, no bogies, no pantograph, and no coiling vans and inlets). The sound of the TR 07 seemed to be generated by mechanical sources at lower speeds and aerodynamic sources at higher speeds, especially those of flow separation. The turbulent boundary layer seems not to be the most important source at top speed. The microphone arrays were installed to locate the sound sources during operation, especially at high speeds (Barsikow et al. 1987, 1988; King and Bechert 1979). The measurements showed that (1) the main sound sources are located in the lower part of the TR 07, in the region of the flaps, which cover the levitation and guidance systems; (2) the distribution of the sources over the length is not constant, i.e., there is a strong source at the lower part of the nose; and (3) the upper part of the vehicle is very calm, so the turbulent boundary layer does not seem to be the dominant sound source, even at $400 \mathrm{~km} / \mathrm{h}$.

Figure 21 gives wayside noise levels, showing the effect of the aerodynamic component for the TR 06 and TR 07 vehicles (King et al. 1993).

\subsection{Aerodynamic Braking}

The cruising speed of maglev vehicles is expected to be higher than the landing speed of modern jet planes. Because aerodynamic form drag is proportional to the square of speed and the frontal area, i.e.,

$$
\mathrm{F}_{\mathrm{d}}=0.5 \rho \mathrm{V}^{2} \mathrm{AC} \mathrm{Do}_{0},
$$

$F_{d}$ can be used for braking.

In general, aerodynamic brakes are used as a backup for the maglev systems. The main brake system for maglev vehicles is the regenerative brake, a type of electric brake. In case the main brake system fails, the vehicle will also be equipped with a disk brake system as a mechanical backup brake system, along with the aerodynamic brake system, an arrangement that offers a relatively simple and effective solution in the high-speed range (Guglielmo et al. 1993).

The aerodynamic brake system is the safest brake system from the viewpoint of fire prevention in the high-speed range when used on maglev vehicles as an independent brake system. This system is already popular in aeronautics in that 


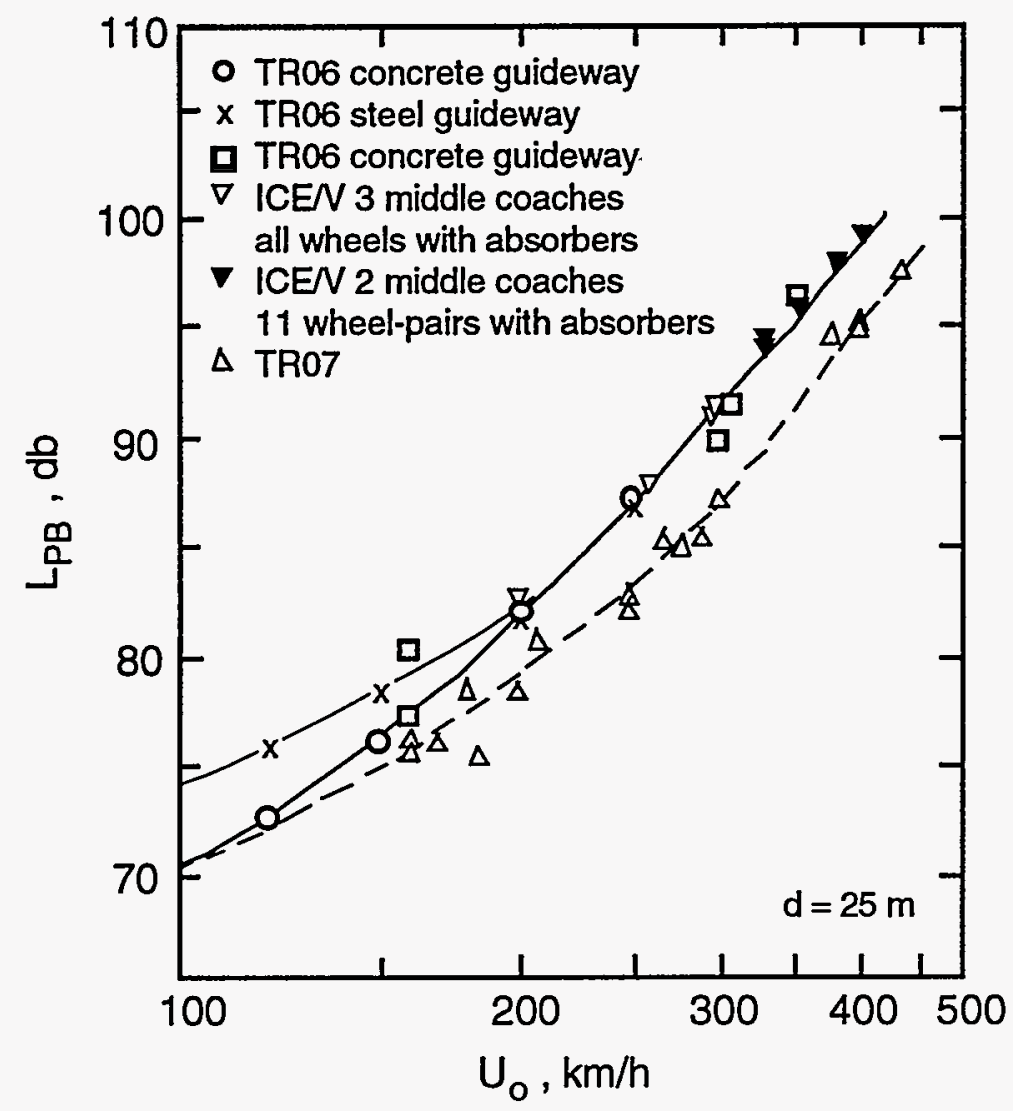

Fig. 21. Wayside noise levels showing the effect of the aerodynamic component (adapted from King et al. 1993)

it is used as the air brake device on the fuselage of jet fighters and as the ground spoiler mounted on the wings of passenger aircraft (Yoshimura and Okamoto 1993).

The aerodynamic braking requirements vary with the operational design of the system. For safety, $-0.2 \mathrm{~g}$ is considered to be the maximum deceleration rate. The braking force should be great enough to stop the vehicle within $6000 \mathrm{~m}$ without exceeding $-0.2 \mathrm{~g}$ (Oda et al. 1989). Several factors should be considered when determining the needs of aerodynamic braking:

- The aerodynamic brake should be tested in a wind tunnel to select the appropriate parameters.

- The effect on vehicle response should checked by a full-scale model or computer simulations. 
- The vehicle should not be allowed to displace more than an acceptable distance both laterally and vertically.

In Japan, a 1/25-scale maglev model with aerodynamic brake panels was tested in a wind tunnel, and a full-scale model (the MLU 001) was tested at the Miyazaki test track at speeds up to $350 \mathrm{~km} / \mathrm{h}$ (Oda et al. 1989). The new full-scale model, the MLU 002N vehicle for the Miyazaki test track, has been designed to install two sets of aerodynamic brake devices. Its design concept and major specifications of aerodynamic brake devices can be found in the literature (Yoshimura and Okamoto 1993).

\subsection{Control of Aerodynamic Effects}

To reduce the pressure gradient of a tunnel-generated compression wave, which is proportional to the third power of vehicle speed, a hood with openings can be provided at the tunnel entrance, and the vehicle nose can be streamlined. A hood with openings also reduces the aerodynamic force on the vehicle entering the tunnel. Inside the tunnel, bypasses or side branches can be used to decrease the pressure gradient. Furthermore, sound-absorbing materials can be placed on the tunnel walls. Some of these methods have been applied to the SanyoShinkansen line as well as to experimental maglev systems in Japan (Matsunuma et al. 1989).

Aerodynamic noise may be reduced by using sound-absorbing materials for the lower surface of the vehicle and/or the guideway and by making the vehicle surface smooth. Experience with the Transrapid TR 006 and TR 007 showed that significant improvements resulted from smoothing the connection between the vehicle body and magnetic coiling.

The dominant factor for high-speed trains and maglev systems is aerodynamic drag. Because the major effect for vehicles is from skin friction, which is proportional to the vehicle surface, it is advantageous to make broader vehicles and tunnels instead of longer vehicles. However, for a single maglev vehicle, long slender shapes are preferred for a fixed payload volume (Philco-Ford Corp. 1975).

The aerodynamic problems for maglev systems have some unique features not encountered by other vehicles. This follows from the high operating speeds and the relatively compliant suspension systems. At this time, a basic understanding of these problems is available. However, precise prediction of the aerodynamic effects remains difficult because of the lack of extensive 
aerodynamic data for maglev systems, particularly at speeds in the range of 350$500 \mathrm{~km} / \mathrm{h}$.

\subsection{Aerodynamic Design of Maglev Vehicles}

Because maglev trains will run on the guideway at a speed of $>500 \mathrm{~km} / \mathrm{h}$, it will be necessary that the vehicles have a superior frontal shape, which means that the shape of the nose of the head car must be superior in aerodynamic performance, especially with respect to aerodynamic drag, noise, and pressure waves in tunnels. Some basic design concepts are as follows (Takao et al. 1993):

Reduction of aerodynamic drag

- Avoid sharp pressure distribution.

- Avoid separated vortex from bogie frame.

Reduction of aerodynamic noise

- Keep flow laminar.

- Avoid projections.

- Decrease noise from air ducts.

Reduction of pressure waves

- Avoid sharp changes in cross-sectional area of nose shape.

Ride comfort

- Reduce the flow separation of rear car of train.

- Reduce the forces induced when trains pass each other.

Advanced Computational Fluid Dynamics (CFD) technology, which has been developed in the aerospace industry, has been applied to complete the aerodynamic design of maglev vehicle frontal shape (Miyakawa and Hosaka 1993; Takao et al. 1993; Siclari et al. 1993).

The CFD technology consists of four technical elements: 
(1) Geometry definition. Exact mathematical modeling is required to represent the geometry to be evaluated.

(2) Grid generation. To solve the flow field around the geometry, the threedimensional space must be discretized to a system of grid points.

(3) Flow solver. The flow solver is based on the finite-difference scheme that solves the air-flow-governing equations, or the Navier-Stokes equations. Therefore, the solver exactly evaluates the viscous effects of the air flow around a vehicle.

(4) Graphic result. The simulated digital values are converted into graphic visualization to obtain meaningful results for engineers.

CFD technology in the aerodynamic design of maglev vehicle frontal shape includes the attractive merits that it

- Develops aerodynamic geometry with high quality in a short period of time. The number of configurations considered and defined in a design study may add up to more than 50 .

- Can simulate the motion of the vehicle relative to the ground by implementing moving boundary conditions on the guideway surface. The velocity of the train relative to the ground significantly influences the flow field of the frontal shape, especially the stagnation position at the front edge of the vehicle.

- Can account for the Reynolds number effects of actual operating conditions. The Reynolds number of an actual train is 47.5 million, based on the length of the frontal shape, whereas the wind tunnel test Reynolds number is only 4.8 million.

- Can provide computed results that represent a variety of visualized images of the flow field to provide physical insight. The visualized information is often quite helpful in solving problems that optimize the geometry.

Figures 22 and 23 present the aerodynamic designs of the Japanese MLU 002 with the CFD technology (Miyakawa and Hosaka 1993) 


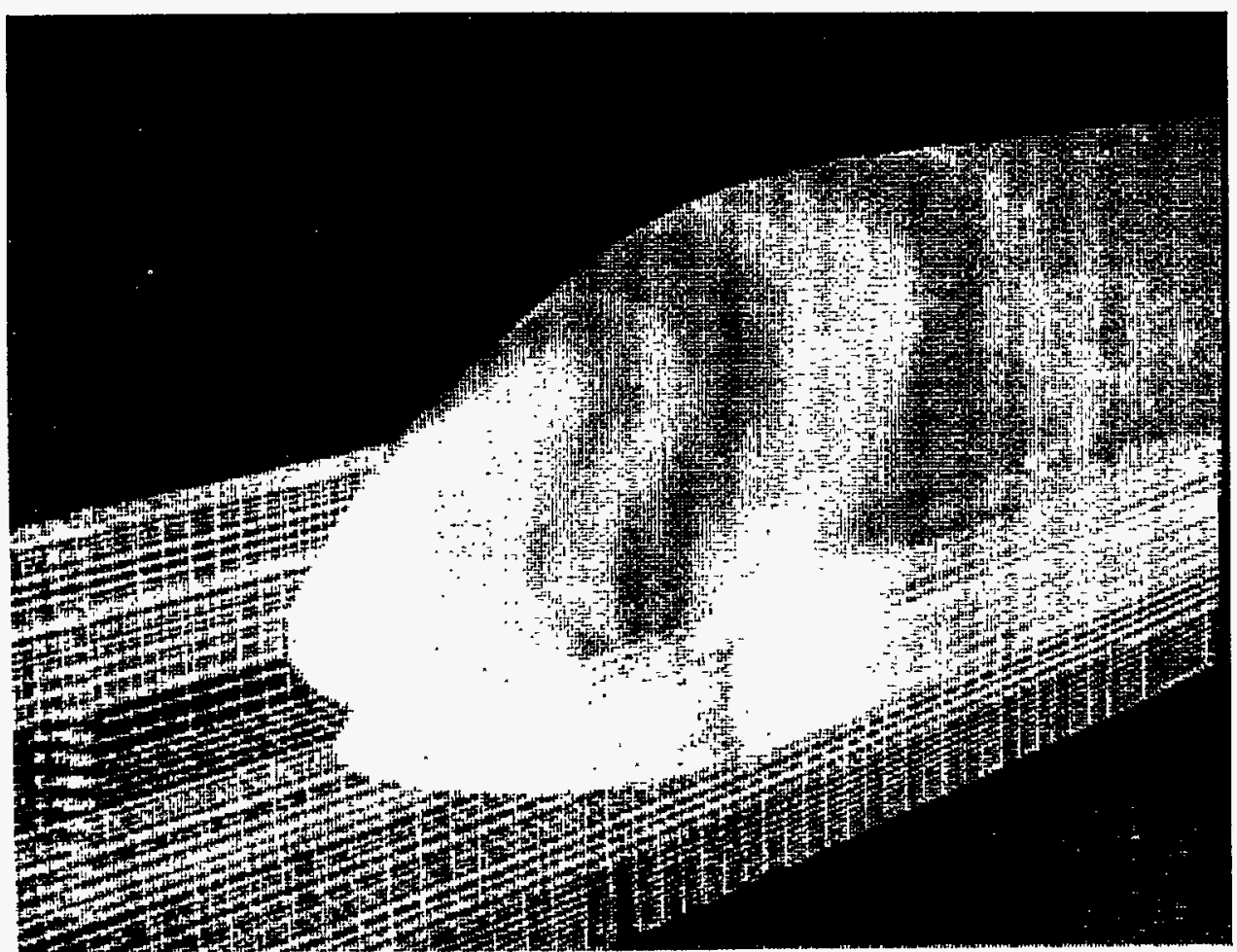

Fig. 22. Pressure distribution on MLU 002 (Nose car condition)

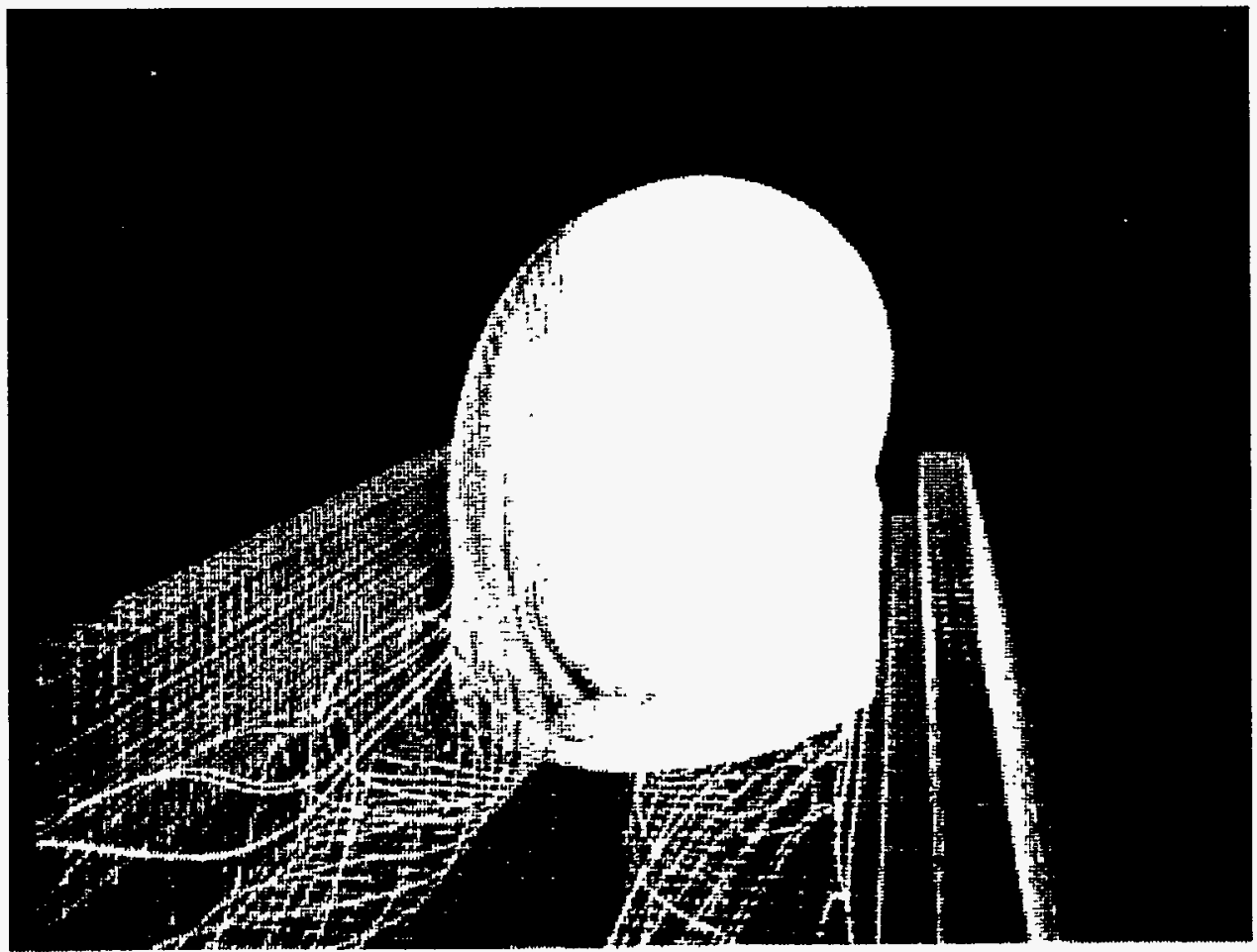

Fig. 23. Space streamline around MLU 002 (Rear car condition) 


\section{Conclusions}

Based on state-of-the-art technology for maglev dynamics, it is possible to identify critical areas for future research to resolve unsettled issues. Some of the areas for future research are listed below.

- Quantify the motion-dependent magnetic force components due to vehicle motion and guideway oscillations. With these force components, the dynamic stability of the vehicle, including vehicle/guideway interaction, can be analyzed and compared with experimental results.

- Develop/modify/improve a set of computer codes for dynamic simulation of various factors, such as vehicle stability, vehicle/guideway interactions, aerodynamic effects. To predict system performance, it is necessary to consider the coupled vehicle/guideway system. Ultimately, because guideway costs may critically influence economic feasibility, a reliable comprehensive analytical simulation technique is needed for final detailed design. A comprehensive code should accommodate multiple vehicles and vehicle elasticity, secondary suspension, guideway dynamics, aerodynamic forces, magnetic forces, guideway irregularities, and feedback control.

- Analyze and perform experiments to study guideway dynamics, with the objective of optimizing guideway design. To surpass existing technology, an innovative design for vehicles and guideways must be developed so that new maglev systems can use high-speed vehicles with good ride comfort at low cost. For example, intentional camber of guideway beams can improve ride comfort under some specific conditions.

- Develop independent and cooperative control methods to suppress not only rigid-body motion but also structural vibration. Through feedback control, the guideway tolerance may be relaxed and its cost may be reduced. Therefore, an optimized design that incorporates the best features of guideway dynamics and control techniques may result in more economical maglev systems.

- Assess existing criteria and develop new criteria for ride comfort. Vertical and lateral acceleration levels have been used frequently in the past to establish ride comfort criteria. The influence of guideway surface and alignment, as well as suspension 
parameters, should be considered in detail. One aim is to relate all of the system parameters to ride comfort. In addition, new or modified criteria for ride comfort may be needed for high-speed maglev systems. In particular, such criteria should take into consideration the nature and frequency of negotiating both lateral and vertical curves at high speed.

Maglev systems offer many important advantages over conventional wheelon-track vehicles. Although some design concepts have been developed to nearly the state of commercial application, new or improved concepts, improved design and construction methods, and new material (including high-temperature superconductors, high-energy permanent magnets, and advanced material for guideways) are expected to enhance the attractiveness of maglev systems even further over the next several years. It is therefore reasonable to expect that maglev systems may indeed be a key transportation mode for the 21st century.

\section{References}

Alonoly, J., and Sankar, S. (1987), A New Concept in Semiactive Vibration Isolation, ASME Trans., J. Mechanisms, Transmissions, and Automation Des., 109(2), pp. 242-247.

Alonoly, J., and Sankar, S. (1988), Semiactive Force Generators for Shock Isolation, J. Sound Vib., 126(1), pp. 145-156.

Alscher, H. (1989), Aero-Acoustic Investigations of the Magnetic Train Transrapid 06, Proc. Int. Conf. Maglev '89, pp. 269-274.

Balow III, F. A., and Sivier, K. R. (1993), Aerodynamic Drag of Maglev Vehicles, Proc. Maglev '93, 13th Int. Conf. on Magnetically Levitated Systems and Linear Drives, May 19-21, 1993, Argonne, IL, pp. 206-211.

Barsikow, B., King, W. F. III, and Pfizenmaier, E. (1987), Wheel/Rail Noise Generated by a High-Speed Train Investigated with a Line Array of Microphones, J. Sound Vib., 118, pp. 99-122.

Barsikow, B., and King, W. F. III (1988), On Removing the Doppler Frequency Shift from Array Measurements of Railway Noise, J. Sound Vib., 120, pp. 190-196.

Bernard, J., Vanderploeg, M., and Shanan, J. (1987), Literature Review: Recent Developments in Vehicle Dynamics, Shock Vib. Digest, 19(4), pp. 10-17. 
Bhadra, D. K., Harder, C. R., and Mansfield, G. (1993), Maglev Secondary Suspension Using Electroactive Fluids, Proc. Maglev '93, 13th Int. Conf. on Magnetically Levitated Systems and Linear Drives, May 19-21, 1993, Argonne, IL, pp. 212-217.

Bohn, G., and Alscher, H. (1986), The Magnetic Train Transrapid 06, Proc. Int. Conf. Maglev and Linear Drives, May 14-16, 1986, Vancouver, B.C., Canada, Publ. by IEEE, 86CH2276-4, pp. 233-242.

Bohn, G., and Steinmetz, G. (1985), The Electromagnetic Suspension System of the Magnetic Train Transrapid, Proc. Int. Conf. Maglev Transport '85, Sept. 17-19, 1985, Keidanren Kaikan, Tokyo, Japan, Publ. by IEEE, Japan, pp. 107-114.

Brock, B. J. (1973), Determination of Guideway Roughness from Construction Tolerances, Proc. 44th Shock and Vibration Symp., pp. 83-90.

Brockie, N. J. W., and Baker, C. J. (1990), The Aerodynamic Drag of High Speed Trains, J. Wind Eng. Ind. Aerodynam., 34, pp. 273-290.

Cai, Y., and Chen, S. S. (1992), Vehicle/Guideway Interaction of Maglev Systems, Report ANL-92/19, Argonne National Laboratory, Argonne, IL.

Cai, Y., and Chen, S. S. (1993), Instability of Electrodynamic Maglev Systems, Proc. 64th Shock and Vibration Symp., Ft. Walton Beach, FL, October 25-28, 1993, pp. 319-326.

Cai, Y., and Chen, S. S. (1995), Numerical Analysis for Dynamic Instability of Electrodynamic Maglev Systems, Shock Vib. J., 2(4), pp. 339-349.

Cai, Y., Chen, S. S., Mulcahy, T. M., and Rote, D. M. (1992a), Dynamic Stability of Maglev Systems, Proc. 63rd Shock and Vibration Symp., 27-29 Oct. 1992, Las Cruces, NM, pp. 533-543.

Cai, Y., Chen, S. S., Mulcahy, T. M., and Rote, D. M. (1992b), Dynamic Stability of Maglev Systems, Report ANL-92/21, Argonne National Laboratory, Argonne, IL.

Cai, Y., Chen, S. S., and Rote, D. M. (1992), Dynamic and Controls in Maglev Systems, Report ANL-92/43, Argonne National Laboratory, Argonne, IL. 
Cai, Y., Chen, S. S., Rote, D. M., and Coffey, H. T. (1993a), Vehicle/guideway Interaction and Ride Comfort of Maglev Systems, Proc. Int. Conf. on Speedup Technology for Railway and Maglev Vehicles, November 22-26, 1993, Yokohama, Japan, Vol. 1, pp. 109-114.

Cai, Y., Chen, S. S., Zhu, S., Mulcahy, T. M., Rote, D. M., and Coffey, H. T. (1993b), Dynamics, Stability, and Control of Maglev Systems, Proc. Maglev '93, 13th Int. Conf. on Magnetically Levitated Systems and Linear Drives, May 19-21, 1993, Argonne, IL, pp. 265-270.

Cai, Y., Zhu, S., Chen, S. S., and Rote, D. M. (1993c), Control of Maglev Suspension Systems, 1993 ASME Pressure Vessels and Piping Conf., ASME, New York, PVP-Vol. 256-2, pp. 57-67.

Cai, Y., Chen, S. S., Rote, D. M., and Coffey, H. T. (1994), Vehicle/Guideway Interaction for High-Speed Vehicles on a Flexible Guideway, J. Sound Vib., 175(5), pp. 625-646.

Cai, Y., Rote, D. M., Mulcahy, T. M., Wang, Z., Chen, S. S., and Zhu, S. (1995), Dynamic Stability Experiment in Maglev Systems, Report ANL-95/10, Argonne National Laboratory, Argonne, IL.

Carmichael, G. E., and Dorn, N. P. (1991), National Maglev Initiative-Annual Report, U.S. Department of Transportation, November, 1991.

Chalasani, R. M. (1987), Ride Performance Potential of Active Suspension Systems - Part I: Simplified Analysis Based on a Quarter-Car Model, ASME, AMD, 80, pp. 187-204.

Chen, S. S. (1987), Flow-Induced Vibration of Circular Cylindrical Tubes, Hemisphere Publishing Co., New York.

Chen, S. S., Rote, D. M., and Coffey, H. T. (1992), A Review of Vehicle/Guideway Interactions in Maglev Systems, Fluid-Structure Interaction, Transient ThermalHydraulics, and Structural Mechanics, ASME, New York, Vol. 231, pp. 81-95.

Chen, S. S., Zhu, S., and Cai, Y. (1993), On the Unsteady-Motion Theory of Magnetic Forces for Maglev, Report ANL-93/39, Argonne National Laboratory, Argonne, IL.

Chiu, W. S., Smith, R. G., and Wormley, D. N. (1971) Influence of Vehicle and Distributed Guideway Parameters on High Speed Vehicle-Guideway Dynamic Interactions, ASME Trans. J. Dynam. Systems, Measurement, Control, 93, pp. 25-34. 
Chu, D., and Moon, F. C. (1983), Dynamic Instabilities in Magnetically Levitated Models, J. Appl. Phys., 54(3), pp. 1619-1625.

Coffey, H. T., Chilton, F., and Hoppie, L. O. (1972), Magnetic Levitation of HighSpeed Ground Vehicles, Proc. Applied Superconductivity Conf, IEEE, New York, Pub. No. 72CH0682-5-TABSC, pp. 62-75.

Coffey, H. T., et al. (1991), Preliminary Design for a Maglev Development Facility, Report ANL/ESD-14, Argonne National Laboratory, Argonne, IL.

Coffey, H. T. (1993), Status and Review of the U. S. Maglev Program, Proc. Int. Conf. on Speedup Technology for Railway and Maglev Vehicles, November 22-26, 1993, Yokohama, Japan, Vol. 1, p. 6.

Danby, G. and Powell, J. (1972), Integrated Systems for Magnetic Suspension and Propulsion of Vehicles, Proc. Applied Superconductivity Conf, IEEE, New York, Pub. No. 72CH0682-5-TABSC.

Daniels, L. E., and Ahlbeck, D. R. (1993), Maglev Vehicle Dynamic Interaction with Aerial Guideways, Proc. Maglev '93, 13th Int. Conf. on Magnetically Levitated Systems and Linear Drives, May 19-21, 1993, Argonne, IL, pp. 218-226.

Daniels, L. E., Ahlbeck, D. R., Stekly, Z. J., and Gregorek, G. M. (1992), Influence of Guideway Flexibility on Maglev Vehicle/Guideway Dynamic Forces, DOT/FRA/NMI-92/09.

Davis, L. C., and Wilkie, D. F. (1971), Analysis of Motion of Magnetic Levitation Systems: Implications, J. Appl. Phys., 42(12), pp. 4779-4793.

Dukkipati, R. V., Osman, M. O. M., and Vallurupalli, S. S. (1992), Real Time Adaptive Control Compared with Stochastic Optimal Control of Active Suspension, Proc. CSME Forum 1992 "Transport 1992+," June 1-4, 1992, Montreal, Canada, Vol. I, pp. 192-198.

Elmadany, M. M. (1990), Optimal Linear Active Suspensions with Multivariable Integral Control, Vehicle System Dynam., 19, pp. 313-329.

Faye, I., Kortum, W., and Schwartz, W. (1989). Modeling, Control Design, and Performance Evaluation of High Speed Ground Vehicle Dynamics, Mech. Struct. Mach., 17(2), pp. 259-281. 
Fearnsides, J. J., Hedrick, J. K., and Firouztash, H. (1974), Specification of Ride Quality Criteria for Transportation Systems: The State of the Art and a New Approach, High Speed Ground Transportation J., 8(2), pp. 125-132.

Flueckiger, K., Mark, S., and McCallum, D. (1993), Modeling and Control of Maglev Vehicles with Aerodynamic and Guideway Disturbances, Proc. Maglev '93, 13th Int. Conf. on Magnetically Levitated Systems and Linear Drives, May 1921, 1993, Argonne, IL, pp. 227-232.

Fryba, L. (1972), Vibration of Solids and Structures Under Moving Loads, Noordhoff International Publishing, Groningen, The Netherlands.

Fujie, J. (1989), Current Status of EDS System in Japan, Proc. Int. Conf. Maglev '89, pp. 81-83.

GangaRao, H. V. S., et al. (1992), State-of-the-Art Assessment of Guideway Systems for Maglev Applications, DOT/FRA/NMI-92/17.

Garg, D. P., and Barrows, T. M. (1981), Modeling and Dynamic Response of Maglev Vehicles Subjected to Crosswind Gusts, J. Dynam. Systems, Measurement, Control, 103, pp. 251-257.

Garg, V. K., and Dukkipati, R. V. (1984), Dynamics of Railway Vehicle Systems, Academic Press.

Gawthorpe, R. G., and Pope, C. W. (1993), Reduced Cross Sections for High Speed Tunnels in Shallow Ground Using Airshafts, Proc. Int. Conf. on Speedup Technology for Railway and Maglev Vehicles, November 22-26, 1993, Yokohama, Japan, Vol. 2, pp. 185-190.

Goodal, R. M., and Kortum, W. (1983), Active Controls in Ground Transportation - A Review of the State-of-the-Art and Future Potential, Vehicle System Dynam., 12, pp. 225-257.

Gottzein, E., Lange, F., and Ossenberg-Franzes, F. (1974), Control System Concept for a Passenger Carrying Maglev Vehicle, High Speed Ground Transportation J., 9(1), pp. 435-447.

Guglielmo, J. J., Zych, T. J., and Sivier, K. R. (1993), Aerodynamic Braking Systems for Maglev Vehicles, Proc. Maglev '93, 13th Int. Conf. on Magnetically Levitated Systems and Linear Drives, May 19-21, 1993, Argonne, IL, pp. 405-410. 
Hammitt, A. G. (1974), Special Aerodynamic Problems of High Speed Ground Transportation Systems, High Speed Ground Transportation J., 8(2), pp. 93-100.

He, J. L., Rote, D. M., and Chen, S. S. (1994), Characteristics and Computer Model Simulation of Magnetic Damping Forces in Maglev System, Report ANL/ESD/TM-66, Argonne National Laboratory, Argonne, IL.

He, J. L., Rote, D. M., and Coffey, H. T. (1992), Survey of Foreign Maglev Systems, Report ANL/ESD-17, Argonne National Laboratory, Argonne, IL.

He, J. L., Rote, D. M., Coffey, H. T., and Wang, Z. (1991), Publications on Maglev Technologies, Report ANL/ESD/TM-29, Argonne National Laboratory, Argonne, IL.

Heinrich, K., and Kretzschmar, R. (1987), Transrapid Maglev System, HestraVerlag Darmstadt.

Hrovat, D., Margolis, D. L., and Hubbard, M. (1988), An Approach Toward the Optimal Semi-Active Suspension, ASME Trans., J. Dynam. Systems, Measurement, Control, 110, pp. 288-296.

Hullender, D. A. (1975), Analytical Models for Certain Guideway Irregularities, J. Dynam. Systems, Measurement, Control, 97, pp. 417-423.

Hullender D. A., and Bartley, T. M. (1975), Defining Guideway Irregularity Power Spectra in Terms of Construction Tolerances and Constraints, High Speed Ground Transportation J., 9(1), pp. 355-368.

Iguchi, M., and Hara, H. (1985), A Resonance-Eliminated Design of Simply Supported Beam for a Guideway of a High Speed Maglev System, Proc. Int. Conf. on Maglev Transport '85, pp. 217-224.

Inone, H., and Kokubun, N. (1993), Development of Superconducting Magnetically Levitated Train and Its Role, Proc. Int. Conf. on Speedup Technology for Railway and Maglev Vehicles, November 22-26, 1993, Yokohama, Japan, Vol. 1, pp. 375-380.

Johnson, L. R., et al. (1989), Maglev Vehicles and Superconductor Technology: Integration of High-Speed Ground Transportation into the Air Travel System, Technical Report ANL/CNSV-67, Argonne National Laboratory, Argonne, IL.

Karnopp, D., Crosby, M. J., and Harwood R. A. (1974), Vibration Control Using Semi-Active Force Generators, ASME Trans., J. Eng. Ind., 96, pp. 619-626. 
Karnopp, D. C., and Margolis, D. (1984), Adaptive Suspension Concepts for Road Vehicles, Vehicle System Dynam., 13, pp. 145-160.

Katz, R. M., Nene, V. D., Ravera, R. J., and Skalski, C. A. (1974), Performance of Magnetic Suspensions for High Speed Vehicles Operating Over Flexible Guideways, J. Dynam. Systems, Measurement, Control, 96, pp. 204-212.

Kim, I. K., Yoo, M. W., Park, C., Chung, H. K., and Kim, K. H. (1993), Maglev Programs in Korea, Proc. Maglev '93, 13th Int. Conf. on Magnetically Levitated Systems and Linear Drives, May 19-21, 1993, Argonne, IL, pp. 41-45.

King, W. F. III, Mackrodt, P. A., and Pfizenmaier, E. (1993), The Aerodynamics and Acoustics of High-Speed Tracked Vehicles, Proc. Int. Conf. on Speedup Technology for Railway and Maglev Vehicles, November 22-26, 1993, Yokohama, Japan, Vol. 2, pp. 65-69.

King, W. F. III, and Bechert, D. W., (1979), On the Sources of Wayside Noise Generated by High-Speed Trains, J. Sound Vib., 66, pp. 311-332.

Kortum, W., Schwartz, W., and Faye, I. (1988), Dynamic Modeling of High Speed Ground Transportation Vehicles for Control Design and Performance Evaluation, Dynamics of Controlled Mechanical Systems, IUTAM/IFAC Symp., Zurich, Switzerland, 1988, pp. 336-350.

Kortum, W., and Utzt, A. (1984), Control Law Design and Dynamic Evaluations for a Maglev Vehicle with a Combined Lift and Guidance Suspension System, ASME Trans., J. Dynam. Systems, Measurement, Control, 106, pp. 286-292.

Kotb, M., Sankar, T. S., and Samaha, M. (1983a), Suspension Bounce Response of Canadian Maglev Vehicle Under Guideway Excitations, Part I: Deterministic Analysis, J. Vib. Acous. Stress Reliability Des., 105, pp. 104-111.

Kotb, M., Sankar, T. S., and Samaha, M. (1983b), Suspension Bounce Response of Canadian Maglev Vehicle Under Guideway Excitations, Part II: Stochastic Modeling and Analysis, J. Vib. Acous. Stress Reliability Des., 105, pp. 261-266.

Lian, J. S., Zhou, J. W., Zhang, K. L., and Jiang, H. (1993), A General Survey of Chinese Maglev Train, Proc. Maglev '93, 13th Int. Conf. on Magnetically Levitated Systems and Linear Drives, May 19-21, 1993, Argonne, IL, pp. 46-50.

Limbert, D. A., Richardson, H. H., and Wormley, D. N. (1979), Dynamics and Control of Combined Lift Guidance Ferromagnetic Vehicle Suspensions, J. Dynam. Systems, Measurement, Control, 101, No. 3. 
Martinelli, G., and Morini, A. (1993), Present Status of Research for Maglev in Italy, Proc. Maglev '93, 13th Int. Conf. on Magnetically Levitated Systems and Linear Drives, May 19-21, 1993, Argonne, IL, pp. 51-53.

Masada, E. (1993), Development of Maglev Transportation in Japan: Present State and Future Prospects, Proc. Maglev '93, 13th Int. Conf. on Magnetically Levitated Systems and Linear Drives, May 19-21, 1993, Argonne, IL, pp. 1-6.

Matsunuma, S., et al. (1989), A Study on the Characteristics of the Aerodynamics of the Magnetically Levitated Transportation System (MAGLEV), Proc. Int. Conf. Maglev '89, pp. 275-280.

McCormac, A. W., Wilson, J. N., and Klassen, N. D. (1992), Active Seat Suspension Systems for Off-Road Vehicles, Proc. CSME Forum 1992 "Transport 1992+," June 1-4, 1992, Montreal, Canada, Vol. I, pp. 180-185.

Menden, W., Mayer, W. J., and Rogg, D. (1989), State of Development and Future Prospects of the Maglev-Systems Transrapid, M-Bahn and Starlim, Proc. Int. Conf. Maglev '89, pp. 11-18.

Miller, L., and Konigorski, U. (1993), Maglev Vehicle Transrapid 07 - Prospective Analysis of the Performance in Revenue Service, Proc. Int. Conf. on Speedup Technology for Railway and Maglev Vehicles, November 22-26, 1993, Yokohama, Japan, Vol. 1, pp. 404-408.

Miyakawa, J., and Hosaka, S. (1993), Aerodynamic Design of Frontal Shape for JR Maglev Train, Proc. Int. Conf. on Speedup Technology for Railway and Maglev Vehicles, November 22-26, 1993, Yokohama, Japan, Vol. 1, pp. 174-179.

Moon, F. C. (1974), Laboratory Studies of Magnetic Levitation in the Thin Track Limit, IEEE Trans. on Magnetics MAG-10(3), pp. 439-442.

Moon, F. C. (1977), Vibration Problems in Magnetic Levitation and Propulsion, Transport Without Wheels, E. R. Laithwaite, ed., Elek Science, London, pp. 122-161.

Moritoh, Y., Zenda, Y., Shimizu, Y., and Nagakura, K. (1993), Aerodynamic Noise of Highspeed Railway Cars, Proc. Int. Conf. on Speedup Technology for Railway and Maglev Vehicles, November 22-26, 1993, Yokohama, Japan, Vol. 2, pp. 45-48. 
Nakagawa, T. and Nagai, M. (1993), A study of Active-Suspensions for an ElectroMagnetically Levitated Vehicle - Comparison between $H_{\infty}$ and LQ Control, Proc. Int. Conf. on Speedup Technology for Railway and Maglev Vehicles, November 2226, 1993, Yokohama, Japan, Vol. 2, pp. 93-97.

North, B. H. (1985), Birmingham Airport Maglev - The Development and Design of the Support Structure and Guideway, Proc. Int. Conf. on Maglev Transport '85, pp. 237-242.

Oda, K., Azakami, M., and Yoshimura, M. (1989), Development of Aerodynamic Brake of Maglev Vehicle for Emergency Use, Proc. Int. Conf. Maglev '89, pp. 281-286.

Ohno, E., Iwamoto, M., and Yamada, T. (1973), Characteristic of Superconductive Magnetic Suspension and Propulsion for High-Speed Trains, Proc. IEEE 61(5), pp. 579-586.

Olsson, M. (1985), Finite Element, Modal Co-Ordinate Analysis of Structures Subjected to Moving Loads, J. Sound Vib., 99(1), pp. 1-12.

Ozeki, M. (1993), Current Status of Research and Development of Superconducting Maglev System in Japan, Proc. Int. Conf. on Speedup Technology for Railway and Maglev Vehicles, November 22-26, 1993, Yokohama, Japan, Vol. 1, p. 7.

Parker, J. H., Boon, C. J., Dawson, G. E., and Eastham, T. R. (1993), High Speed Rail and maglev in Canada, Proc. Int. Conf. on Speedup Technology for Railway and Maglev Vehicles, November 22-26, 1993, Yokohama, Japan, Vol. 1, pp. 387-392.

Pepler, R. D., et al. (1978), Development of Techniques and Data for Evaluating Ride Quality, Vol. 1: Summary, Report No. DOT-TSC-RSPD-77-1, I, Dunlap and Associates, Inc., Darien, CT.

Peters, J. L. (1983), Aerodynamics of Very High Speed Trains and Maglev Vehicles: State of Art and Future Potential, Int. J. Vehicle Design, Technological Advances in Vehicle Design Series, SP3, Impact of Aerodynamics on Vehicle Design.

Phelan, R. S. (1993a), High Performance Maglev Guideway Design, Doctoral Dissertation, MIT Department of Civil and Environmental Engineering. 
Phelan, R. S. (1993b), Reduction of Guideway Residual Vibration Through Strategic Vehicle Pad Spacing Arrangements, Proc. Maglev '93, 13th Int. Conf. on Magnetically Levitated Systems and Linear Drives, May 19-21, 1993, Argonne, IL, pp. 195-200.

Philco-Ford Corp. (1975), Conceptual Design and Analysis of the Tracked Magnetically Levitated Vehicle Technology Program, Repulsion Scheme. Vol. I. Technical Studies, Report DOT-FT-40024 (Task 1), Newport Beach, CA.

Pickersgill, P. (1990), Nonlinear Analysis of a Ferromagnetic Suspension for a Contactless Rail Vehicle, MS Thesis, MIT Department of Mechanical Engineering.

Raschbichler, H. G., and Wackers, M. (1993), The German Magnetic Levitation Train: First Transrapid.Revenue Application Berlin-Hamburg, Proc. Int. Conf. on Speedup Technology for Railway and Maglev Vehicles, November 22-26, 1993, Yokohama, Japan, Vol. 1, pp. 91-96.

Ravera, R. J., and Angeres, J. R. (1974), Selection of Candidate Guideway Parameters for High Speed Tracked Levitated Vehicles, High Speed Ground Transportation J., 8(2), pp. 17-31.

Reitz, J. R. (1970), Forces on Moving Magnets due to Eddy Currents, J. Appl. Phys., 41, pp. 2067-2071.

Rhodes, R. G., and Mulhall, B. E. (1981), Magnetic Levitation for Rail Transport, Clarendon Press Oxford, New York.

Richardson, H. H., and Wormley, D. N. (1974), Transportation Vehicle/BeamElevated Guideway Dynamic Interactions: A State-of-the-Art Review, J. Dynam. Systems, Measurement, Control, 96, pp. 169-179.

Robinson, C. G., and Baker, C. J. (1990), The Effect of Atmospheric Turbulence on Train, J. Wind Eng. Ind. Aerodynam., 34, pp. 251-272.

Rogg, D. (1986), The Research and Development Program 'Magnetically Suspended High Speed Transport Systems' in the Federal Republic of Germany, Int. Conf. on Maglev and Linear Drives, Publication IEEE 86CH2276, pp. 31-38.

Rote, D. M. (1993), Status of U. S. Maglev Program, Proc. Maglev '93, 13th Int. Conf. on Magnetically Levitated Systems and Linear Drives, May 19-21, 1993, Argonne, IL, pp. 1-4. 
Sato, Y., Matsuura, A., and Satoh, Y. (1985), Development of Guideway for Maglev, Proc. Int. Conf. on Maglev Transport '85, pp. 243-250.

Schmitz, K. P. (1993), Sound Measurements on TRANSRAPID 07 - Methods and Results, Proc. Int. Conf. on Speedup Technology for Railway and Maglev Vehicles, November 22-26, 1993, Yokohama, Japan, Vol. 2, pp. 33-38.

Siclari, M. J., Carpenter, G., and Ende, R. (1993), Aerodynamic Analysis of the Grumman Maglev Vehicle, Proc. Maglev '93, 13th Int. Conf. on Magnetically Levitated Systems and Linear Drives, May 19-21, 1993, Argonne, IL, pp. 259-264.

Sinha, P. K. (1987), Electromagnetic Suspension, Dynamics and Control, Peter Peregrinus Ltd., London.

Smith, C. C., Gilchrist, A. J., and Wormley, D. N. (1975), Multiple and Continuous Span Elevated Guideway-Vehicle Dynamic Performance, ASME Trans., J. Dynam. Systems, Measurement, Control, 97, pp. 30-40.

Smith, C. C., McGehee, D. Y., and Healey, A. J. (1978), The Prediction of Passenger Riding Comfort from Acceleration Data, ASME Trans., J. Dynam. Systems, Measurement, Control, 100, pp. 34-41.

Smith, C. C., and Wormley, D. N. (1975), Response of Continuous Periodically Supported Guideway Beams to Traveling Vehicle Loads, ASME Trans., J. Dynam. Systems, Measurement, Control, 97, pp. 21-29.

Snyder, J. E., and Wormley, D. N. (1977), Dynamic Interactions Between Vehicles and Elevated, Flexible Randomly Irregular Guideways, J. Dynam. Systems, Measurement, Control, 99, pp. 23-33.

Stanway, R., Sproston, J. L., and Wu, X. (1989), Variable Suspension Damping Using Electro-Rheological Fluids, IMechE C382/034, pp. 547-558.

Sussman, M. E. (1984), Statistical Ground Excitation Models for High Speed Vehicle Dynamic Analysis, High Speed Ground Transportation J., 8(3), pp. 145-154.

Takano, Y., Torii, A., Terada, K., Sebata, M., Iida, A., Hattori, M., and Kohama, Y. (1993), Noise Reduction on the New NOZOMI Shinkansen Cars, Proc. Int. Conf. on Speedup Technology for Railway and Maglev Vehicles, November 22-26, 1993, Yokohama, Japan, Vol. 2, pp. 39-44. 
Takao, K., Yoshimura, M., and Sakai, K. (1993), Aerodynamic Design of JR Maglev Train Frontal Shape -- Part II, Proc. Int. Conf. on Speedup Technology for Railway and Maglev Vehicles, November 22-26, 1993, Yokohama, Japan, Vol. 1, pp. 180-185.

Uher, R. A. (1989), MAGLEV: An Emerging Transportation Technology to Meet an Imminent Transportation Need, Proc. Int. Conf. Maglev '89, pp. 115-122.

Vu-Quoc, L., and Olsson, M. (1989), Formulation of a Basic Building Block Model for Interaction of High Speed Vehicles on Flexible Structures, ASME Trans., J. Appl. Mech., 56, pp. 451-458.

Wang, Z., Chen, S. S., and Rote, D. M. (1991), Present Status of Computational Tools for Maglev Development, Report ANL/ESD/TM-24, Argonne National Laboratory, Argonne, IL.

Wiescholek, U., Mayer, W. J., and Rogg,.D. (1993a), High-Speed Magnetic Levitation Train Transrapid, Planning of the Development Program until 1995 and Prospects of Utilization in the Federal Republic of Germany, Proc. Maglev '93, 13th Int. Conf. on Magnetically Levitated Systems and Linear Drives, May 19-21, 1993, Argonne, IL, pp. 22-28.

Wiescholek, U., Mayer, W. J., and Rogg, D. (1993b), The Transrapid High-Speed Maglev System in Germany - Development Program and Future Prospects, Proc. Int. Conf. on Speedup Technology for Railway and Maglev Vehicles, November 2226, 1993, Yokohama, Japan, Vol. 1, pp. 369-374.

Wilkie, D. F. (1972), Dynamics, Control and Ride Quality of a Magnetically Levitated High Speed Ground Vehicle, Transportation Research, 6, pp. 343-369.

Wong, J. X., Wu, X. M., Sturk, M., and Bortolotto, C. (1992), On the Applications of Electro-Rheological Fluids to the Development of Semiactive Suspension Systems for Ground Vehicles, Proc. CSME Forum 1992 "Transport 1992+," June 1-4, 1992, Montreal, Canada, Vol. I, pp. 186-191.

Wormley, D. N., Thornton, R. D., Yu, S. H., and Cheng, S. (1992), Interactions between Magnetically Levitated Vehicles and Elevated Guideway Structures, DOT/FRA/NMI-92/23.

Wormer, W. (1993), Medical Aspects into the Effects of Air Pressure Changes on Passenger Comfort of Highspeed Railway in Tunnels, Proc. Int. Conf. on Speedup Technology for Railway and Maglev Vehicles, November 22-26, 1993, Yokohama, Japan, Vol. 2, pp. 167-172. 
Wu, X. M., Stanway, R., and Sproston, J. L. (1990), Electro-Rheological Fluids and Their Applications in Power Transmission and Active Suspension, Proc. 22nd Int. Symp. on Automotive Technology and Automation, Florence, Italy, May 14-18, 1990, pp. 823-830.

Wyczalek, F. A. (1993), Maglev Transit Technology in Russia, Proc. Maglev '93, 13th Int. Conf. on Magnetically Levitated Systems and Linear Drives, May 19-21, 1993, Argonne, IL, pp. 88-93.

Yabuno, H., and Takabayashi, Y. (1989), Bouncing and Pitching Oscillations of a Magnetically Levitated Vehicle Caused by Guideway Roughness, Proc. Int. Conf. Maglev '89, pp. 405-410.

Yoshimura, M., and Okamoto, H. (1993), Development of Aerodynamic Brake System for MLU002N on Miyazaki Test Track, Proc. Int. Conf. on Speedup Technology for Railway and Maglev Vehicles, November 22-26, 1993, Yokohama, Japan, Vol. 1, pp. 168-173.

Yoshioka, H., and Miyamoto, M. (1986), Dynamic Characteristics of Maglev Vehicle MLUOO1 - Guideway Irregularity Test, Int. Conf. on Maglev and Linear Drives, Publication IEEE 86.

Zhu, S., Chen, S. S., Cai, Y., and Rote, D. M. (1994), Magnetic Damping for Maglev, 1994 Winter Annual Meeting, ASME, New York, PVP-Vol. 289, pp. 1-10.

Zicha, J. H. (1986), Civil Aspects of Maglev Design, Int. Conf. on Maglev and Linear Drives, Publication IEEE 86CH2276, pp. 69-87. 


\section{Distribution for ANL-95/38}

\section{Internal}

Y. Cai (20)

R. D. Carlson

S. S. Chen (20)

H. T. Coffey

H. Drucker

J. L. He

J. R. Hull

L. R. Johnson

C. A. Malefyt
T. M. Mulcahy

R. B. Poeppel

D. M. Rote

W. J. Shack

R. A. Valentin

M. W. Wambsganss (3)

Z. Wang

R. W. Weeks

TIS Files

External

DOE-OSTI for distribution per UC-1500 (355)

ANL Libraries

\section{ANL-E}

ANL-W

Manager, Chicago Field Office, DOE

Director, Technology Management Div., DOE-CH

D. L. Bray, DOE-CH

T. Crawford, DOE-CH

Energy Technology Division Review Committee:

H. K. Birnbaum, University of Illinois, Urbana

R. C. Buchanan, University of Cincinnati, Cincinnati, $\mathrm{OH}$

M. S. Dresselhaus, Massachusetts Institute of Technology, Cambridge, MA

S.-N. Liu, Fremont, CA

H. S. Rosenbaum, Fremont, CA

R. K. Shah, University of Kentucky, Lexington

S. Smialowska, Ohio State University, Columbus

R. E. Smith, Altran Corp., Huntersville, NC

O. P. Manley, DOE, Washington, DC

J. S. Coleman, DOE, Washington, DC

D. Frederick, DOE, Washington, DC

J. T. Harding, DOT, Washington, DC

F. C. Moon, Cornell University, Ithaca, NY

D. N. Wormley, Pennsylvania State University, University Park, PA

R. D. Thornton, Massachusetts Institute of Technology, Cambridge, MA 